\title{
Utilização de duas variantes da fluorescência de raios X (EDXRF e TXRF) na determinação de chumbo em águas e sedimentos
}

LIZ MARY BUENO DE MORAES

Dissertação apresentada ao Centro de Energia Nuclear na Agricultura, Universidade de São Paulo, como parte dos requisitos para a obtenção do título de Mestre em Ciências, Área de Concentração: Energia Nuclear na Agricultura.

PIR A C I C A B A Estado de São Paulo - Brasil

Novembro - 2004 


\section{Utilização de duas variantes da fluorescência de raios X (EDXRF e TXRF) na determinação de chumbo em águas e sedimentos}

LIZ MARY BUENO DE MORAES

Química

Orientador: Prof. Dr. VIRGÍLIO FRANCO DO NASCIMENTO FILHO

Dissertação apresentada ao Centro de Energia Nuclear na Agricultura, Universidade de São Paulo, como parte dos requisitos para a obtenção do título de Mestre em Ciências, Área de Concentração: Energia Nuclear na Agricultura.

PIR A C I C A B A

Estado de São Paulo - Brasil

Novembro - 2004 
A DEVS

pela minha vida, agradeço e ofereço.

À minha família, em especial, à minha mãe e meu pai, pelo amor incondicional, dedico. 


\section{AGRADECIMENTOS}

Ao Prof. Dr. Virgílio Franco do Nascimento Filho, pela oportunidade, orientação, incentivo, compreensão, paciência e amizade dedicados.

Aos meus amigos do Laboratório de Instrumentação Nuclear/CENA: Ana Carla F. Gomes, Fábio Lopes, Richard M. da Cunha e Silva, Luís A. Senicato, Alfredo José F. Mello e Felipe Vitti, pela ajuda e discussão, essenciais para o desenvolvimento deste trabalho, e acima de tudo, pela amizade.

Aos colegas do Laboratório de Química Analítica/CENA: Prof. Dr. Francisco José Krug e o amigo Dário dos Santos Júnior, pelas discussões construtivas. Às técnicas de laboratório, lolanda Rufini (Tatinha) e Sheila Perdigão, pela ajuda em algumas análises e empréstimo de materiais, e principalmente pela amizade.

Aos colegas de outros laboratórios e seções do CENA, em especial aos amigos da APG e Comissão Organizadora do Encontro Científico dos Pós-Graduandos no CENA/USP, pela amizade e carinho.

À Profa. Dra. Jacinta Enzweiler, do Instituto de Geociências da UNICAMP, por fornecer as amostras certificadas de sedimento e solo.

A Carlos Perez, técnico da linha de luz XRF, do Laboratório Nacional de Luz Síncrotron, Campinas/SP, pela ajuda nas análises por TXRF.

Ao CNPq pela bolsa concedida e ao CENA/USP pela formação, infra-estrutura e condições técnicas necessárias à realização deste trabalho. 
Aos meus amigos e amigas que sempre me apoiaram com palavras de carinho e afeto.

Aos meus pais Elza e Edevarde, por serem a razão da minha vida e sempre acreditarem em mim. Às minhas irmãs Jaqueline e Kellen, por estarem presentes a todo o momento. À minha avó Carolina, pelas orações, carinho e amor dedicados. Aos meus tios Agamenon, Maria Cristina, Amilton e Evanir, pelo amor e carinho. Amo vocês.

À minha pátria amada, BRASIL.

"Embora ninguém possa voltar atrás e fazer um novo começo, qualquer um pode começar agora e fazer um novo fim". 


\section{SUMÁRIO}

Pág.

LISTA DE FIGURAS ….............................................................. viii

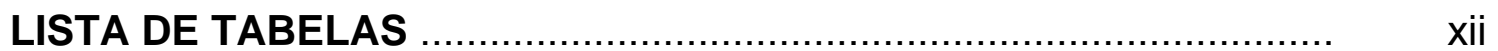

LISTA DE ABREVIATURAS E SÍMBOLOS ....................................... xvi

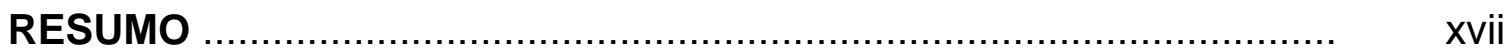

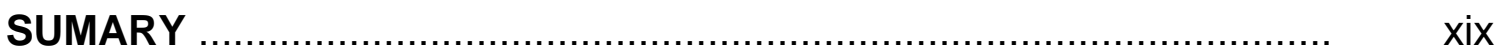

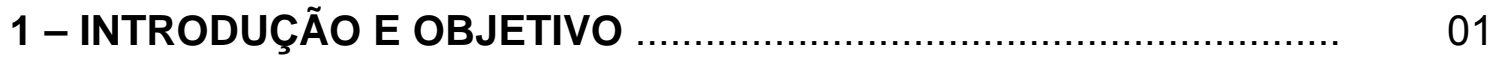

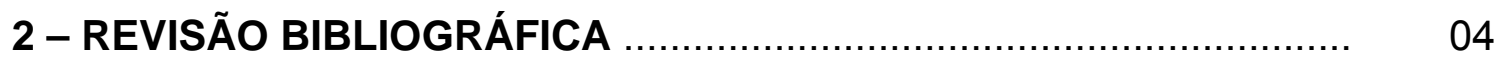

2.1 - Pré-concentração ...................................................... 07

3 - FUNDAMENTOS TEÓRICOS …................................................. 10

3.1 - Fluorescência de raios X ............................................. 10

3.1.1 - Excitação dos elementos ................................... 11

3.1.2 - Dispersão dos raios X ....................................... 12

3.1.3 - Detecção e medida dos raios X ........................... 13

3.2 - Equação fundamental da fluorescência de raios X ............ 14

3.2.1 - Amostra semi-espessa ..................................... 22

3.2.2 - Amostra fina ................................................ 23

3.3 - Fluorescência de raios X por reflexão total ....................... 23

3.3.1 - Análise quantitativa .......................................... 25

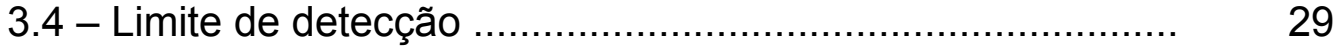

3.4.1 - Amostra fina por EDXRF ……………............. 29

3.4.2 - Amostra semi-espessa por EDXRF …................ 30

3.4.3 - Amostra líquida por TXRF ................................ 31 


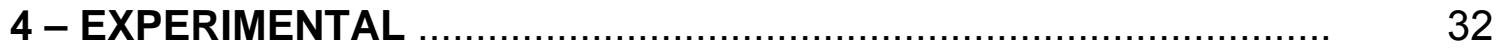

4.1 - Coleta e preparo das amostras ...................................... 32

4.1 .1 - Água ............................................................. 32

4.1.2 - Sedimento em suspensão ................................. 33

4.1 .3 - Sedimento de fundo ......................................... 34

4.2 - Pré-concentração da água para EDXRF ......................... 34

4.3 - Preparação das amostras de água para TXRF ................. 35

4.4 - Excitação e detecção ..................................................... $\quad 36$

4.4.1 - Excitação e detecção em EDXRF ....................... 36

4.4.2 - Excitação e detecção em TXRF .......................... 38

4.5 - Reagentes e soluções ................................................ 39

4.6 - Amostras certificadas .................................................... 41

5 - RESULTADOS E DISCUSSÃO …………................................ 42

5.1 - Análise de água por EDXRF com pré-concentração .......... 42

5.1.1 - Curva de sensibilidade elementar ....................... 42

5.1 .2 - Teste de recuperação em soluções padrão .......... 44

5.1.3 - Resultados das análises de amostras de água por EDXRF com pré-concentração .................... 46

5.2 - Análise de sedimento em suspensão por EDXRF ............. 53

5.3 - Análise de água por TXRF ............................................ 56

5.3.1 - Sensibilidade elementar para $\mathrm{Pb}$ e análise de amostra certificada ........................................ 56

5.3.2 - Teste de recuperação de $\mathrm{Pb}$ em solução-padrão. $\quad 57$

5.3.3 - Teste de recuperação de $\mathrm{Pb}$ nas amostras de água ...................................................... 58

5.3.4 - Análise de Pb em amostras de água ................... 59

5.3.5 - Sensibilidade elementar para outros elementos em TXRF 
5.3.6 - Análise de outros elementos em amostra certificada por TXRF ....................................... 63

5.3.7 - Análise de outros elementos em água por TXRF.. $\quad 70$

5.4 - Análise de sedimento de fundo por EDXRF ..................... 74

5.4.1 - Análise de $\mathrm{Pb}$ em amostras certificadas ............. 74

5.4.2 - Análise de Pb em amostras de sedimentos de fundo ............................................................. $\quad 75$

5.4.3 - Análise de outros elementos em amostras de sedimentos de fundo

5.5 - Comparação das concentrações de $\mathrm{Pb}$ encontrado nas amostras de água nas análises realizadas por EDXRF (com pré-concentração) e TXRF (direto)

5.6 - Comparação das concentrações dos elementos encontrados nas amostras de água nas análises realizadas por EDXRF (com pré-concentração) e TXRF (direto) 


\section{LISTA DE FIGURAS}

Pág.

Figura 1. Resolução de alguns detectores para os raios $X$ característicos emitidos pela prata

Figura 2. Representação esquemática da geometria de excitação para feixe de radiação eletromagnética em fluorescência de raios $X$

Figura 3. Dependência do coeficiente de absorção de massa em função da energia, para os elementos $\mathrm{Ca}$, $\mathrm{Cu}$ e U

Figura 4. Valores da razão de salto (jump ratio) em função do número atômico

Figura 5. Representação esquemática da dependência entre as variáveis na equação fundamental de fluorescência de raios $X$ para excitação de radiação eletromagnética

Figura 6. Representação esquemática da refração e reflexão total de um feixe de radiação monoenergético em função do ângulo de incidência

Figura 7. Esquema do local de amostragem e os pontos de coleta ......

Figura 8. Suportes de quartzo contendo alíquotas das amostras, após secagem em estufa à temperatura de $28 \pm 3^{\circ} \mathrm{C}$

Figura 9. Foto do sistema excitação/detecção EDXRF do Laboratório de Instrumentação Nuclear do CENA/USP; em destaque o porta amostra

Figura 10. Foto do sistema de excitação/detecção TXRF da linha de fluorescência de raios $X$ do Laboratório Nacional de Luz Síncrotron, Campinas/SP (no destaque o porta-amostra com o suporte de quartzo contendo a amostra seca na posição de irradiação) 
Figura 11. Foto da imagem produzida pela câmara CCD do feixe de reflexão total na linha de fluorescência de raios $X$ do Laboratório Nacional de Luz Síncrotron, Campinas/SP, utilizando o suporte de quartzo

Figura 12. Sensibilidade elementar em função do número atômico para padrões de filme fino fabricados pela MicroMatter, para raios $\mathrm{X}$ característicos $\mathrm{K} \alpha$

Figura 13. Espectro dos raios $X$ obtidos por EDXRF proveniente da solução-padrão SM após pré-concentração com APDC ........

Figura 14. Espectro dos raios $X$ obtidos por EDXRF proveniente da amostra de água PCC após pré-concentração com APDC ..

Figura 15. Distribuição das concentrações de $\mathrm{Pb}\left(\mu \mathrm{L} \mathrm{L}^{-1}\right)$ presente nas amostras de água coletadas nos diferentes pontos de amostragem

Figura 16. Distribuição das concentrações $\left(\mu \mathrm{g} \mathrm{L}^{-1}\right)$ dos elementos encontrados nas amostras de água, determinadas por EDXRF, após pré-concentração com APDC (escala linear)...

Figura 17. Distribuição das concentrações $\left(\mu \mathrm{g} \mathrm{L}^{-1}\right)$ dos elementos encontrados nas amostras de água, determinadas por EDXRF, após pré-concentração com APDC (escala logarítmica)

Figura 18. Espectro dos raios $X$ obtido por EDXRF proveniente da amostra de sedimento em suspensão PDR

Figura 19. Distribuição das concentrações $\left(\mu \mathrm{g} \mathrm{g}^{-1}\right)$ dos elementos encontrados nas amostras de sedimento em suspensão, determinadas por EDXRF (escala linear) .............................

Figura 20. Distribuição das concentrações $\left(\mu \mathrm{g} \mathrm{g}^{-1}\right)$ dos elementos encontrados nas amostras de sedimento em suspensão, determinadas por EDXRF (escala logarítmica) 
Figura 21. Curva de calibração obtida para $\mathrm{Pb}$ por TXRF a partir de soluções com concentrações conhecidas de $\mathrm{Pb}$.....

Figura 22. Espectro dos raios $X$ obtido por TXRF proveniente da amostra de água POÇO, com adição de $1000 \mu \mathrm{g} \mathrm{L}^{-1}$ de $\mathrm{Pb}$ para o teste de recuperação (o elemento $\mathrm{Ga}$ foi adicionado como padrão interno)

Figura 23. Distribuição das concentrações de $\mathrm{Pb}\left(\mu \mathrm{L} \mathrm{L}^{-1}\right)$ presente nas amostras de água, determinadas por TXRF

Figura 24. Sensibilidade elementar em função do número atômico, para os elementos presentes na solução-padrão $P M$, elementos camada $\mathrm{K}$

Figura 25. Sensibilidade elementar em função do número atômico, para os elementos presentes na solução-padrão PM, elementos camada $\mathrm{L}$

Figura 26. Distribuição dos valores certificado e obtido para as concentrações $\left(\mu \mathrm{g} \mathrm{L}^{-1}\right)$ dos elementos contidos na amostra certificada de água SRM1640/NIST, determinada por TXRF.

Figura 27. Espectro dos raios $X$ obtidos por TXRF proveniente de um suporte de quartzo limpo

Figura 28. Espectro de raios $\mathrm{x}$ obtido por TXRF proveniente de um suporte de lucite limpo

Figura 29. Espectro de raios $x$ obtido por EDXRF proveniente de um suporte de quartzo e lucite limpos

Figura 30. Espectro dos raios $X$ obtidos por TXRF proveniente de uma amostra de branco de solução $\left(0 \mu \mathrm{g} \mathrm{L}^{-1}\right)$ com adição do padrão interno $\mathrm{Ga}\left(500 \mu \mathrm{g} \mathrm{L}^{-1}\right)$ em suporte de quartzo

Figura 31. Distribuição das concentrações $\left(\mu \mathrm{g} \mathrm{L}^{-1}\right)$ dos elementos encontrados nas amostras de água, determinadas por TXRF (escala linear) 
Figura 32. Distribuição das concentrações $\left(\mu \mathrm{g} \mathrm{L}^{-1}\right)$ dos elementos encontrados nas amostras de água, determinadas por TXRF (escala logarítmica)

Figura 33. Espectro dos raios $X$ obtido por EDXRF proveniente da amostra de sedimento de fundo PSP na forma de pastilha ...

Figura 34. Distribuição das concentrações de $\mathrm{Pb}\left(\mu \mathrm{g} \mathrm{g}^{-1}\right)$ presente nas amostras de sedimento de fundo, determinadas por EDXRF, na forma de pastilhas

Figura 35. Distribuição das concentrações $\left(\mu \mathrm{g} \mathrm{g}^{-1}\right)$ dos elementos encontrados nas amostras de sedimento de fundo, determinadas por EDXRF, na foram de pastilhas (escala linear)

Figura 36. Distribuição das concentrações $\left(\mu \mathrm{g} \mathrm{g}^{-1}\right)$ dos elementos encontrados nas amostras de sedimento de fundo, determinadas por EDXRF, na forma de pastilhas (escala logarítmica) 


\section{LISTA DE TABELAS}

Pág.

Tabela 1. Concentrações $\left(\mu \mathrm{g} \mathrm{L}^{-1}\right)$ dos elementos constituintes das soluções-padrão SM e PM

Tabela 2. Concentrações $\left(\mu \mathrm{g} \mathrm{cm}^{-2}\right)$ dos padrões monoelementares de filme fino fabricados pela MicroMatter

Tabela 3. Valores das sensibilidades elementares $\left(\mathrm{cps} \mu \mathrm{g}^{-1} \mathrm{~cm}^{2}\right)$ para os raios $\mathrm{X}$ característicos $\mathrm{K} \alpha$ obtidas através da curva de sensibilidade elementar e pontualmente para $\mathrm{Te}$ e $\mathrm{Pb}$,

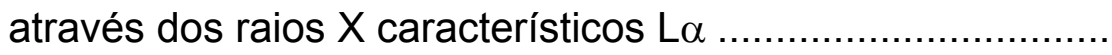

Tabela 4. Recuperação na pré-concentração de $\mathrm{Pb}$ em filtros de éster de celulose Millipore $(n=3)$

Tabela 5. Concentrações $\left(\mu \mathrm{g} \mathrm{L}^{-1}\right)$ e recuperação (\%) para as duas soluções-padrão, SM e PM ( $n=3)$

Tabela 6. Concentrações e desvio padrão $\left(\mu \mathrm{g} \mathrm{L}^{-1}\right)$ e limite de detecção $\left(\mu \mathrm{g} \mathrm{L}^{-1}\right)$ do $\mathrm{Pb}$ nas amostras de água, determinadas por EDXRF, após pré-concentração com APDC, e $300 \mathrm{~s}$ de excitação/deteç̧ão $(n=3)$

Tabela 7. Concentrações e desvios padrão $\left(\mu \mathrm{g} \mathrm{L}^{-1}\right)$ dos elementos encontrados nas amostras de água, determinadas por EDXRF, após pré-concentração com APDC $(n=3)$

Tabela 8. Limites de detecção $\left(\mu \mathrm{g} \mathrm{L}^{-1}\right)$ para os elementos encontrados nas amostras de água, determinadas por EDXRF, após préconcentração com APDC e 300 s de excitação/detecção .....

Tabela 9. Concentrações $\left(\mu \mathrm{g} \mathrm{g}^{-1}\right)$ dos elementos encontrados nas amostras de sedimento em suspensão, determinadas por EDXRF 
Tabela 10. Limites de detecção $\left(\mu \mathrm{g} \mathrm{g}^{-1}\right)$ para os elementos encontrados nas amostras de sedimento em suspensão, determinadas por EDXRF em 300s de excitação/detecção

Tabela 11. Concentração $\left(\mu \mathrm{g} \mathrm{L}^{-1}\right)$ de $\mathrm{Pb}$ obtida para a amostra certificada de água SRM1640 produzida pelo NIST,

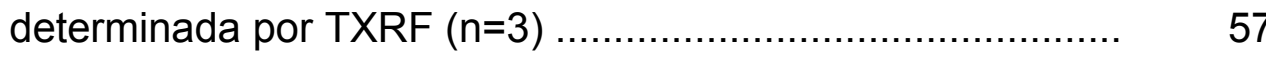

Tabela 12. Recuperação para $\mathrm{Pb}$ na solução-padrão SM ..................... 57

Tabela 13. Teste de Recuperação para $\mathrm{Pb}$ nas amostras de água,

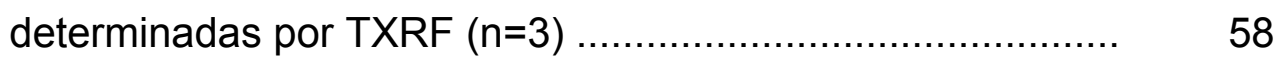

Tabela 14. Concentração e desvio padrão $\left(\mu \mathrm{g} \mathrm{L}^{-1}\right)$ de $\mathrm{Pb}$ encontrado nas amostras de água, determinadas por TXRF $(n=3) \ldots \ldots . .60$

Tabela 15. Limites de detecção $\left(\mu \mathrm{g} \mathrm{L}^{-1}\right)$ para $\mathrm{Pb}$ encontrado nas amostras de água, determinadas por TXRF, em $200 \mathrm{~s}$ de excitação/ detecção

60

Tabela 16. Sensibilidade elementar $\left(\mathrm{cps}_{\mu} \mathrm{g}^{-1} \mathrm{~L}\right)$ por TXRF para os elementos que compõem a solução-padrão PM, analisados por raios $\mathrm{X} \mathrm{K \alpha}(\mathrm{Ti}$ ao $\mathrm{Br})$ e $\mathrm{L} \alpha(\mathrm{Ag}$ ao $\mathrm{Pb})$............................

Tabela 17. Concentração $\left(\mu \mathrm{g} \mathrm{L}^{-1}\right)$ dos elementos contidos na amostra certificada de água SRM1640/NIST, determinada por TXRF $(n=3)$

Tabela 18. Concentração e desvio padrão $\left(\mu \mathrm{g} \mathrm{L}^{-1}\right)$ dos elementos encontrados nas amostras de água, determinadas por TXRF $(n=3)$

Tabela 19. Limites de detecção $\left(\mu \mathrm{g} \mathrm{L}^{-1}\right)$ para s elementos encontrados nas amostras de água, determinadas por TXRF em 200s de excitação/detecção

Tabela 20. Concentrações $\left(\mu \mathrm{g} \mathrm{g}^{-1}\right)$ de $\mathrm{Pb}$ obtidas nas amostras certificadas de solo SRM2711 e de sedimento SRM1646a, 
produzidas pelo NIST, e analisadas por EDXRF na forma de pastilhas $(n=3)$

Tabela 21. Concentração e desvio padrão $\left(\mu \mathrm{g} \mathrm{g}^{-1}\right)$ de $\mathrm{Pb}$ encontrado nas amostras de sedimento de fundo, determinadas por EDXRF, na forma de pastilha $(n=3)$. Para comparação são dados os limites TEL e PEL

Tabela 22. Limites de detecção $\left(\mu \mathrm{g} \mathrm{g}^{-1}\right)$ para $\mathrm{Pb}$ encontrado nas amostras de sedimento de fundo, determinadas por EDXRF, na forma de pastilha em $500 \mathrm{~s}$ de excitação/detecção

Tabela 23. Fatores de absorção para os elementos encontrados nas amostras de sedimento de fundo, obtidos com o auxílio do programa AXIL

Tabela 24. Concentrações e desvio padrão $\left(\mu \mathrm{g} \mathrm{g}^{-1}\right)$ para os elementos encontrados nas amostras de sedimento de fundo, determinadas por EDXRF, na forma de pastilhas $(n=3)$. Para comparação são dados os limites TEL e PEL

Tabela 25. Limites de detecção $\left(\mu \mathrm{g} \mathrm{g}^{-1}\right)$ para os elementos encontrados nas amostras de sedimento de fundo, determinadas por EDXRF, na forma de pastilhas em $500 \mathrm{~s}$ de excitação/ detecção

Tabela 26. Resultados obtidos para as concentrações e desvio padrão $\left(\mu \mathrm{g} \mathrm{L}^{-1}\right)$ de $\mathrm{Pb}$ nas amostras de água pré-concentradas com APDC (EDXRF) e sem preparo químico (TXRF)

Tabela 27. Resultados obtidos para os limites de detecção $\left(\mu \mathrm{g} \mathrm{L}^{-1}\right)$ de $\mathrm{Pb}$ nas amostras de água pré-concentradas com APDC (EDXRF) e sem preparo químico (TXRF)

Tabela 28. Resultados obtidos para as concentrações e desvio padrão $\left(\mu \mathrm{L} \mathrm{L}^{-1}\right)$ dos elementos encontrados nas amostras de água 
pré-concentradas com APDC (EDXRF) e sem preparo

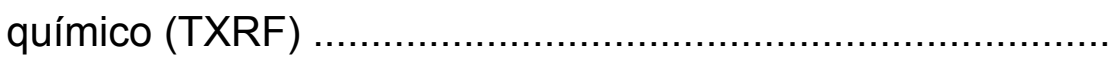

Tabela 29. Resultados obtidos para os limites de detecção $\left(\mu \mathrm{g} \mathrm{L}^{-1}\right)$ dos elementos encontrados nas amostras de água préconcentradas com APDC (EDXRF) e sem preparo químico

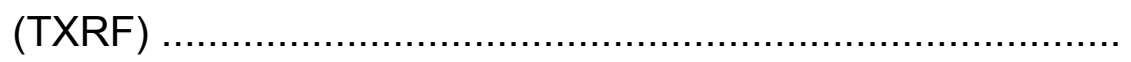




\section{LISTA DE ABREVIATURAS E SÍMBOLOS}

AAS Atomic Absorption Spectrometry = Espectrometria de absorção atômica

AES Atomic Emission Spectrometry = Espectrometria de emissão atômica

APDC ammonium pyrrolidinedithiocarbamate $=$ pirrolidina ditiocarbamato de amônio

AXIL Analysis of $\boldsymbol{X}$-ray spectra by Iterative Least squares fitting

CONAMA Conselho Nacional do Meio Ambiente

DDTC diethyldithiocarbamate

EDXRF Energy Dispersive X-Ray Fluorescence

FAAS Flame Atomic Absorption Spectrometry = Espectrometria de absorção atômica com chama

ICP-MS Inductively Coupled Plasma-Mass Spectrometry = Espectrometria de massas com plasma acoplado indutivamente

ICP-OES Inductively Coupled Plasma Optical Emission Spectrometry = Espectrometria de emissão óptica com plasma acoplado indutivamente

LNLS Laboratório Nacional de Luz Síncrotron

NADDTC sodium diethyldithiocarbamate

NIST National Institute of Standards \& Technology

PEL Probable Effect Level

SRM Standard Reference Material

TEL Threshold Effect Level

TXRF Total X-Ray Fluorescence

WDXRF Wavelength Dispersive $X$-Ray Fluorescence

XRF X-Ray Fluorescence 


\title{
Utilização de duas variantes da fluorescência de raios X (EDXRF e TXRF) na determinação de chumbo em águas e sedimentos
}

\author{
Autor: Liz Mary Bueno de Moraes \\ Orientador: Prof. Dr. Virgílio Franco do Nascimento Filho
}

RESUMO

Este trabalho teve como objetivo principal a utilização de duas variantes da técnica analítica de fluorescência de raios $X$, dispersiva em energia EDXRF e reflexão total TXRF, na determinação de $\mathrm{Pb}$ em amostras de águas superficiais e subterrâneas, e em sedimentos em suspensão e de fundo. Cinco amostras de cada matriz foram coletadas em uma área contaminada, nas proximidades da desativada fábrica de baterias Indústria Acumuladores Ajax Ltda., localizada no km 229 da rodovia Jaú-Ipaussu, em Bauru, SP. As variantes EDXRF com pré-concentração com APDC e medida direta por TXRF mostraram resultados satisfatórios na determinação de $\mathrm{Pb}$ em soluções-padrão e amostra certificada de água natural SRM1640, produzida pelo NIST, obtendo-se concentrações compatíveis com os valores esperados. A primeira técnica resultou em limite de detecção da ordem de $0,70 \mu \mathrm{g} \mathrm{L}^{-1}$, com tempo de análise de $300 \mathrm{~s}$, melhor que a segunda técnica $\left(4,46 \mu \mathrm{g} \mathrm{L}^{-1}\right)$, em $200 \mathrm{~s}$. Estas duas variantes também foram utilizadas para outros elementos químicos, como o $\mathrm{Ti}, \mathrm{Cr}, \mathrm{Mn}, \mathrm{Fe}, \mathrm{Co}, \mathrm{Ni}, \mathrm{Cu}, \mathrm{Zn}$ e $\mathrm{Br}$, onde a EDXRF mostrou também melhores limites de detecção para todos os elementos. Para $\mathrm{Ni}, \mathrm{Cu}$ e $\mathrm{Zn}$, importantes na indústria de baterias, foram encontrados os limites de $0,34-0,27$ e $0,24 \mu \mathrm{g} \mathrm{L}^{-1}$, respectivamente, enquanto que por TXRF foram encontrados os valores ao redor de $1 \mu \mathrm{g} \mathrm{L}^{-1}$. Na validação destas duas metodologias para análise de água, a EDXRF mostrou resultados mais próximos aos valores esperados, enquanto que por TXRF foram superestimados na maioria das vezes, com exceção para $\mathrm{As}$, Se e $\mathrm{Pb}$. Este erro foi devido a uma 
interferência espectral ocasionada provavelmente pela presença dos elementos $\mathrm{Ti}$ ao $\mathrm{Zn}$ nos componentes metálicos do arranjo experimental, ausentes no suporte refletor de quartzo, colimador do detector ou solução do padrão interno. Sem a eliminação dessa interferência, os resultados obtidos por TXRF para estes elementos, com exceção para $\mathrm{As}$, Se e $\mathrm{Pb}$, só podem ser utilizados como qualitativos. Para análise de sedimentos em suspensão foi utilizada a técnica de EDXRF, assumindo a amostra como filme fino, atingindo limite de detecção da ordem de $2 \mu \mathrm{g} \mathrm{g}^{-1}$ para $\mathrm{Pb}$, enquanto que para o $\mathrm{Cu}$ e $\mathrm{Zn}$ o limite de detecção foi da ordem de $5 \mu \mathrm{g} \mathrm{g}^{-1}$, em $300 \mathrm{~s}$. Para sedimento de fundo foi utilizada a mesma técnica, mas admitindo a amostra como espessa, corrigindo-se o efeito matriz através do fator de absorção, validando-a pela análise de amostras certificadas de sedimento (SRM1646a/NIST) e solo (SRM2711/NIST). O limite de detecção para $\mathrm{Pb}$ ficou em torno de $2 \mu \mathrm{g} \mathrm{g}^{-1}$, e para outros elementos os limites foram de 3,07 $\mu \mathrm{g} \mathrm{g}^{-1}$ para Ni, 2,12 $\mu \mathrm{g} \mathrm{g}^{-1}$ para Cu e $1,50 \mu \mathrm{g} \mathrm{g}^{-1}$ para $\mathrm{Zn}$, em $500 \mathrm{~s}$. Com base nos valores máximos permitidos para $\mathrm{Pb}$, estabelecidos pela Portaria 1469/00 e Resolução 20/1986 CONAMA, duas amostras de água mostraram-se contaminadas pelos resultados obtidos pela variante EDXRF, e quatro pelos resultados da TXRF. Para os outros elementos, apesar da interferência na TXRF, por esta técnica uma amostra de água ultrapassou o limite permissível para $\mathrm{Cu}$ e todas as cinco para Zn, e pela EDXRF uma amostra para Ni e Cu em água, e três para $\mathrm{Zn}$. Na legislação brasileira não há limite máximo permitido para $\mathrm{Pb}$ e outros elementos em solos e sedimentos, e portanto foram adotados os limites TEL (Threshold Effect Level, nível limiar do efeito) e PEL (Probable Effect Level, nível provável do efeito), utilizados pela Agência Ambiental Canadense. As amostras de sedimento em suspensão mostraram concentrações de $\mathrm{Pb}$ menores que o limite de detecção, e das cinco amostras de sedimento de fundo, uma amostra apresentou valor acima do limite TEL, e outra, coletada num ponto bem ao lado da fábrica, acima do limite PEL. Para os outros elementos Ni, Cu e Zn, nenhuma das amostras de sedimento em suspensão ou de fundo não ultrapassaram os limites TEL. 


\title{
Use of two variants of X-ray fluorescence (EDXRF and TXRF) in the determination of lead in waters and sediments
}

\author{
Author: Liz Mary Bueno de Moraes \\ Adviser: Prof. Dr. Virgílio Franco do Nascimento Filho
}

SUMARY

This study had as main objective the use of two variants of the analytical technique of X-ray fluorescence, energy dispersive - EDXRF and total reflection - TXRF, for the determination of $\mathrm{Pb}$ in superficial and underground water and in suspended and bottom sediment samples. Five samples of each matrix were collected in a contaminated area near the closed battery plant, Indústria de Acumuladores Ajax Ltd., located on km 229 of the Jaú-Ipaussu highway, near the city of Bauru in São Paulo State, Brazil. The two variants - EDXRF with preconcentration with APDC and TXRF direct measurement - had shown satisfactory results in the determination of $\mathrm{Pb}$ in standard solutions and certified natural water sample SRM1640/NIST, obtaining compatible concentrations with the expected values. The first technique resulted in a $0.70 \mu \mathrm{g} \mathrm{L}^{-1}$ limit of detention, with $300 \mathrm{~s}$ analysis time, and the second one $4.46 \mu \mathrm{g} \mathrm{L}^{-1}$ in $200 \mathrm{~s}$. These two variants were also used for other chemical elements, such as $\mathrm{Ti}, \mathrm{Cr}, \mathrm{Mn}, \mathrm{Fe}, \mathrm{Co}, \mathrm{Ni}, \mathrm{Cu}, \mathrm{Zn}$ and $\mathrm{Br}$. EDXRF also showed better limits of detection for all the elements. For $\mathrm{Ni}$, $\mathrm{Cu}$ and $\mathrm{Zn}$, important in the industry of batteries, the limits of $0.34,0.27$ and 0.24 $\mu \mathrm{g} \mathrm{L}^{-1}$, respectively, were found, while with TXRF the values of around $1 \mu \mathrm{g} \mathrm{L}^{-1}$ were achieved. In the validation of these two methodologies for water analysis, the EDXRF showed results nearer to the expected values, while with TXRF the results were overestimated most of the times, with the exceptions of As, Se and Pb. This error was due to a spectral interference caused probably by the presence of the elements $\mathrm{Ti}$ to $\mathrm{Zn}$ in the metallic parts of the experimental arrangement, absent in 
the quartz reflecting support, detector collimator or internal standard solution. Without the elimination of this interference, the results for TXRF for these elements, with the exceptions of $\mathrm{As}$, Se and $\mathrm{Pb}$, can only be used as qualitative results. For analysis of suspended sediments, the EDXRF technique was used, assuming the sample as thin film, the limit of detection of around $2 \mu \mathrm{g} \mathrm{g}^{-1}$ for $\mathrm{Pb}$ was reached, while that for $\mathrm{Cu}$ and $\mathrm{Zn}$ was around $5 \mu \mathrm{g} \mathrm{g}^{-1}$, in $300 \mathrm{~s}$. For bottom sediments the same technique was used, but admitting the sample as thick, the matrix effect through the absorption factor was corrected, validating it for the analysis of certified samples of sediment (SRM1646a/NIST) and soil (SRM2711/NIST). The limit of detention for $\mathrm{Pb}$ was around $2 \mu \mathrm{g} \mathrm{g}^{-1}$ and for other elements the limits were 3.07, 2.12 and $1.50 \mu \mathrm{g} \mathrm{g}^{-1}$ for $\mathrm{Ni}, \mathrm{Cu}$ and $\mathrm{Zn}$, respectively, in $500 \mathrm{~s}$. On the basis of the Brazilian allowed maximum values for $\mathrm{Pb}$, established by Decree 1469/00 and Resolution 20/1986 CONAMA, two water samples were shown to be contaminated by the results gotten with variant EDXRF, and four by the results of TXRF. For the other elements from the TXRF results (despite the interference) one water sample exceeded the permissible limit for $\mathrm{Cu}$ and all the five for $\mathrm{Zn}$, and for the EDXRF results one sample for $\mathrm{Ni}$ and $\mathrm{Cu}$ and three for $\mathrm{Zn}$. In the Brazilian legislation there is no maximum limit allowed for $\mathrm{Pb}$ and other elements in soils and sediments; therefore, TEL (Threshold Effect Level) and PEL (Probable Effect Level) limits from the Canadian Environment Agency were adopted. The suspended sediment samples showed $\mathrm{Pb}$ concentrations lesser than the limit of detection. From the five bottom sediment samples, one sample presented a value above the TEL limit, and another one, collected in a point very close to the plant, above the PEL limit. For the other elements, $\mathrm{Ni}, \mathrm{Cu}$ and $\mathrm{Zn}$, none of the suspended or bottom sediment samples exceeded the TEL limits. 


\section{1 - INTRODUÇÃO E OBJETIVO}

O chumbo é um poluente ambiental extremamente tóxico de fácil absorção, sendo conhecido os seus efeitos perniciosos desde o começo da era cristã. A exposição aguda ou crônica pode causar desordens metabólicas e neuropsicológicas. Os sintomas neurológicos clássicos da exposição a esse elemento são a encefalopatia em crianças e a neurotoxicidade periférica em adultos e, além disso, interfere na produção de hemoglobina, resultando em anemia (Turner, 1990).

Também causa dano irreversível aos néfrons, levando a uma redução gradual na eficiência da excreção do ácido úrico. Constata-se igualmente, correlação entre altos níveis de chumbo durante a gravidez e maior freqüência de natimortos e abortos, podendo o transporte transplacentário deste elemento comprometer o sistema nervoso central do feto.

Também são associados altos níveis de chumbo na corrente sangüínea dos pais com a má formação congênita em crianças, pois os níveis costumeiramente encontrados em alguns locais de trabalho podem ser prejudiciais à espermatogênese. Há ainda evidências limitadas de que possa ser carcinogênico em seres humanos, sendo cânceres de rins os mais estreitamente associados à sua exposição.

De um modo geral, os compostos deste elemento são nocivos 
para os animais. O efeito da absorção do elemento nas plantas não parece grave, mas estas o acumulam, o qual será posteriormente absorvido pelos animais em caso de ingestão. Não há muitas referências no caso de contaminação de águas, sendo mais estudadas as contaminações em alimentos e plantas.

As fontes naturais de emissão para a atmosfera constituem-se basicamente na erosão do solo e emissões vulcânicas. As concentrações de chumbo no ar dependem dos locais considerados, ocorrendo menores concentrações em regiões rurais remotas e maiores nos arredores de minas de chumbo e em grandes centros metropolitanos.

A emissão antropogênica é muito maior em relação às emissões naturais. Uma das primeiras fontes antropogênicas foi a descoberta do beneficiamento de minérios de chumbo-prata. Porém, esse tipo de emissão se intensificou com a cunhagem da prata a cerca de 2.500 anos, durante o Império Romano.

Houve uma época em que a combustão da gasolina também contribuiu para as emissões antropogênicas, quando se utilizava o chumbo tetraetila na forma de aditivo. Hoje há outras fontes emissoras, onde os destaques são as indústrias recicladoras de baterias e fundições.

Este trabalho teve como objetivo principal a utilização da fluorescência de raios $\mathrm{X}(\mathrm{XRF})$ na determinação quantitativa de $\mathrm{Pb}$ dissolvido em amostras de águas superficiais e subterrâneas, e em sedimentos em suspensão e de fundo do córrego Vargem Limpa e do rio Bauru, nas proximidades da desativada Indústria Acumuladores Ajax Limitada, localizada no km 229 da Rodovia Jaú-Ipaussu, no município de Bauru, SP. 
Para tanto, na análise das amostras foram utilizadas duas variantes da fluorescência de raios $X$ denominadas por dispersão de energia (EDXRF) e por reflexão total (TXRF), sendo realizadas em duas instituições: (1) no Centro de Energia Nuclear na Agricultura (CENA/USP), em Piracicaba, SP, e (2) no Laboratório Nacional de Luz Síncrotron (LNLS), em Campinas, SP.

Esse trabalho posteriormente servirá de base para um outro mais detalhamento da região, com maior número de amostras de águas naturais, sedimentos em suspensão e de fundo, e também amostras de material particulado em suspensão (aerossol), incluindo ainda estudo de disponibilidade e fracionamento isotópico. 


\section{2 - REVISÃO BIBLIOGRÁFICA}

A fluorescência de raios $X$ (XRF $-X$-Ray Fluorescence) fundamenta-se na medida das intensidades dos raios $X$ característicos emitidos pelos elementos químicos componentes da matriz, quando devidamente excitada. Até 1966 a XRF era realizada unicamente na sua variante fluorescência de raios $X$ por dispersão de comprimento de onda (WDXRF Wavelength Dispersive X-Ray Fluorescence), utilizando-se espectrômetros baseados na lei de Bragg, os quais necessitam de um movimento sincronizado e preciso entre o cristal difrator e o detector.

Com o desenvolvimento do detector semicondutor de $\mathrm{Si}(\mathrm{Li})$ na década de 1960, capaz de discriminar diretamente raios $X$ de energias próximas, foi possível o surgimento de outra variante, denominada fluorescência de raios X por dispersão de energia (EDXRF - Energy Dispersive $X$-Ray Fluorescence).

Esta variante EDXRF, apesar de ter em geral menor sensibilidade analítica e maior interferência espectral, tem a vantagem do custo bastante reduzido e tem sido utilizada para uma série de aplicações em amostras sólidas (Zucchi \& Nascimento Filho, 1995). Com o recente desenvolvimento nos últimos dez anos de outros detectores semicondutores, capazes de trabalhar à temperatura ambiente, esta variante tem possibilitado outras aplicações, inclusive análise in situ (Argyraki et al., 1997; Bernick et al., 1995). 
A técnica de fluorescência de raios $X$ por reflexão total (TXRF Total Reflection X-Ray Fluorescence) é uma variante da EDXRF, e foi introduzida por Yoneda \& Horiuchi (1971). O princípio físico e aplicações foram desenvolvidos por Aiginger \& Wobrauscheck (1974) e os primeiros trabalhos datam da década de 1980.

Essa técnica vem sendo bastante desenvolvida nos últimos anos e tem sido aplicada principalmente para a análise de elementos-traço (na faixa de $\mathrm{ppb}$ ), diretamente em amostras líquidas (da ordem de microlitros), sem a necessidade de pré-concentração (Almeida, 2001; Cunha e Silva et al., 2002; Prange et al., 1993).

Em relação à determinação química dos elementos: ferro, manganês e zinco, a técnica de espectrometria de absorção atômica com chama (FAAS), apresenta-se satisfatória em alguns extratos; porém, quando se trata de cromo, cobre, níquel e chumbo a técnica se mostra insuficiente quanto à sensibilidade (Davidson et al., 1994). Os métodos espectrofotométricos comumente utilizados para o chumbo empregam reagentes tradicionais (Jin et al., 1987; Depena et al., 1995), entretanto, o seu emprego em análises em larga escala pode ser limitado devido a dificuldades operacionais (Sartini, 1995).

Para este tipo de estudo, envolvendo matrizes líquidas e sólidas, a técnica analítica de fluorescência de raios $X$ tem um grande potencial de aplicação. Por ser não destrutiva e instrumental, e ainda por permitir a análise de vários elementos simultaneamente, de modo rápido e a baixo custo, tem sido utilizada onde há necessidade de correlação entre os elementos essenciais e tóxicos. Assim, ela tem sido empregada para a avaliação qualitativa e quantitativa da composição química em vários tipos de matrizes, de interesse industrial, biológico, agropecuário, agroindustrial, geológico e ambiental (Nascimento Filho, 1999). 
Normalmente, a XRF é utilizada para amostras sólidas, permitindo a determinação simultânea ou seqüencial da concentração de vários elementos, sem a necessidade de digestão química da amostra, e conseqüentemente a destruição da amostra, como na maioria dos equipamentos convencionais de análises químicas. Pelo fato de não necessitar de digestão prévia, apresenta alta velocidade analítica. Deve ser lembrado que os instrumentos convencionais têm leitura rápida, mas necessitam de um tempo longo na digestão de amostras sólidas.

Em análises quantitativas a EDXRF tem a desvantagem de requerer métodos teóricos e experimentais para correção do efeito matriz, como absorção e/ou reforço dos raios $X$ característicos, sendo este efeito devido às interações dos elementos componentes da amostra (Tertian \& Claisse, 1982).

Este efeito de matriz não ocorre na TXRF, pois são utilizadas massas muito pequenas das amostras depositadas em um suporte, de modo a formar um filme fino. Dessa forma, não há necessidade de correção para o efeito matriz, podendo-se utilizar nas análises quantitativas uma regressão linear simples entre a intensidade dos raios $X$ e a concentração do elemento presente nas amostras.

Para a análise de amostras sólidas, a TXRF deve ser precedida de digestão química e diluição apropriada, como a utilizada em fotometria de chama, espectrofotometria, absorção/emissão atômica (AAS e AES) e suas variantes (ICP-0ES, ICP-MS). Apesar do tempo gasto nesta digestão, apresenta a vantagem de necessitar diminutas quantidades da amostra, da ordem de miligramas (Ayala et al., 1991), e de ser multielementar e simultânea.

Queralt et al. (2003) trabalharam com amostras de águas de córregos e vegetação em torno de áreas de minas de $\mathrm{Pb}-\mathrm{Zn}$ abandonadas. As 
amostras não sofreram digestão química, sendo analisadas diretamente por TXRF e EDXRF, respectivamente. Para tanto, obtiveram o valor de $5 \mu \mathrm{g} \mathrm{L}^{-1}$ como limite de detecção para o Pb por TXRF em amostras de água.

\section{1 - Pré-concentração}

Para amostras líquidas pode-se recorrer a uma pré-concentração, empregando-se troca iônica, precipitação, quelação, etc., transformando-a em amostra sólida. Apesar de os instrumentos convencionais utilizarem amostras líquidas diretamente, a XRF ainda com o procedimento de pré-concentração se apresenta interessante, pois é uma técnica multielementar e simultânea (Eksperiandova, 2002).

Ellis et al. (1982a, b) utilizaram o procedimento de préconcentração com ADPC para os elementos $\mathrm{Cr}, \mathrm{Mn}, \mathrm{Fe}, \mathrm{Co}, \mathrm{Ni}, \mathrm{Cu}, \mathrm{Zn}, \mathrm{As}$, Se, $\mathrm{Ag}, \mathrm{Cd}, \mathrm{Sb}, \mathrm{Hg}, \mathrm{Tl}$ e $\mathrm{Pb}$ em quantidades traços em amostras de água. Todos os elementos considerados, com exceção do $\mathrm{Cr}$ (III), $\mathrm{Mn}$ (II) e $\mathrm{TI}$ (I) foram recuperados. Cr (III) é na maior parte inerte por conta da estabilidade da espécie $\mathrm{Cr}\left(\mathrm{H}_{2} \mathrm{O}\right)_{6}{ }^{3+}$ enquanto complexos de $\mathrm{Mn}(\mathrm{II})$ são particularmente instáveis e complexos de $\mathrm{TI}(\mathrm{I})$ são solúveis. As sensibilidades por EDXRF são boas para todos os elementos, exceto para Sb (III), devido à baixa excitação da linha de emissão $L \alpha$, rendendo valores de limite de detecção de aproximadamente $0,3 \mu \mathrm{g}$ (3 ppb) e desvio padrão relativo com valores menores ou iguais a $5 \%$. 0 $\mathrm{Pb}$ não sofreu interferências espectrais desses elementos, nem da salinidade e da alta concentração dos íons $\mathrm{Ca}^{2+}$ da solução (Van Grieken, 1982).

Ulrich \& Hopke (1977) comparando diversos métodos de préconcentração em XRF, concluíram que APDC a pH 4 era o melhor agente precipitante não específico, superior ao DDTC para $\mathrm{Zn}$ e $\mathrm{Pb}$. Encontraram 
recuperações adequadas para $\mathrm{Fe}, \mathrm{Ni}, \mathrm{Cu}, \mathrm{Zn}, \mathrm{Se}, \mathrm{Pb}, \mathrm{Hg}, \mathrm{Cd}, \mathrm{Ti}, \mathrm{Cr}$, Th e TI, independente do nível de concentração do íon alcalino.

Elder et al. (1975) obteve precipitados em pH 2 com uma solução recém preparada de APDC em recuperações quantitativas para o $\mathrm{Cu}, \mathrm{Hg}$ e $\mathrm{Pb}$, embora não para $\mathrm{Fe}$ e $\mathrm{Zn}$, mas notaram uma forte depressão nas recuperações do zinco em água natural.

Pradzynski et al. (1976) usaram APDC e um carregador de $\mathrm{Fe}^{3+} \mathrm{e}$ reportaram limites de detecção de $1 \mu \mathrm{g} \mathrm{L}^{-1}$ para $\mathrm{V}, \mathrm{Cr}, \mathrm{Mn}, \mathrm{Cu}, \mathrm{Zn}, \mathrm{As}$, Se, Hg e $\mathrm{Pb}$, mas não verificaram a influência de íons majoritários e material húmico.

Há outros quelantes que também podem ser empregados para pré-concentração. Lau \& Ho (1993) utilizaram o quelante polimérico piperazina1,4-bis (ditiocarbamato). Elementos como $\mathrm{Fe}, \mathrm{Co}, \mathrm{Ni}, \mathrm{Co}, \mathrm{Zn} \mathrm{Hg}$ e $\mathrm{Pb}$ foram quantificados a partir de amostras de água, na faixa de $\mathrm{pH}$ 6-7. Os limites de detecção foram da ordem de $\mu \mathrm{g} \mathrm{L}^{-1}$ e os testes de recuperação entre $97 \mathrm{e}$ $105 \%$.

Em um estudo, Holynska et al. (1996) combinaram dois agentes quelantes, NaDDTC e APDC, na proporção de 1:1, e um solvente orgânico (MIBK - metil isobutil cetona) para posterior extração e análise por TXRF. Foram usadas amostras de água duas vezes destilada (branco), amostras de água mineral e de torneira. Os limites de detecção para $\mathrm{Pb}$ foram de $0,06 \mu \mathrm{g} \mathrm{L}^{-1}$ e os testes de recuperação ficaram na faixa de 99,25\%.

Para Alvarez et al. (2000) o melhor agente precipitador (quelante) foi o APDC em pH 4, o qual mostra respostas adequadas para vários metais, incluindo o chumbo, em amostras de águas de chuva. Foram feitos estudos da influência do $\mathrm{pH}$, da estabilidade e da concentração do agente quelante. As 
soluções de APDC se mostraram estáveis dentro de um intervalo de tempo de até $96 \mathrm{~h}$ após a preparação. A acidez da água foi analisada em $\mathrm{pH}$ na faixa de 3 a 7 , garantindo uma precipitação quantitativa. A precipitação com APDC mostrou ser um método relativamente simples e comprovado para atingir um fator de concentração de até 1000, que pode ser usado em EDXRF com um limite de detecção da ordem de $1 \mu \mathrm{g} \mathrm{L}^{-1}$.

Simabuco et al. (1998) coletaram amostras de água de três cidades e as submeteram a pré-concentração com APDC, obtendo limites de detecção de $8 \mu \mathrm{g} \mathrm{L}^{-1}$ para os elementos $\mathrm{Fe}, \mathrm{Cu}, \mathrm{Zn}$ e Pb (Kump et al., 1997).

Almeida et al. (2002) usaram uma matriz diferente, no caso álcool, e realizaram a pré-concentração, obtendo boa resposta para os elementos $\mathrm{Fe}$, $\mathrm{Cu}$ e $\mathrm{Zn}$, com limites de deteç̧ão na faixa de $\mathrm{ng} \mathrm{L}^{-1}$. As concentrações desses elementos se encontram nessa faixa, para amostras analisadas de aguardentes de cana.

Também se pode utilizar um feixe branco de radiação síncrotron (sem filtro) para excitação das amostras no modo de energia dispersiva. Simabuco et al. (1998) analisaram amostras de água de rios, pré-concentradas com uma solução $1 \%$ de APDC. A suspensão foi filtrada em membrana de celulose de 0,45 $\mu \mathrm{m}$ de porosidade, secas e analisadas. O limite de detecção para $\mathrm{Pb}$ encontrado foi de $8,08 \mu \mathrm{g} \mathrm{L}^{-1}$. 


\section{3 - FUNDAMENTOS TEÓRICOS}

\section{1 - Fluorescência de raios $X$}

A análise por fluorescência de raios $X$ é um método qualiquantitativo baseado na medida das intensidades (números de raios $X$ detectados por unidade de tempo) dos raios $X$ característicos emitidos pelos elementos que constituem a amostra, quando devidamente excitada (Bertin, 1975; Nascimento Filho, 1999). Os raios $X$ emitidos por tubo de raios $X$, ou raios $X$ ou gama por uma fonte radioativa, podem ser utilizados na excitação dos elementos, os quais, por sua vez, emitirão linhas espectrais com energias características e cujas intensidades estão relacionadas com a sua concentração na amostra.

Quando um átomo de um elemento presente em uma amostra é excitado, este tende a ejetar os elétrons dos níveis internos, e como conseqüência disto, elétrons dos níveis mais afastados realizam um salto quântico para preencher a vacância. Cada transição eletrônica constitui uma perda de energia para o elétron, e esta energia é emitida na forma de um fóton de raios $X$, de energia característica, podendo ser utilizado para a identificação do elemento emissor (Lederer et al., 1967).

Assim, de modo resumido, a análise por fluorescência de raios $X$ consiste em três fases: (1) excitação dos elementos que constituem a amostra; 
(2) dispersão dos raios X característicos emitidos e (3) detecção e medida desses raios $X$.

\subsection{1 - Excitação dos elementos}

Para provocar a emissão dos raios $X$ característicos pelos elementos que constituem a amostra, a excitação pode ser feita de vários modos: (1) por partículas carregadas aceleradas, como elétrons, prótons ou íons; (2) por raios X e gama, partículas alfa e beta, emitidos por radionuclídeos; e (3) por raios $X$ gerados em tubos. Deste modo, as máquinas geradoras de raios $\mathrm{X}$ têm sido as mais utilizadas, mas em análises de amostras com altos teores têm-se empregado fontes radioativas. Dependendo da energia da radiação $\mathrm{X}$ ou gama emitida pelo radionuclídeo utilizado, pode-se enfocar uma faixa ou outra de elementos de interesse.

Dentre os radionuclídeos utilizados como fontes de excitação, os mais interessantes do ponto de vista experimental, têm sido aqueles que se desintegram por captura eletrônica, com conseqüente emissão de raios $\mathrm{X}$, como $\circ{ }^{55} \mathrm{Fe}$ (meia-vida física de 2,7 anos; emissor de raios $\mathrm{X} \mathrm{Mn}-\mathrm{K} \alpha$, de 5,9 $\mathrm{keV})$ e ${ }^{109} \mathrm{Cd}(1,27$ anos; raios $\mathrm{X} \mathrm{Ag}-\mathrm{K} \alpha, 22,2 \mathrm{keV})$, e por emissão de partícula alfa, como o ${ }^{238} \mathrm{Pu}\left(86,4\right.$ anos; raios X U-L, de 13,6 e 17,2 keV) e ${ }^{241} \mathrm{Am}$ (428 anos; raios $\mathrm{X} \mathrm{Np-L}$, de 13,9 e 17,7 keV, e ainda os raios gama de 59,5 keV).

O tubo de raios-X é a fonte mais utilizada para geração de energia necessária para excitação, sendo o do tipo Coolidge (Ohlweiler, 1981). Um tubo altamente evacuado contendo um cátodo em forma de filamento de tungstênio (W) e um ânodo maciço (alvo) de molibdênio (Mo). Circuitos distintos servem para aquecer o filamento e acelerar os elétrons emitidos pelo cátodo em direção ao alvo. Sob impacto contra o alvo, os elétrons são levados à condição de 
repouso, transferindo sua energia cinética aos átomos do alvo de molibdênio (material anódico) $O$ resultado é a emissão de raios $X$ na forma de um espectro contínuo. Nem toda a energia elétrica se converte em energia radiante, o restante perde-se na forma de calor, por isso a necessidade de refrigerar o tubo.

Como já mencionado, para haver a produção de raios $\mathrm{X}$ característicos há necessidade de se retirar elétrons localizados nos níveis mais internos dos átomos, por exemplo, camada $\mathrm{K}$, e para isto a energia mínima para excitação deve ser superior à energia de ligação do elétron nesta camada, denominada energia de ligação eletrônica. Após ocorrer a ionização, um elétron mais externo tende a ocupar a vacância, havendo desse modo a emissão de raios $\mathrm{X}$ de energia característica, cujo valor depende da diferença da energia de ligação do elétron nos dois níveis eletrônicos.

\subsection{2 - Dispersão dos raios $X$}

Os métodos de dispersão usados na maioria dos espectrômetros de raios $X$ podem ser classificados em duas categorias: dispersão por comprimento de onda (WDXRF) e dispersão por energia (EDXRF), também chamada de não-dispersivo.

Na WDXRF há necessidade de um instrumento específico, onde os raios $\mathrm{X}$ característicos são selecionados por um cristal, de acordo com seus comprimentos de onda, obedecendo à lei de Bragg da difração.

No caso da EDXRF, os raios $X$ são selecionados através de pulsos eletrônicos produzidos em um detector apropriado, sendo as amplitudes destes pulsos diretamente proporcionais às energias dos raios $\mathrm{X}$. 


\subsection{3 - Detecção e medida dos raios X}

Os detectores mais utilizados na WDXRF são os proporcionais a gás e os cintiladores sólidos de $\mathrm{Nal}(\mathrm{TI})$, denominados de baixa resolução (notese que neste caso a separação dos raios $X$ é feita pelo cristal difrator), e na EDXRF, os semicondutores de $\mathrm{Si}(\mathrm{Li}), \mathrm{Ge}(\mathrm{Li})$ e Ge hiperpuro, denominados de alta resolução, pois têm a habilidade de separar diretamente os raios $X$ característicos (Figura 1).

$\mathrm{Na}$ EDXRF, o detector semicondutor de $\mathrm{Si}(\mathrm{Li})$ é empregado na detecção de raios $X$ de energia entre 1 a $25 \mathrm{keV}$, ou seja, raios X K (transição camada $L \rightarrow K$ ) emitidos pelos elementos de número atômico na faixa de 11 $(\mathrm{Na})$ a $50(\mathrm{Sn})$ e raios $X L$ (transição $\mathrm{M} \rightarrow \mathrm{L}$ ) dos elementos pesados, na faixa de $31(\mathrm{Ga})$ a $92(\mathrm{U})$. Para os raios $\mathrm{X} \mathrm{K}$ de alta energia, emitidos pelos elementos de número atômico alto $(Z>50)$, são mais aconselhados o uso dos detectores de $\mathrm{Ge}(\mathrm{Li})$ e Ge hiperpuro, devido à sua maior eficiência de detecção nesta região.

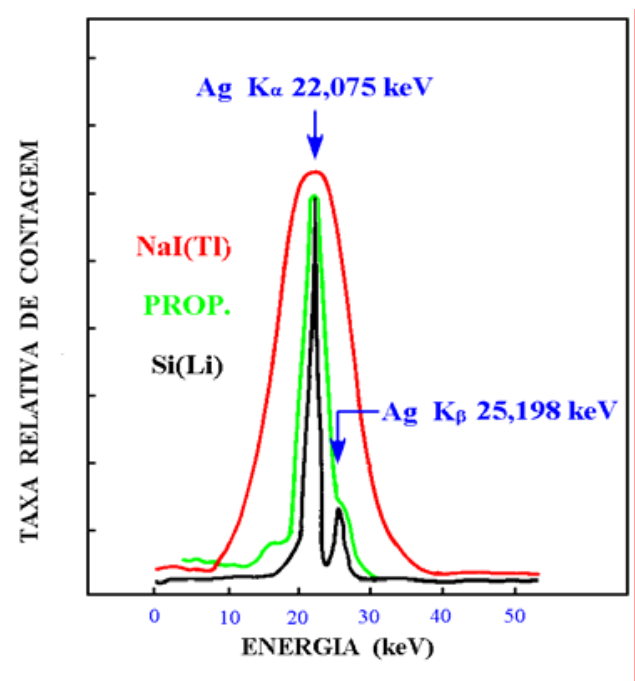

Figura 1. Resolução de alguns detectores para os raios $X$ característicos emitidos pela prata. 


\section{2 - Equação fundamental da fluorescência de raios $X$}

Para excitações com radiações eletromagnéticas, como as realizadas com tubos de raios $\mathrm{X}$ e fontes radioativas, há uma relação simples entre a intensidade de uma linha característica $(K \alpha$ ou $L \alpha)$ e a concentração do analito, como será visto a seguir.

Assumindo que a amostra seja homogênea, com espessura uniforme $\mathbf{D}$ e desprezando os efeitos de reforço, a equação que descreve a intensidade da linha $\mathrm{K} \alpha$ do analito de interesse produzida numa camada $\mathbf{d x}$ a uma profundidade $\mathbf{x}$ (Figura 2) pode ser escrita como produto de três probabilidades (Nascimento Filho, 1999): (1) a probabilidade da absorção do feixe de radiação eletromagnética primária ou de excitação pela amostra, atravessando a espessura $x / \operatorname{sen} \theta$; (2) a probabilidade de excitação e posterior emissão do raio $\mathbf{X}$ Kạdo analito presente na camada $\mathbf{d x}$; e (3) a probabilidade de absorção do raio $X$ característico Kạao atravessar a espessura $x / \operatorname{sen} \theta$, ser detectado.

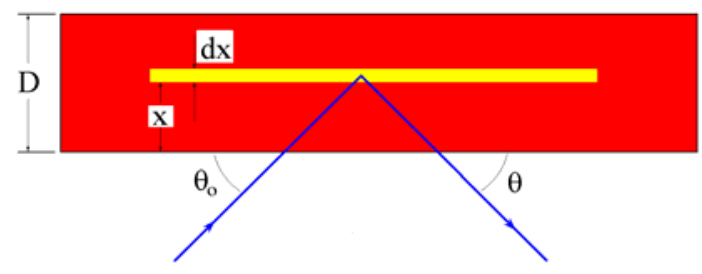

Figura 2. Representação esquemática da geometria de excitação para feixe de radiação eletromagnética em fluorescência de raios $X$. 
A probabilidade $\mathbf{P}_{\mathbf{1}}$ de absorção do raio $\mathrm{X}$ primário pela amostra, atravessando a espessura $x / \operatorname{sen} \theta_{0}$ pode ser expressa através da equação 1 :

$$
\mathrm{P}_{1}=\mathrm{e}^{-\mu_{0} \cdot \rho_{0} \cdot \mathrm{x} / \operatorname{sen} \theta_{\mathrm{o}}}
$$

onde:

$\mu_{0}=$ coeficiente de absorção de massa da matriz $\left(\mathrm{cm}^{2} \mathrm{~g}^{-1}\right)$ na energia dos fótons incidentes;

$\rho_{\mathrm{o}}=$ densidade da matriz $\left(\mathrm{g} \mathrm{cm}^{-3}\right) ; \mathrm{e}$

$\theta_{\mathrm{o}}=$ ângulo de incidência (entre a direção do feixe incidente e a superfície da amostra).

O valor de $\mu_{\mathrm{o}}$ pode ser calculado como a somatória dos produtos dos coeficientes de absorção de massa pela fração em massa de todos os elementos presentes na amostra.

A probabilidade $\mathbf{P}_{2}$ da radiação de excitação produzir uma vacância nos átomos de um analito contidos na camada $\mathbf{d x}$, com conseqüente produção de raios $X$ característicos:

$$
\mathrm{P}_{2}=\tau \cdot\left(1-\frac{1}{\mathrm{j}}\right) \cdot \mathrm{w} \cdot \mathrm{f} \cdot \rho \cdot \mathrm{dx}
$$

onde:

$\tau=$ coeficiente de absorção de massa para efeito fotoelétrico do analito $\left(\mathrm{cm}^{2}\right.$

$\left.\mathrm{g}^{-1}\right)$ na energia de excitação; 
$\mathbf{j}$ = razão de salto (jump ratio) $\mathrm{K} \rightarrow \mathrm{L}$;

$\mathbf{w}=$ rendimento da fluorescência da camada $\mathrm{K}$;

$\mathbf{f}=$ fração de fótons $\mathrm{K}$ emitidos como raios $\mathrm{K} \alpha$ característicos do analito; e

$\rho=$ "densidade" $\left(\mathrm{g} \mathrm{cm}^{-3}\right)$ ou concentração do analito em base de volume na camada $\mathbf{d x}$.

O coeficiente de absorção para o efeito fotoelétrico exatamente na energia do corte de absorção (Figura 3), tem dois valores: um superior, que indica a probabilidade de se retirar elétrons de todas as camadas $K, L, M$, etc., e um inferior, que indica a probabilidade de se retirar elétrons de todas as camadas, com exceção da camada K (ou seja, camadas L, M, etc.).

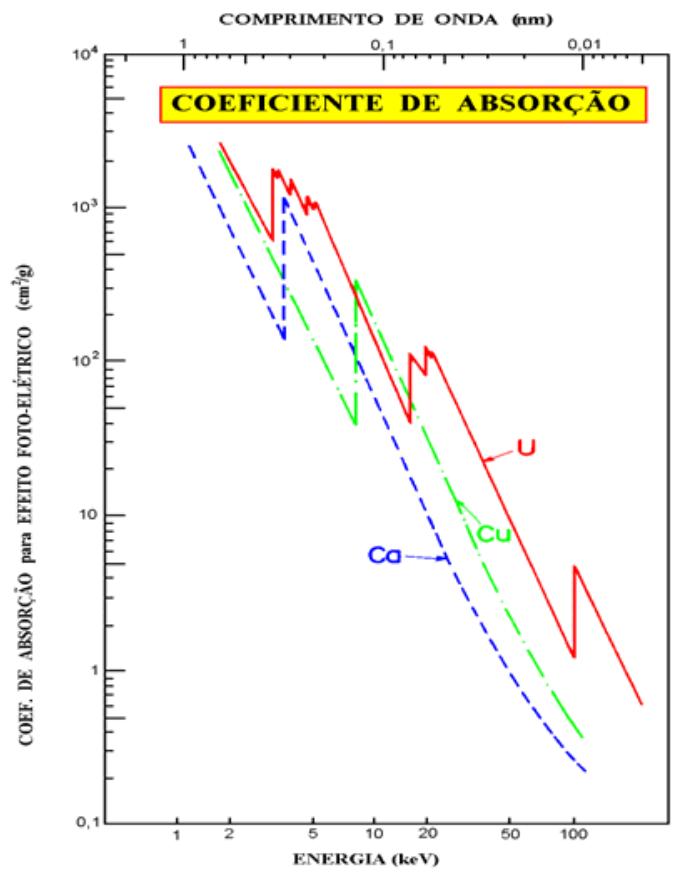

Figura 3. Dependência do coeficiente de absorção de massa em função da energia, para os elementos $\mathrm{Ca}$, $\mathrm{Cu}$ e U. 
Desse modo, a razão entre os valores, superior e inferior, denominada de razão de salto ou jump ratio, indica a probabilidade de se retirar elétrons de todas as camadas em relação à probabilidade das camadas $L, M$, etc. Por outro lado, o termo $(\mathbf{1 - 1 / j})$ representa probabilidade de se ionizar a camada $\mathrm{K}$ em relação a todas as camadas $\mathrm{K}, \mathrm{L}$, M, etc., e assim, o termo $\tau$.(11/j) representa o número de ionizações ocorridas na camada K (Figura 4).

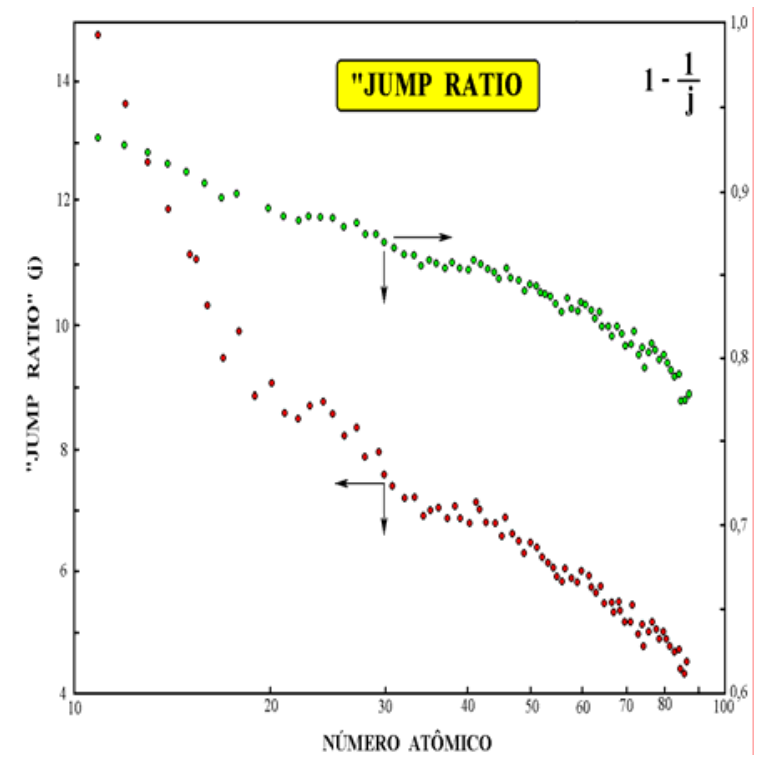

Figura 4: Valores da razão de salto (jump ratio) em função do número atômico

Os parâmetros fundamentais $\tau,(\mathbf{1 - 1 / j )}$, w e f da equação 2 são descritos conceitualmente como:

$\tau=$ coeficiente de absorção de massa para o efeito fotoelétrico do analito $\left(\mathrm{cm}^{2} \mathrm{~g}^{-1}\right)$ na energia de excitação, ou seja, probabilidade de retirar elétron de todas as camadas (K, L, M, etc.);

$\mathbf{j}$ = razão de salto (jump ratio) do analito para a camada $\mathrm{K}$,

$\mathbf{1 - 1 / j}=$ probabilidade de retirar elétrons da camada $\mathrm{K}$; 
$\mathbf{w}$ = rendimento de fluorescência para a camada $\mathrm{K}$, ou seja, probabilidade de haver emissão de raio $X$ característico $\mathrm{K}$ em relação às vacâncias da camada $\mathrm{K}$;

f = intensidade de emissão, ou seja, probabilidade de haver emissão do raio $\mathrm{X}$ característico $\mathrm{K} \alpha$ em relação aos raios $\mathrm{X}$ característicos $\mathrm{K}$ (em outras palavras, $\mathrm{K} \alpha+\mathrm{K} \beta)$.

Esses parâmetros, para um dado analito, dependem unicamente da energia de excitação e podem ser agrupados em um único termo $\mathbf{K}$, denominado de constante dos parâmetros fundamentais, e a assim a equação 2 pode ser reescrita como:

$$
\mathrm{P}_{2}=\mathrm{K} . \rho \cdot \mathrm{dx}
$$

A constante dos parâmetros fundamentais $\mathrm{K}$ corresponde ao termo:

$$
K=\tau .\left(1-\frac{1}{j}\right) \cdot w \cdot f
$$

A probabilidade, $\mathbf{P}_{3}$, é a do raio $X K \alpha$ característico produzido na camada $\mathbf{d x}$, não ser absorvido na espessura $\mathbf{x}$ e atingir o detector, produzindo um pulso eletrônico (ou uma contagem), dada por:

$$
P_{3}=e^{-\mu \cdot \rho_{0} \cdot x / \operatorname{sen} \theta} \cdot \varepsilon
$$

onde: 
$\mu=$ coeficiente de absorção de massa da matriz $\left(\mathrm{cm}^{2} \mathrm{~g}^{-1}\right)$;

$\varepsilon=$ eficiência do detector na energia dos fótons característicos, e

$\theta$ = ângulo de emergência (entre a superfície da amostra e a direção do feixe emergente).

A eficiência $\varepsilon$ do detector pode ser calculada teoricamente a partir das dimensões dos componentes do detector (camadas ativa e morta de $\mathrm{Si}$, camada de ouro, janela de Be, etc.), especificados pelo fabricante, distância entre a amostra e detector, e condições de excitação (sob vácuo, ar ou gás hélio).

Assim, a intensidade fluorescente dI (ou a taxa de contagem) produzida pelo analito contido na camada $\mathbf{d x}$ pode então ser descrita como:

$$
\mathrm{dI}=\mathrm{G} \cdot \mathrm{e}^{-\mu_{0} \cdot \rho_{0} \cdot \mathrm{x} / \operatorname{sen} \theta_{0}} \cdot \tau \cdot \mathrm{w} \cdot\left(1-\frac{1}{\mathrm{j}}\right) \cdot \mathrm{f} \cdot \rho \cdot \mathrm{dx} \cdot \mathrm{e}^{-\mu \cdot \rho_{0} \cdot \mathrm{x} / \operatorname{sen} \theta} \cdot \varepsilon
$$

onde:

$\mathbf{G}=$ fator de geometria.

Sendo G é uma constante de proporcionalidade e depende da geometria do sistema de excitação-detecção, da corrente do tubo ou da atividade da fonte, etc., contudo, não depende do próprio analito.

A equação 6 pode ser descrita como: 
$\mathrm{dI}=\mathrm{G} \cdot \mathrm{e}^{-\left(\mu_{0} / \operatorname{sen} \theta+\mu / \operatorname{sen} \theta_{0}\right) \cdot \rho_{0} \mathrm{x}} \cdot \tau \cdot \mathrm{w} \cdot\left(1-\frac{1}{\mathrm{j}}\right) \cdot \mathrm{f} \cdot \rho_{0} \cdot \varepsilon \cdot \mathrm{d} \mathrm{x}$

Definindo-se o coeficiente de absorção de massa total $\chi$ como:

$$
\chi=\mu_{0} / \operatorname{sen} \theta_{0}+\mu / \operatorname{sen} \theta
$$

Pode-se reescrever a equação 7 na forma:

$$
\mathrm{dI}=\mathrm{G} \cdot \varepsilon \cdot \mathrm{K} \cdot \mathrm{e}^{-x \cdot \rho_{0} \cdot \mathrm{x}} \cdot \rho \cdot \mathrm{dx}
$$

Integrando a equação acima sob a espessura total D da amostra, obtém-se a intensidade fluorescente $\mathbf{I}$ (contagens $\mathrm{s}^{-1}$ ) para um dado analito:

$$
\mathrm{I}=\mathrm{G} \cdot \varepsilon \cdot \mathrm{K} \cdot \rho \cdot \frac{1-\mathrm{e}^{-\chi \cdot \rho_{0} \cdot \mathrm{D}}}{\chi \cdot \rho_{0}}
$$

A razão $\rho / \rho_{o}$ representa a "densidade" do analito em relação à densidade da matriz e, portanto, é a própria concentração $\mathbf{C}$ do analito na amostra, ou seja, a concentração fracional do analito em base de massa (g analito/g matriz). Sendo assim:

$$
\mathrm{I}=\mathrm{G} \cdot \varepsilon \cdot \mathrm{K} \cdot \mathrm{C} \cdot \frac{1-\mathrm{e}^{-\chi \cdot \rho_{0} \cdot \mathrm{D}}}{\chi}
$$


Já, a sensibilidade do espectrômetro de raios X, representada por $S$, para o analito, pode ser descrita da seguinte maneira:

$$
S=\text { G.e.K }
$$

Desse modo pode-se redefinir a equação 11 assim:

$$
I=S . C \cdot \frac{1-\mathrm{e}^{-\chi \cdot \rho_{0} \cdot D}}{\chi}
$$

Em alguns casos, ao invés de se referir à concentração $C$ do analito em base de massa, prefere-se referir à densidade superficial $\mathbf{c}$ do analito na amostra (g analito/ $\mathrm{cm}^{2}$ matriz), ou seja:

$$
c=C \cdot \rho_{o} \cdot D
$$

e, portanto, pode-se reescrever a equação 11 na forma:

$$
I=\text { S.c. } \frac{1-\mathrm{e}^{-\chi \cdot \rho_{0} \cdot D}}{\chi \cdot \rho_{\mathrm{o}} \cdot \mathrm{D}}
$$

A razão apresentada na equação 15 é denominada de fator de absorção A para o analito:

$$
\mathrm{A}=\frac{1-\mathrm{e}^{-\chi \cdot \rho_{0} \cdot D}}{\chi \cdot \rho_{\mathrm{o}} \cdot \mathrm{D}}
$$

Assim, a equação 15 pode ser reescrita na forma: 


$$
\mathrm{I}=\text { S.c.A }
$$

Desta forma, a concentração dos analitos na amostras, em termos de densidade superficial $\mathbf{c}$, está relacionada com a intensidade $\mathbf{I}$ dos raios $\mathrm{X}$ característicos $\mathrm{K} \alpha$ ou $\mathrm{L} \alpha$, com a sensibilidade elementar $\mathbf{S}$, experimental ou teoricamente determinada, e o fator de absorção $\mathbf{A}$.

\subsection{1 - Amostras semi-espessa e espessa}

No caso de amostras semi-espessa ou espessa, a radiação incidente e o raio $X$ característico são absorvidos de modo considerável, e sendo assim, para se calcular a concentração do analito faz-se necessária a determinação teórica ou experimental do fator de absorção.

Os métodos experimentais propostos para isto são o denominado de "emissão/transmissão" ou "do irradiador" (Simabuco, 1993), e também o de "espalhamento coerente/incoerente". Teoricamente também se pode calcular o fator de absorção através da equação 16 , tendo os valores da densidade superficial da amostra c $\left(\rho_{0} D\right.$ - g matriz $/ \mathrm{cm}^{2}$ matriz) e do coeficiente de absorção de massa total $\chi$ (equação 8). Esse cálculo pode ser realizado com o auxílio de programas específicos, como por exemplo, o programa AXIL, onde os valores dos coeficientes de absorção de massa, em função da energia das radiações eletromagnéticas, etc., estão armazenados na memória do programa. 


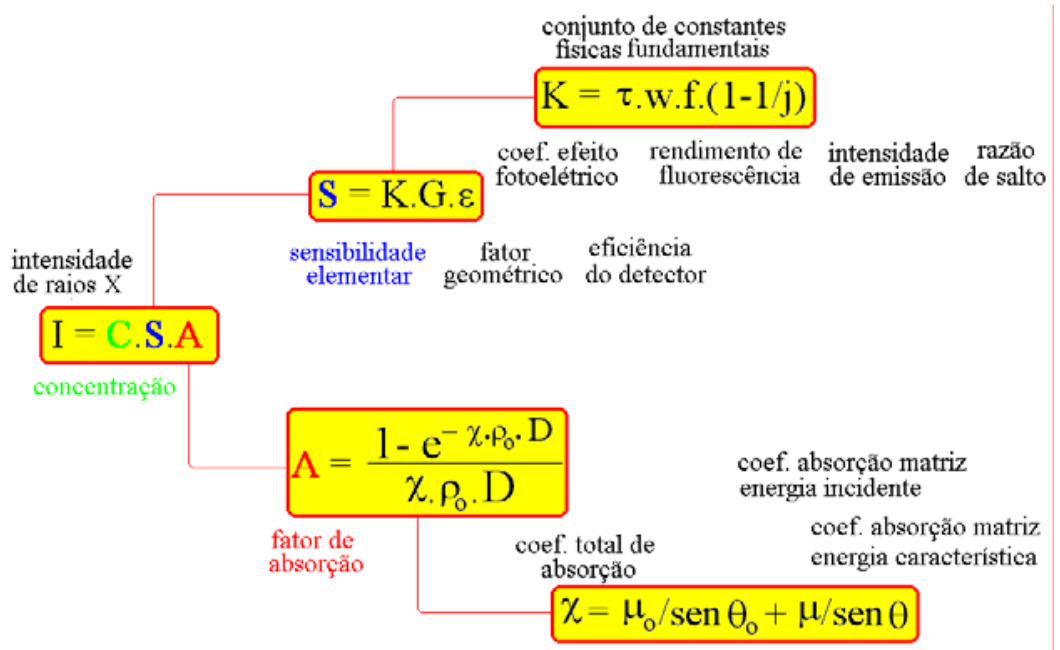

Figura 5. Representação esquemática da dependência entre as variáveis na equação fundamental de fluorescência de raios $X$ para excitação de radiação eletromagnética.

\subsection{2 - Amostra fina}

Para amostras consideradas finas, ou filmes finos, o termo $\chi \cdot \rho_{0} . D$ na equação 16 tende a zero, ou seja, $\chi \cdot \rho_{0} . D \rightarrow 0$, e o termo $\mathrm{e}^{-\chi \cdot \rho o . D} \rightarrow$ 1- $\chi \cdot \rho_{0} . D$, e nesta condição, o fator de absorção tem valor unitário, ou seja, $\mathbf{A}=1$, como mostra a equação 18.

$$
\text { I = S.C }
$$

\section{3 - Fluorescência de raios X por reflexão total}

Quando um feixe de radiação monocromática deslocando-se em um meio com índice de refração $\mathbf{n}_{1}$ incide sobre uma superfície plana de outro meio com índice de refração $\mathbf{n}_{\mathbf{2}}$, podem ocorrer dois fenômenos: (a) refração, 
em que o feixe penetra no meio $\mathbf{n}_{2}$ e sofre uma mudança de direção, e (b) reflexão total, onde o feixe é refletido na superfície do meio $\mathbf{n}_{2}$ e o ângulo de incidência é igual ao ângulo de emergência.

Para que o fenômeno da reflexão total ocorra, o ângulo de incidência deve ser menor que um determinado ângulo, denominado ângulo crítico $\phi_{\text {crit. }}$ Por outro lado, se o ângulo de incidência for igual ao ângulo crítico, o feixe monocromático seguirá paralelo à superfície do meio $\mathbf{n}_{2}$ (Figura 6).

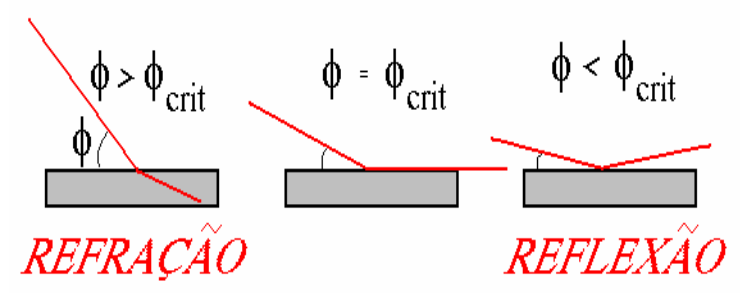

Figura 6. Representação esquemática da refração e reflexão total de um feixe de radiação monoenergético em função do ângulo de incidência.

Esse ângulo crítico é definido pela lei de Snell (equação 19) sendo dependente da densidade eletrônica do material refletor e da energia do feixe monoenergético. Por exemplo, utilizando-se um refletor de quartzo e feixe monocromático $\mathrm{K} \alpha$ do $\mathrm{Mo}$, com energia de 17,44 keV, o ângulo crítico será de 6,4 minutos.

$$
\phi_{\text {crit }}=\frac{99,1}{E} \sqrt{\frac{\rho 0 . Z}{A}}
$$

onde:

$\phi_{\text {crit }}=$ ângulo crítico (minuto); 
$\mathbf{E}=$ energia do feixe incidente $(\mathrm{keV})$;

$\rho_{0}=$ densidade do material refletor $\left(\mathrm{g} \mathrm{cm}^{-3}\right)$;

$\mathbf{Z}=$ número de elétrons em um átomo ou molécula componente do material refletor (elétrons $\mathrm{mol}^{-1}$ );

$\mathrm{A}$ = átomo-grama ou molécula-grama do material refletor $\left(\mathrm{g} \mathrm{mol}^{-1}\right)$.

Na técnica de TXRF, uma alíquota de 10 a $50 \mu \mathrm{L}$ da amostra é pipetada e seca sobre um suporte refletor, formando um filme fino, e excitada na geometria de reflexão total. Deste modo, o feixe incidente será totalmente refletido não adentrando no suporte, e conseqüentemente, não produzirá espalhamento por efeitos Rayleigh e Compton, e também resultará em um baixo nível de background. Mesmo assim, os elementos componentes da amostra serão excitados pelo feixe incidente antes e depois de ser refletido.

Pode-se reduzir a distância entre a amostra e detector de 3 a 5 $\mathrm{mm}$, enquanto na EDXRF essa distância é de 2 a $4 \mathrm{~cm}$, aumentando assim a eficiência de detecção dos raios $X$ característicos maximizando a razão pico/background.

\subsection{1 - Análise quantitativa}

Em TXRF o fator de absorção mostrado na equação 17 torna-se unitário $(\mathrm{A}=1)$ devido à formação de um filme fino, e deste modo a concentração do analito pode ser correlacionada diretamente com a intensidade e à sensibilidade. 
Mas há outros fatores, como flutuações no gerador de raios $\mathrm{X}$, emissão de raio $X$ pelo ânodo, erros operacionais (como pipetagem), erro de geometria, etc., que necessitam ser corrigidos e para isso se utiliza um elemento químico como padrão interno, por exemplo, o $\mathrm{Ga}$, para corrigir essas instabilidades de sistema. Neste caso o elemento utilizado como padrão interno não pode fazer parte da amostra, ou deve ocorrer em concentrações baixíssimas.

Deste modo a equação 18 pode ser reescrita fazendo-se as correções das intensidades pela adição de um elemento químico (não componente da amostra em análise) como padrão interno (Nascimento Filho et al., 1999). Para o analito a equação 15 é descrita como:

$$
I_{i}=S_{i} . C_{i} . A_{i}
$$

onde $A_{i}=1$, no caso de amostras finas, e assim a equação 20 pode ser reescrita:

$$
\mathrm{I}_{\mathrm{i}}=\mathrm{S}_{\mathrm{i}} \cdot \mathrm{C}_{\mathrm{i}}
$$

Para o padrão interno a equação 17 é descrita desta maneira:

$$
\mathrm{I}_{\mathrm{p}}=S_{\mathrm{p}} \cdot \mathrm{C}_{\mathrm{p}} \cdot \mathrm{A}_{\mathrm{p}}
$$

onde $A_{p}=1$, para o caso de amostras finas, e assim a equação 22 será: 


$$
\mathrm{I}_{\mathrm{p}}=\mathrm{S}_{\mathrm{p} \cdot \mathrm{C}_{\mathrm{p}}}
$$

Realizando a razão entre as equações 21 e 23 obtem-se:

$$
\frac{I_{i}}{I_{p}}=\frac{S_{i}}{S_{p}} \cdot \frac{C_{i}}{C_{p}}
$$

onde:

$\mathbf{I}_{\mathbf{i}}=$ intensidade do analito $(\mathrm{cps})$;

$\mathbf{I}_{\mathbf{p}}=$ intensidade dos raios $\mathrm{X}$ característicos do padrão interno (cps);

$S_{\mathrm{i}}=$ sensibilidade do analito $\left(\mathrm{cps} \mu \mathrm{g}^{-1} \mathrm{~cm}^{2}\right)$;

$S_{p}=$ sensibilidade do padrão interno $\left(\operatorname{cps~} \mu \mathrm{g}^{-1} \mathrm{~cm}^{2}\right)$;

$\mathbf{C}_{\mathbf{i}}=$ densidade superficial do analito $\left(\mathrm{g} \mathrm{cm}^{-2}\right)$;

$\mathbf{c}_{\mathbf{p}}=$ densidade superficial do padrão interno $\left(\mathrm{g} \mathrm{cm}^{-2}\right)$;

A razão entre a sensibilidade do analito $S_{i}$ pela sensibilidade do padrão interno $S_{p}$, pode ser denominada de sensibilidade relativa $S_{i}$, e, portanto:

$$
\frac{\mathrm{I}_{\mathrm{i}}}{\mathrm{I}_{\mathrm{p}}}=\frac{\mathrm{C}_{\mathrm{i}}}{\mathrm{C}_{\mathrm{p}}} \cdot S_{\mathrm{i}}{ }^{\prime}
$$

A equação 24 representa a relação entre as intensidades e densidades superficiais do analito e do padrão interno.

Faz-se necessária a conversão das densidades superficiais em concentrações. Quando se toma uma alíquota $\lambda$ (microlitros ou $\mathrm{cm}^{3}$ ) de uma 
solução com concentração do analito $C_{\mathbf{i}}$ ( $g$ analito/ $\mathrm{cm}^{3}$ de solução), tem-se que a massa $\mathbf{m}_{\mathbf{i}}(\mathrm{g})$ do analito é dada por:

$$
\mathrm{m}_{\mathrm{i}}=\mathrm{C}_{\mathrm{i} .} \lambda
$$

A densidade superficial do analito é dada pela razão entre a concentração $\mathbf{C}$ (g analito) pela área do "spot" $\mathbf{A}\left(\mathrm{cm}^{2}\right)$ após secar a alíquota $\lambda$ $\left(\mathrm{cm}^{3}\right)$ sobre o refletor de quartzo, e, portanto tem-se para o analito:

$$
\mathrm{C}_{\mathrm{i}}=\frac{\mathrm{C}_{\mathrm{i}}}{\mathrm{A}}
$$

e para o padrão interno:

$$
c_{p}=\frac{C_{p}}{A}
$$

onde:

$C_{\mathbf{i}}=$ concentração do analito $\left(\mathrm{g} \mathrm{cm}^{-3}\right.$ de solução);

$\mathrm{C}_{\mathrm{p}}=$ concentração do padrão interno $\left(\mathrm{g} \mathrm{cm}^{-3}\right.$ de solução);

$\mathbf{A}=$ área do "spot" $\left(\mathrm{cm}^{2}\right)$.

Substituindo $\mathbf{c}_{\mathbf{i}}$ e $\mathbf{c}_{\mathbf{p}}$ na equação 25 , temos:

$$
\frac{\mathrm{I}_{\mathrm{i}}}{\mathrm{I}_{\mathrm{p}}}=\frac{\mathrm{C}_{\mathrm{i}}}{\mathrm{C}_{\mathrm{p}}} \cdot S_{\mathrm{i}}{ }^{\prime}
$$

e rearranjando a equação 29 , pode-se escrever: 


$$
\frac{\mathrm{I}_{\mathrm{i}}}{\left(\mathrm{I}_{\mathrm{p}} / \mathrm{C}_{\mathrm{p}}\right)}=\mathrm{C}_{\mathrm{i} . \mathrm{S}_{\mathrm{i}}{ }^{\prime}}
$$

Fazendo-se $\mathbf{R}_{\mathbf{i}}$ o primeiro termo da equação 30 :

$$
R_{i}=\frac{I_{i}}{\left(I_{p} / C_{p}\right)}
$$

e substituindo a equação 31 na 30 , tem-se:

$$
\mathrm{R}_{\mathrm{i}}=\mathrm{Si}^{\prime} \cdot \mathrm{C}_{\mathrm{i}}
$$

onde:

$\mathbf{R}_{\mathbf{i}}=$ intensidade relativa $\left(\mathrm{g} \mathrm{cm}^{-3}\right)$ dos raios $\mathrm{X}$ característicos do analito;

$\mathbf{C}_{\mathbf{i}}=$ concentração do analito $\left(\mathrm{g} \mathrm{cm}^{3}\right)$;

$\mathrm{S}_{\mathrm{i}}{ }^{\prime}=$ sensibilidade relativa do analito (adimensional);

\section{4 - Limite de detecção}

\subsection{1 - Amostra fina por EDXRF}

Conforme descrito em detalhes por Curie (1968), o limite de detecção em fluorescência de raios $X$ em amostras finas, é pode ser calculado através da equação: 


$$
L D=\frac{3}{S} \sqrt{\frac{I_{i(B G)}}{t}}
$$

onde:

LD = limite de detecção para o analito $\left(\mathrm{g} \mathrm{cm}^{-2}\right)$;

$\mathbf{I}_{\mathbf{i}(\mathbf{B G})}=$ intensidade (cps) do background sob o pico do analito;

$\mathbf{S}=$ sensibilidade do analito $\left(\mathrm{cps} \mathrm{g}^{-1} \mathrm{~cm}^{2}\right)$;

$\mathbf{t}=$ tempo de excitação/detecção (s).

\subsection{2 - Amostras semi-espessa e espessa por EDXRF}

No caso de amostras semi-espessas e espessas deve ser levado em consideração o fator de absorção. Assim, o limite de detecção pode ser dado pela equação:

$$
L D=\frac{3}{S A} \sqrt{\frac{I_{(B G)}}{t}}
$$

onde:

LD = limite de detecção para o analito $\left(\mathrm{g} \mathrm{cm}^{-2}\right)$;

$\mathbf{I}_{\mathbf{i}(\mathbf{B G})}=$ intensidade (cps) do background sob o pico do analito;

$\mathbf{S}=$ sensibilidade do analito $\left(\mathrm{cps} \mathrm{g}^{-1} \mathrm{~cm}^{2}\right)$;

A = fator de absorção (adimensional);

$\mathbf{t}=$ tempo de excitação/detecção (s). 


\subsection{3 - Amostra líquida por TXRF}

Na TXRF para se calcular o limite de detecção, utiliza-se a mesma fórmula para amostras finas (equação 33), porém, deve ser levado em consideração o padrão interno, como descrito por Nascimento Filho et al. (1999).

$$
\mathrm{LD}=3 \frac{\mathrm{C}_{\mathrm{Ga}}}{\mathrm{IGa}_{\mathrm{Ga}} S_{\mathrm{i}}^{\top}} \sqrt{\frac{\mathrm{I}_{\mathrm{i}(\mathrm{BG})}}{\mathrm{t}}}
$$

onde:

LD = limite de detecção para o analito $\left(\mathrm{g} \mathrm{cm}^{-3}\right)$;

$\mathbf{I}_{\mathbf{i}(\mathrm{BG})}=$ intensidade (cps) do background sob o pico do analito;

$\mathbf{S}^{\prime}{ }_{\mathrm{i}}=$ sensibilidade relativa do analito (adimensional);

$\mathrm{C}_{\mathrm{Ga}}=$ concentração do padrão interno $\mathrm{Ga}\left(\mathrm{g} \mathrm{cm}^{-3}\right)$;

$\mathbf{I}_{\mathrm{Ga}}=$ intensidade dos raios $\mathrm{X}$ característicos do padrão interno $\mathrm{Ga}$ (cps);

$\mathbf{t}=$ tempo de excitação/detecção (s). 


\section{4 - EXPERIMENTAL}

\section{1 - Coleta e preparo das amostras}

\subsection{1 - Água}

Foram coletadas amostras de águas superficiais e subterrâneas em três pontos do córrego Vargem Limpa, um ponto no rio Bauru e um ponto em um poço artesiano de uma propriedade em frente à indústria Acumuladores Ajax Ltda, conforme pode ser visto na Figura 7. Como controle foi utilizada amostra de água deionizada.

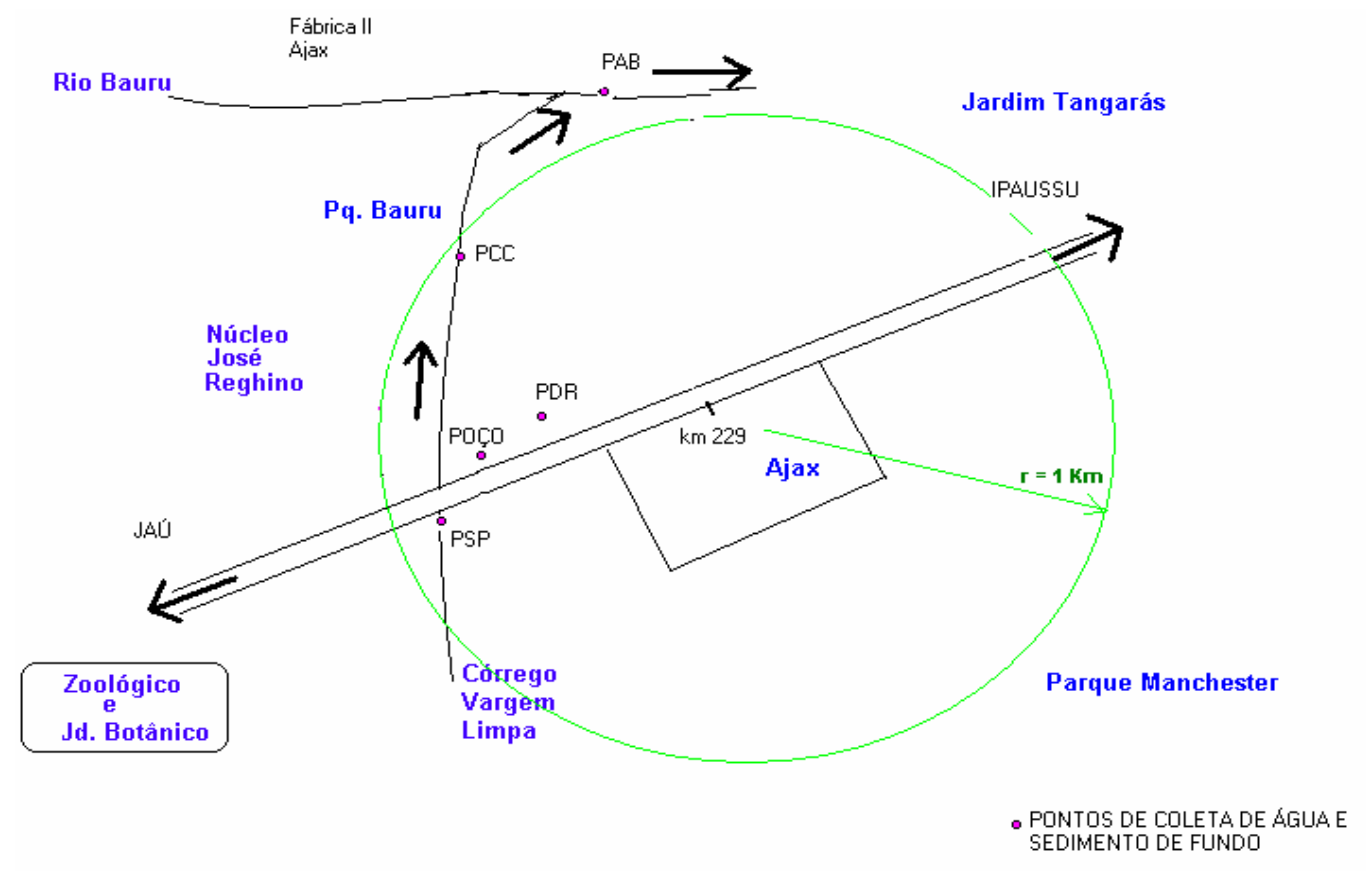

Figura 7: Esquema do local de amostragem e os pontos de coleta. 
As amostras foram codificadas da seguinte maneira:

- PSP = Ponto sobre a ponte na rodovia SP 225 - córrego Vargem Limpa

- POÇO = Poço Artesiano de sítio Estrela Guia

- PDR = Ponto no dreno do sítio Estrela Guia

- PCC $=$ Ponto no antigo Country Club

- PAB = Ponto no porto de areia do Alemão no rio Bauru

As amostras coletadas foram acondicionadas em garrafas

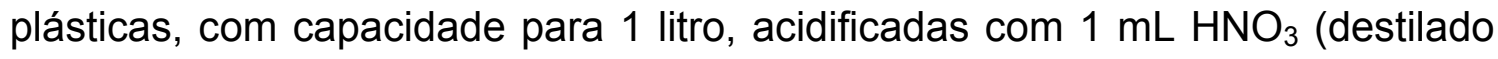
abaixo do ponto de ebulição em destilador de quartzo) para preservar as condições de coleta e evitar proliferação de fungos. As garrafas foram armazenadas em freezer .

Posteriormente, foram filtradas em membranas de éster de celulose, de 0,45 $\mu \mathrm{m}$ de porosidade e $47 \mathrm{~mm}$ de diâmetro, fabricados pela Millipore, para a retenção de sedimentos em suspensão.

\subsection{2 - Sedimento em suspensão}

As amostras dos sedimentos em suspensão foram obtidas através da filtragem das amostras de água e ficaram retidas em filtros de éster de celulose, de $45 \mu \mathrm{m}$ de porosidade e $47 \mathrm{~mm}$ de diâmetro, fabricados pela Millipore. Os filtros foram secos em estufa à temperatura de $28 \pm 3^{\circ} \mathrm{C}$ e submetidos à análise direta por EDXRF, como amostras finas, considerando-se $15,205 \mathrm{~cm}^{2}$ a área efetiva (local de deposição) no filtro. Essa técnica é a mesma utilizada para aerossol (material particulado em suspensão). 


\subsection{3 - Sedimento de fundo}

Com o auxílio de uma draga, foi coletado sedimento de fundo do córrego Vargem Limpa em três pontos e do rio Bauru em um ponto próximo ao porto de areia (Figura 7). Depois de secas, peneiradas e moídas (granulometria 100 mesh), as amostras dos sedimentos de fundo foram analisadas diretamente por EDXRF, na forma de pastilhas de $31 \mathrm{~mm}$ de diâmetro, com massa total de $1,7 \mathrm{~g}$, após homogeneização de $0,5 \mathrm{~g}$ de sedimento com 1,2 $\mathrm{g}$ de ácido bórico. As amostras certificadas SRM2711 e SRM1646a fabricadas pelo NIST (item 4.5) também passaram pelo mesmo processo de preparo e análise.

No preparo das pastilhas foi utilizado um agitador automático da marca Retsch, modelo MM2, para homogeneização da amostra (sedimento de fundo) com o ácido bórico, e posteriormente uma prensa automática até 35 toneladas da marca SPEX, modelo 3624B X-PRESS.

\section{2 - Pré-concentração da água para EDXRF}

Na pré-concentração foi utilizado o agente quelante não específico APDC. A $100 \mathrm{~mL}$ da amostra de água, que passou pela filtração para retenção do sedimento em suspensão, foi adicionado $\mathrm{NaOH}$ diluído para ajustar o $\mathrm{pH}$ ao valor 3; em seguida, foi adicionado $1 \mathrm{~mL}$ da solução de APDC $2 \%$ e agitou-se por 20 minutos. Após esta etapa deixou-se a solução em repouso por 10 minutos e em seguida foi agitada e filtrada em membranas de éster de celulose, de $0,45 \mu \mathrm{m}$ de porosidade e $47 \mathrm{~mm}$ de diâmetro, fabricadas pela Millipore. Em seguida, o filtro foi seco em estufa à temperatura de $28 \pm 3^{\circ} \mathrm{C}$ (Almeida et al., 2002; Simabuco et al., 2000). As amostras foram feitas em triplicatas, utilizando-se a média entre elas para a quantificação do $\mathrm{Pb}$. 
Foram preparadas soluções multielementares padrão a partir de soluções monoelementares padrão produzidas pela Aldrich, para serem realizados os testes de recuperação. Estas foram submetidas aos mesmos tratamentos das amostras de água para pré-concentração.

No preparo da pré-concentração foram utilizados uma bomba de vácuo, um agitador magnético e um conjunto de funis Duran Schott com capacidade para $250 \mathrm{~mL}$, resultando em filtros com 15,205 cm² de área efetiva.

\section{3 - Preparação das amostras de água para TXRF}

Para a análise por TXRF foram adicionadas alíquotas contendo o elemento $\mathrm{Ga}$ como padrão interno (proveniente da solução estoque $\mathrm{Ga} 10$ $\mathrm{mg} \mathrm{L}^{-1}$ ) às amostras e soluções-padrão (item 3.3.1). Também foi utilizada para o teste de recuperação a solução estoque de $\mathrm{Pb} 10 \mathrm{mg} \mathrm{L}^{-1}$. Abaixo está o esquema de preparo da amostra para um volume final de $1 \mathrm{~mL}$ em tubos Eppendorf:

$>$ amostras de água sem adição de $P b: 50 \mu \mathrm{L}$ padrão interno + $950 \mu \mathrm{L}$ da amostra.

$>$ amostras de água com adição de $P b: 50 \mu \mathrm{L}$ padrão interno $+100 \mu \mathrm{L}$ solução de $\mathrm{Pb}+850 \mu \mathrm{L}$ da amostra.

$>$ soluções-padrão: $50 \mu \mathrm{L}$ padrão interno $+950 \mu \mathrm{L}$ da solução-padrão.

> amostra certificada: $50 \mu \mathrm{L}$ padrão interno $+950 \mu \mathrm{L}$ da amostra certificada.

Posteriormente foram pipetados $10 \mu \mathrm{L}$ de amostra em suportes de quartzo (30 $\mathrm{mm}$ de diâmetro e 4,1 $\mathrm{mm}$ de espessura), secos em estufa à temperatura de $28 \pm 3^{\circ} \mathrm{C}$ e levados para análise por TXRF (Figura 8). 


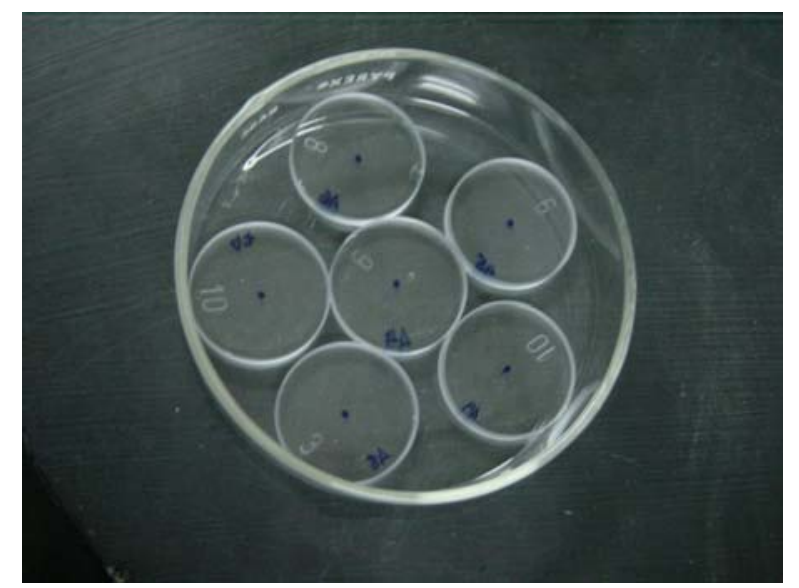

Figura 8. Suportes de quartzo contendo alíquotas das amostras, após secagem em estufa à temperatura de $28 \pm 3^{\circ} \mathrm{C}$.

\section{4 - Excitação e detecção}

\subsection{1 - Excitação e detecção em EDXRF}

As medidas por EDXRF (filtros e pastilhas) foram realizadas no Laboratório de Instrumentação Nuclear do Centro de Energia Nuclear na Agricultura -CENA/USP.

O conjunto usado para a excitação foi composto de um tubo de raios $\mathrm{X}$ com $2 \mathrm{~kW}$ de potência máxima, com alvo de Mo e filtro de $\mathrm{Zr}$, acoplado a um gerador de alta tensão, produzindo os raios $\mathrm{X} \mathrm{K \alpha}=17,44 \mathrm{keV}$. As condições de alta tensão e amperagem foram $25 \mathrm{kV}$ e $10 \mathrm{~mA}$. O tempo de excitação/detecção utilizado para os filtros (água pré-concentrada e sedimento em suspensão) foi de $300 \mathrm{~s}$ e para as pastilhas (sedimento de fundo) $500 \mathrm{~s}$. 
O sistema de detecção dos raios $X$ foi composto por um espectrômetro baseado em um detector semicondutor de $\mathrm{Si}(\mathrm{Li})$, de alta resolução, com janela de Be de 12,7 $\mu \mathrm{m}$ de espessura e resolução de $165 \mathrm{eV}$ a 5,89 keV, $80 \mathrm{~mm}^{2}$ de área ativa e $3 \mathrm{~mm}$ de espessura (modelo SLP-10160-P), acoplado a um módulo amplificador (modelo 572) e placa multicanal (modelo ACE-4K-W3), fabricados pela EG\&G Ortec, inserida em um microcomputador.

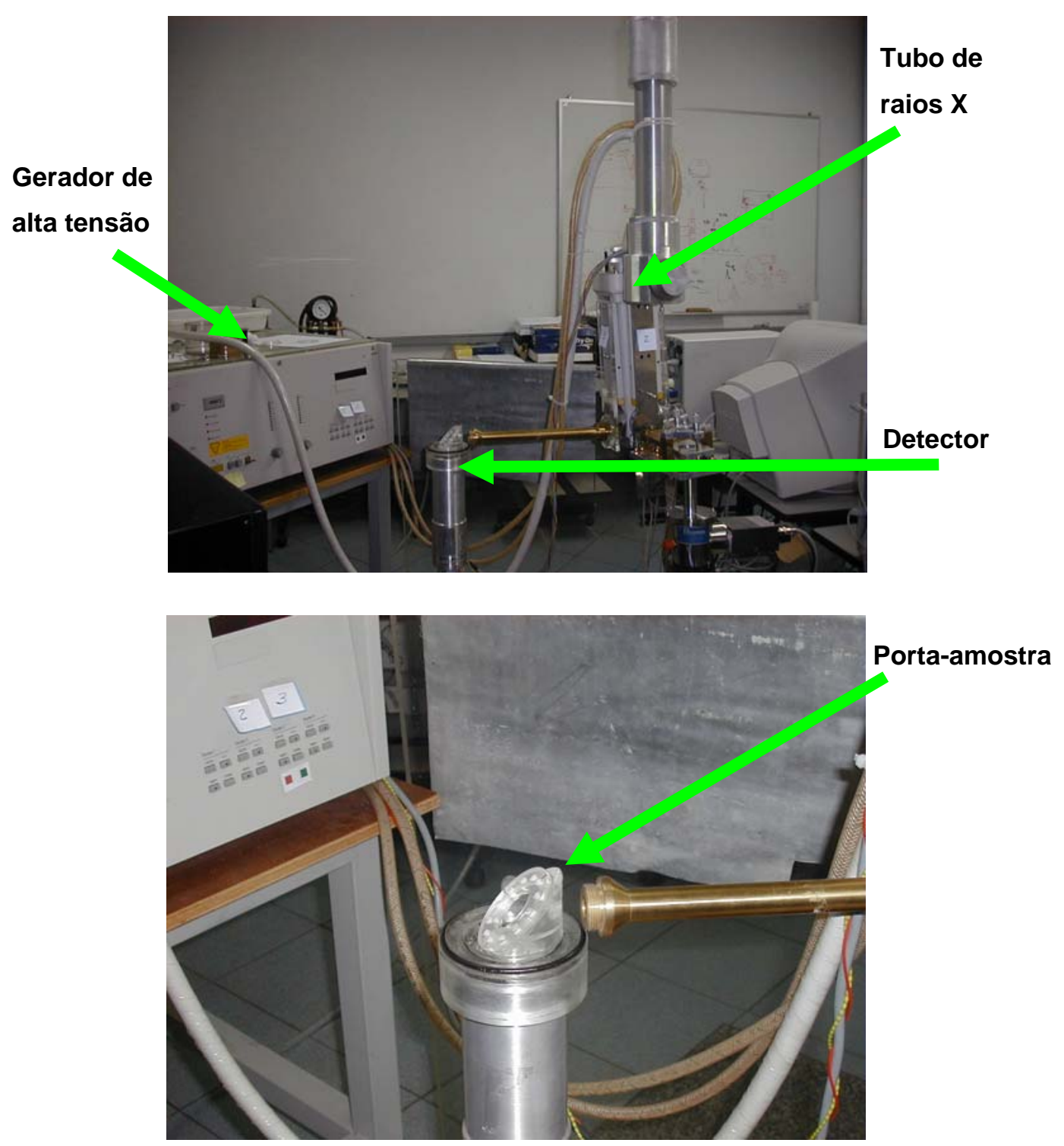

Figura 9. Foto do sistema excitação/deteç̧ão EDXRF do Laboratório de Instrumentação Nuclear, do CENA/USP, destacando o porta-amostra. 


\subsection{2 - Excitação e detecção em TXRF}

A excitação das amostras (água nos suportes de quartzo) foi realizada no Laboratório Nacional de Luz Síncrotron (LNLS), em Campinas/SP, nas seguintes condições operacionais: feixe branco com energia máxima de 25 $\mathrm{keV}$, com altura de $0,2 \mathrm{~mm}$ e largura de $5 \mathrm{~mm}$, filtro de Al no feixe, colimador de Ta no detector e tempo de excitação/detecção de 200 s. Na detecção foram utilizados um espectrômetro de raios X com detector semicondutor de $\mathrm{Ge}$ hiperpuro.
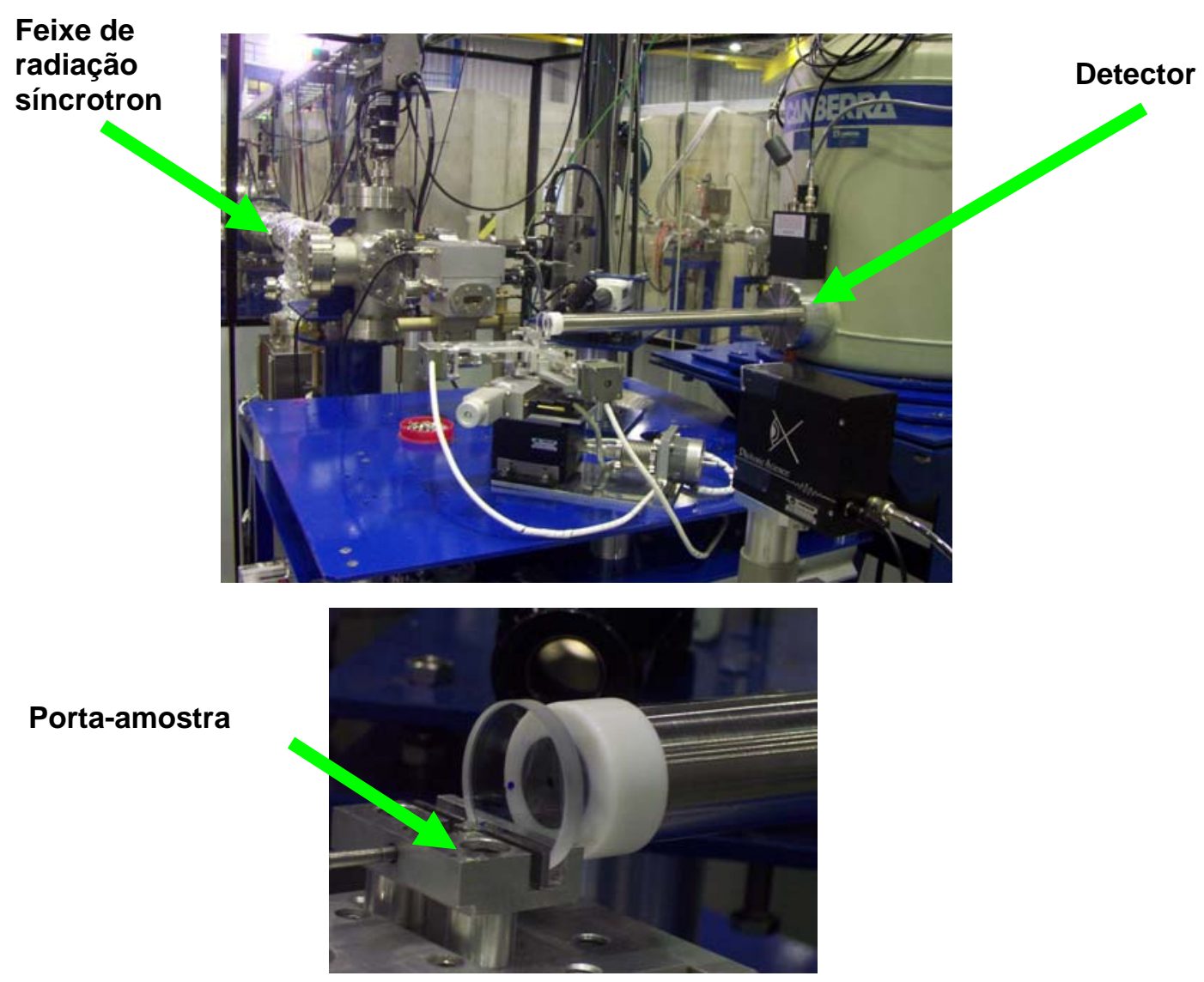

Figura 10. Foto do sistema de excitação/detecção por TXRF da linha de fluorescência de raios $X$ do Laboratório Nacional de Luz Síncrotron, Campinas/SP, destacando o porta-amostra com o suporte de quartzo contendo a amostra seca na posição de irradiação. 


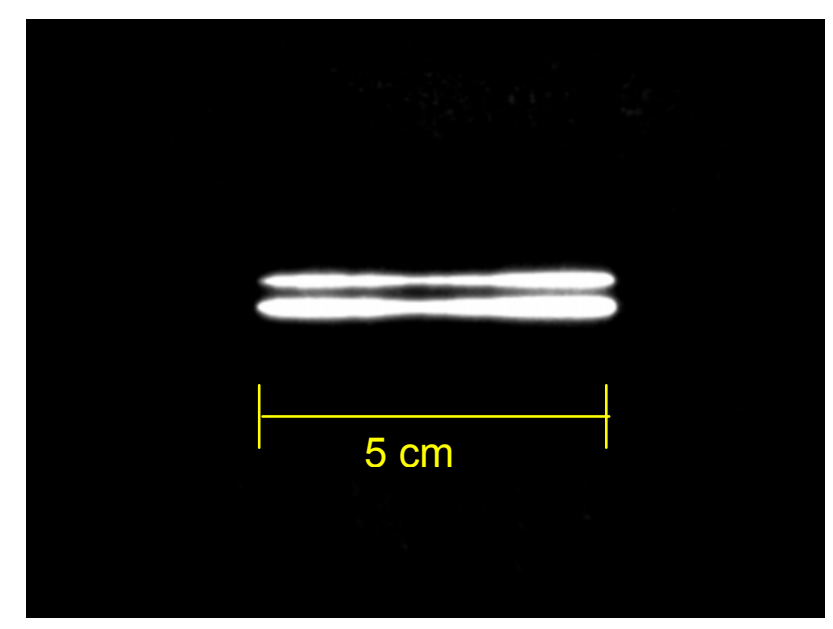

Figura 11. Foto da imagem produzida pela câmara CCD do feixe de reflexão total na linha de fluorescência de raios $X$ do Laboratório Nacional de Luz Síncrotron, Campinas/SP, utilizando o suporte de quartzo.

\section{5 - Reagentes e soluções}

$\mathrm{O}$ ácido $\mathrm{HNO}_{3}$ utilizado foi o de grau suprapur para acidificar as amostras e preparar o banho para a descontaminação das vidrarias e recipientes de conserva das amostras.

A solução, para pré-concentração, de APDC $2 \%(\mathrm{~m} / \mathrm{v})$ foi preparada a partir do reagente 1-pyrrolidinecarbodithioic acid, ammoniun salt 97\% (ácido 1-pirrolidinacarboditióico, sal de amônio 97\%), produzido pela Aldrich.

Foram preparadas soluções de $\mathrm{Pb}$ nas concentrações de 0,100 , 500 e $1000 \mu \mathrm{g} \mathrm{L}^{-1}$, a partir de uma solução estoque de $\mathrm{Pb}$ de $10 \mathrm{mg} \mathrm{L}^{-1}$ e esta foi obtida de uma solução-padrão produzida pela Aldrich. As soluções de $\mathrm{Pb}$ foram utilizadas na determinação da curva de calibração. 
O padrão interno utilizado foi uma solução estoque de $\mathrm{Ga}$ preparado numa concentração de $10 \mathrm{mg} \mathrm{L}^{-1}$ a partir de uma solução-padrão produzida pela Aldrich.

As soluções-padrão, Solução Multielementar (SM) e Padrão Multielementar (PM) (Tabela 1), utilizadas para os testes de recuperação, foram preparadas a partir de soluções-padrão multielementares e monoelementares produzidas pela Aldrich. Todas as diluições foram preparadas com água deionizada do sistema deionizador de água MILLI-Q da Millipore.

Tabela 1. Concentrações $\left(\mu \mathrm{L} \mathrm{L}^{-1}\right)$ dos elementos constituintes das soluçõespadrão SM e PM.

\begin{tabular}{ccc}
\hline Elementos & SM & PM \\
\hline $\mathrm{Ti}$ & 1000 & - \\
$\mathbf{V}$ & - & 1000 \\
$\mathrm{Cr}$ & - & 1000 \\
$\mathrm{Mn}$ & - & 1000 \\
$\mathrm{Fe}$ & 500 & 1000 \\
$\mathrm{Co}$ & - & 1000 \\
$\mathrm{Ni}$ & 1000 & 2000 \\
$\mathrm{Cu}$ & - & 1000 \\
$\mathbf{Z n}$ & 1000 & 2000 \\
$\mathrm{Ag}$ & - & 2000 \\
$\mathrm{Cd}$ & - & 2000 \\
$\mathrm{Ba}$ & - & 1000 \\
$\mathrm{~Pb}$ & 1000 & 2000 \\
\hline
\end{tabular}




\section{6 - Amostras certificadas}

Para a validação da metodologia de determinação de chumbo total em água pelas variantes da fluorescência de raios $X$, foi utilizada uma amostra certificada de água SRM1640 Natural Water Standard Reference Material, produzida pelo NIST. Para sedimento foram utilizados dois padrões de sedimento: SRM1646a - Estuarine Sediment e SRM2711 - Montana Soil, ambos produzidos pelo NIST.

Para a determinação das sensibilidades elementares foram utilizados padrões monoelementares de filme fino, produzidos pela MicroMatter/USA. As concentrações desses padrões estão expressas na Tabela 2.

Tabela 2. Concentrações $\left(\mu \mathrm{g} \mathrm{cm}^{-2}\right)$ dos padrões monoelementares de filme fino fabricados pela MicroMatter.

\begin{tabular}{cc}
\hline Elementos-Padrão & Concentração \\
\hline $\mathbf{C l}$ & 24,21 \\
$\mathbf{K}$ & 26,69 \\
$\mathrm{Ca}$ & 30,90 \\
$\mathrm{Sc}$ & 21,87 \\
$\mathrm{Ti}$ & 43,30 \\
$\mathrm{Mn}$ & 44,70 \\
$\mathrm{Fe}$ & 49,40 \\
$\mathrm{Cu}$ & 42,30 \\
$\mathrm{Zn}$ & 16,16 \\
$\mathrm{Te}$ & 31,54 \\
$\mathbf{P b}$ & 48,30 \\
\hline
\end{tabular}




\section{5 - RESULTADOS E DISCUSSÃO}

\section{1 - Análise de água por EDXRF com pré-concentração}

\subsection{1 - Curva de sensibilidade elementar}

Utilizando os padrões monoelementares de filmes finos fabricados pela MicroMatter foi determinada a curva de sensibilidade elementar (equação 18), mostrada na Figura 12, para os raios $X$ característicos $K \alpha$.

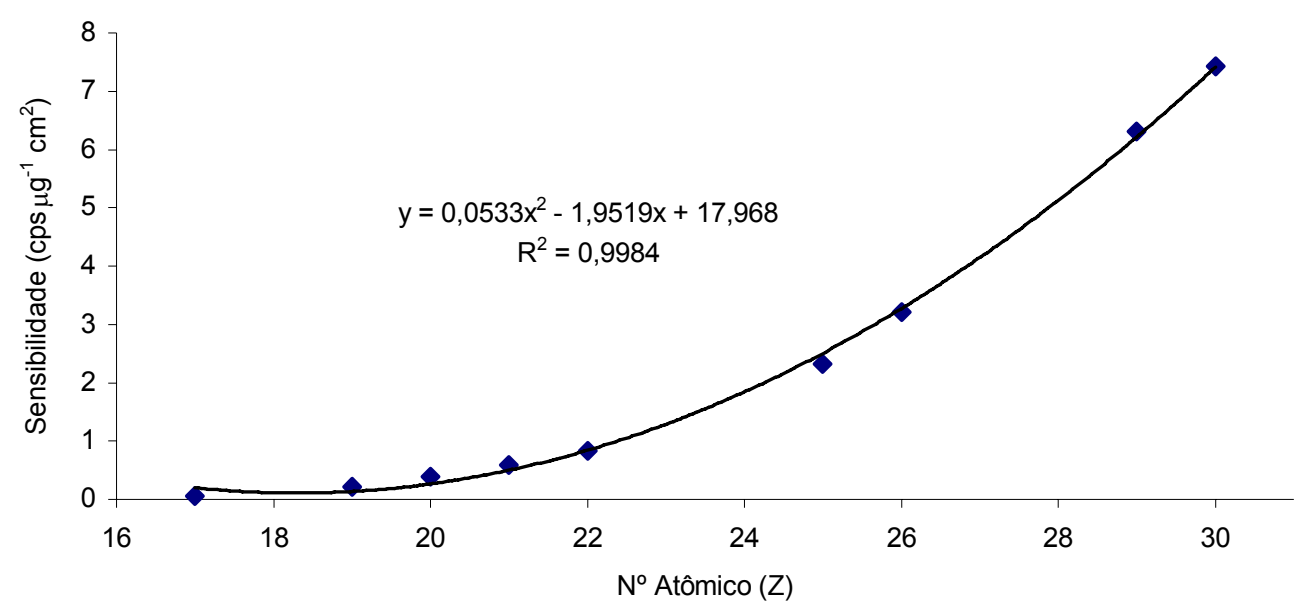

Figura 12. Sensibilidade elementar em função do número atômico para padrões de filme fino fabricados pela MicroMatter, para os raios $X$ característicos $K \alpha$. 
Através da equação de correlação entre o número atômico e a sensibilidade elementar obteve-se os valores das sensibilidades elementares para os analitos de interesse: $\mathrm{Ti}, \mathrm{Mn}, \mathrm{Fe}, \mathrm{Cu}$ e $\mathrm{Zn}$, Tabela 3, que foram utilizadas nos cálculos das concentrações dos analitos nas amostras a partir das intensidades dos raios $\mathrm{X}$ característicos obtidos.

Para os elementos $\mathrm{Te}$ e $\mathrm{Pb}$, as sensibilidades elementares foram calculadas através dos valores das concentrações (Tabela 2) e as intensidades dos raios $X$ característicos $L \alpha$ obtidos, utilizando a equação 18.

Tabela 3. Valores das sensibilidades elementares $\left(\mathrm{cps} \mu \mathrm{g}^{-1} \mathrm{~cm}^{2}\right)$ para os raios $X$ característicos $\mathrm{K} \alpha$ obtidas através da curva de sensibilidade elementar e pontualmente para $T e$ e $\mathrm{Pb}$, através dos raios $\mathrm{X}$ característicos $\mathrm{L} \alpha$.

\begin{tabular}{ccc}
\hline Elementos & $\begin{array}{c}\text { Sensibilidade } \\
\text { Pontual }\end{array}$ & $\begin{array}{c}\text { Sensibilidade } \\
\text { Experimental }\end{array}$ \\
\hline $\mathrm{Ti}$ & 0,8383 & 0,8234 \\
$\mathrm{Cr}$ & - & 1,8232 \\
$\mathrm{Mn}$ & 2,3171 & 2,4830 \\
$\mathrm{Fe}$ & 3,2131 & 3,2494 \\
$\mathrm{Co}$ & - & 4,1224 \\
$\mathrm{Ni}$ & & 5,1020 \\
$\mathrm{Cu}$ & 6,3025 & 6,1882 \\
$\mathbf{Z n}$ & 7,4242 & 7,3810 \\
$\mathrm{Br}$ & - & 14,9440 \\
$\mathrm{Te}$ & 0,1926 & - \\
$\mathbf{P b}$ & 4,6427 & - \\
\hline
\end{tabular}




\subsection{2 - Teste de recuperação em soluções padrão}

Objetivando analisar os efeitos do APDC na pré-concentração do $\mathrm{Pb}$, foram preparadas soluções de concentrações $0,10,50,100,500$ e 1000 $\mu g \mathrm{~L}^{-1}$.

Com a sensibilidade obtida para o $\mathrm{Pb}$ de $4,64 \mathrm{cps}_{\mu \mathrm{g}}^{-1} \mathrm{~cm}^{2}$ e as intensidades dos raios $X$ característicos $L \alpha$ foi calculada a concentração, após a pré-concentração, e com isto a recuperação, conforme Tabela 4.

Nota-se que nas concentrações de 100 e $500 \mu^{-1}$ as recuperações foram satisfatórias da ordem de $85 \%$. Mesmo estando abaixo do esperado, o teste de recuperação provou que é possível pré-concentrar o $\mathrm{Pb}$ quando forem tratadas amostras muito diluídas. Na concentração de 1000 $\mu \mathrm{g} \mathrm{L}^{-1}$ a recuperação foi total. Porém para concentrações entre 10 e $50 \mu \mathrm{g} \mathrm{L}^{-1}$ a recuperação ficou entre 45 e $63 \%$.

Tabela 4. Recuperação na pré-concentração de $\mathrm{Pb}$ em filtros de éster de celulose Millipore $(n=3)$.

\begin{tabular}{cc}
\hline Concentrações $\left(\mu \mathbf{g ~ L}^{-1}\right)$ & Recuperação (\%) \\
\hline $\mathbf{1 0}$ & 45,00 \\
$\mathbf{5 0}$ & 63,00 \\
$\mathbf{1 0 0}$ & 85,42 \\
$\mathbf{5 0 0}$ & 87,40 \\
$\mathbf{1 0 0 0}$ & 101,63 \\
\hline
\end{tabular}

Foram também utilizadas as duas soluções-padrão (item 4.4), SM e PM, para reforçarem o teste de recuperação para $\mathrm{Pb}$ e também para outros 
elementos contidos nestas soluções. A título de ilustração, na Figura 13 encontra-se o espectro de raios $X$ proveniente da solução padrão SM, após préconcentração com APDC, analisada por EDXRF, podendo-se visualizar os picos dos raios $\mathrm{X}$ característicos $\mathrm{K}$ dos elementos $\mathrm{Ti}, \mathrm{Fe}, \mathrm{Ni}$ e $\mathrm{Zn}$ e $\mathrm{L}$ do elemento $\mathrm{Pb}$.

Do mesmo modo anterior foram calculadas as concentrações e a recuperação para os elementos contidos nestas soluções, e os valores obtidos estão expressos na Tabela 5.

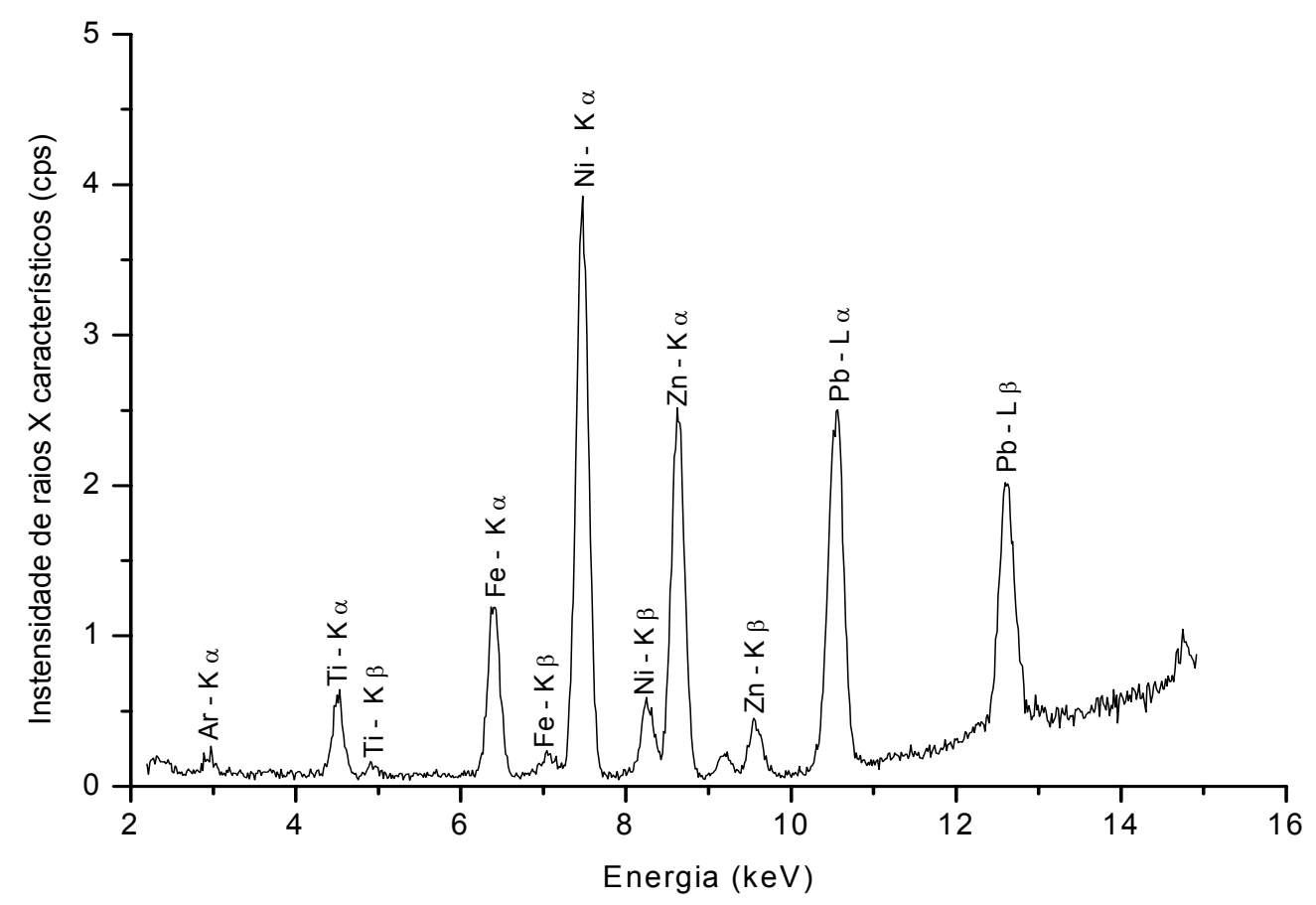

Figura 13. Espectro dos raios $X$ obtido por EDXRF proveniente da soluçãopadrão SM após pré-concentração com APDC. 
Tabela 5. Concentrações ( $\mu \mathrm{g} \mathrm{L}^{-1}$ ) e recuperação (\%) para as duas soluçõespadrão, SM e PM ( $n=3)$.

\begin{tabular}{ccccc}
\hline & \multicolumn{2}{c}{ SM } & \multicolumn{2}{c}{ PM } \\
\hline Elementos & Concentração $\left(\mu \mathbf{g ~ L}^{-1}\right)$ & Recuperação (\%) & Concentração $\left(\mu \mathbf{g ~ L}^{-1}\right)$ & Recuperação (\%) \\
Fe & 500 & 110,99 & 1000 & 96,75 \\
$\mathrm{Co}$ & - & - & 1000 & 102,14 \\
$\mathrm{Ni}$ & 1000 & 117,34 & 2000 & 101,78 \\
$\mathrm{Cu}$ & - & - & 1000 & 94,86 \\
$\mathbf{Z n}$ & 500 & 107,05 & 2000 & 93,34 \\
$\mathrm{~Pb}$ & 1000 & 102,01 & 2000 & 93,06 \\
\hline
\end{tabular}

Comparando as duas soluções-padrão nota-se uma recuperação muito satisfatória tanto para $\mathrm{Pb}$ como para os demais elementos. Porém quando se trabalha com elementos com números atômicos próximos e/ou seguidos, como por exemplo, o Fe e o Co, há uma tendência de um deles mascarar o resultado do outro, havendo uma interferência espectral. Na solução PM o Co se destaca na recuperação em relação ao $\mathrm{Fe}$, e já na solução SM o $\mathrm{Fe}$ tem uma recuperação maior, porque não entra em interferência com o Co, pois este elemento não se encontra nesta solução. Levando em consideração o aumento da concentração do $\mathrm{Fe}$, mesmo assim a recuperação ainda foi um pouco menor na solução PM em relação à solução $S M$, e o mesmo acontecendo para $\mathrm{O} \mathrm{Pb}$, as recuperações foram muito boas nas duas soluções $(93,06$ e $102,01 \%)$.

\subsection{3 - Resultados das análises de amostras de água por EDXRF com pré-concentração}

Depois de realizados os testes de recuperação, as cinco amostras de água foram submetidas à pré-concentração com APDC e analisadas. 
A título de ilustração na Figura 14 o espectro dos raios $X$ proveniente da amostra PCC após pré-concentração com APDC, analisada por EDXRF, podendo-se visualizar os picos dos elementos $\mathrm{Fe}, \mathrm{Zn}$ e $\mathrm{Pb}$ (o pico de Ar é devido ao ar).

Com base na intensidade e sensibilidade foram calculados as concentrações e o limite de detecção para $\mathrm{Pb}$ mostradas na Tabela 6 e Figura 15. Para os demais elementos encontrados nas amostras, os valores das concentrações estão na Tabela 7 e Figuras 16 e 17, e os limites de detecção na Tabela 8.

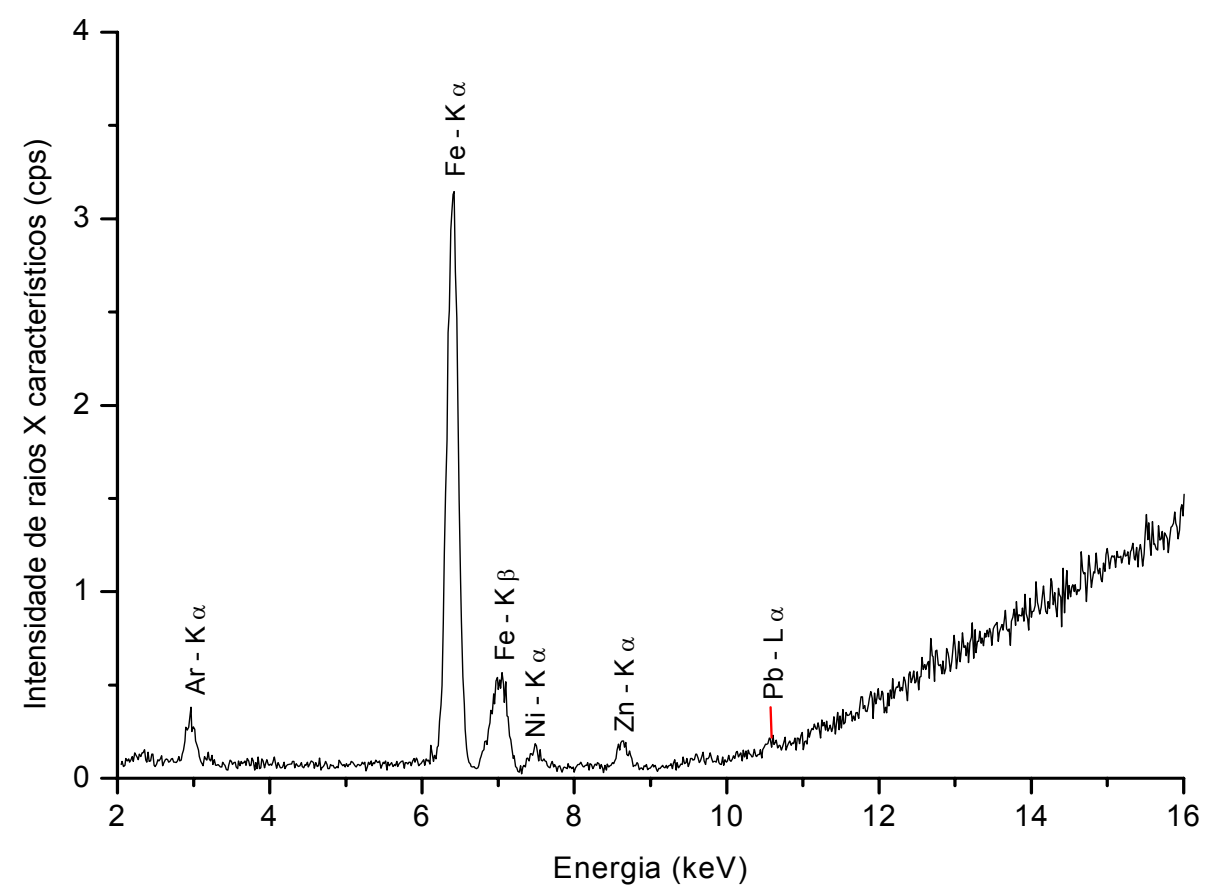

Figura 14. Espectro dos raios $X$ obtido por EDXRF proveniente da amostra de água PCC após pré-concentração com APDC. 
Tabela 6. Concentrações e desvio padrão $\left(\mu \mathrm{g} \mathrm{L}^{-1}\right)$ e limite de detecção $\left(\mu \mathrm{g} \mathrm{L}{ }^{-1}\right)$ do $\mathrm{Pb}$ nas amostras de água, determinadas por EDXRF, após pré-concentração com APDC, e 300 s de excitação/detecção $(n=3)$.

\begin{tabular}{|c|c|c|c|c|c|}
\hline \multicolumn{6}{|c|}{ Concentrações } \\
\hline Elemento & $\mathrm{PDR}^{\star *}$ & $\mathrm{PAB}^{* *}$ & $P C C^{* *}$ & POÇO* & PSP** \\
\hline $\mathbf{P b}$ & $19,27 \pm 1,93$ & $26,62 \pm 3,94$ & $34,84 \pm 0,15$ & $25,01 \pm 1,16$ & $20,03 \pm 2,08$ \\
\hline \multicolumn{6}{|c|}{ Limite de detecção } \\
\hline Elemento & PDR & PAB & PCC & POÇO & PSP \\
\hline $\mathbf{P b}$ & 0,58 & 0,57 & 0,60 & 0,70 & 0,64 \\
\hline
\end{tabular}

* Portaria 1469/00: limite máximo permitido $=10 \mu \mathrm{g} \mathrm{L}^{-1}$

** CONAMA resolução ${ }^{\circ}$ 20/1986: limite máximo permitido $=30 \mu \mathrm{g} \mathrm{L}^{-1}$

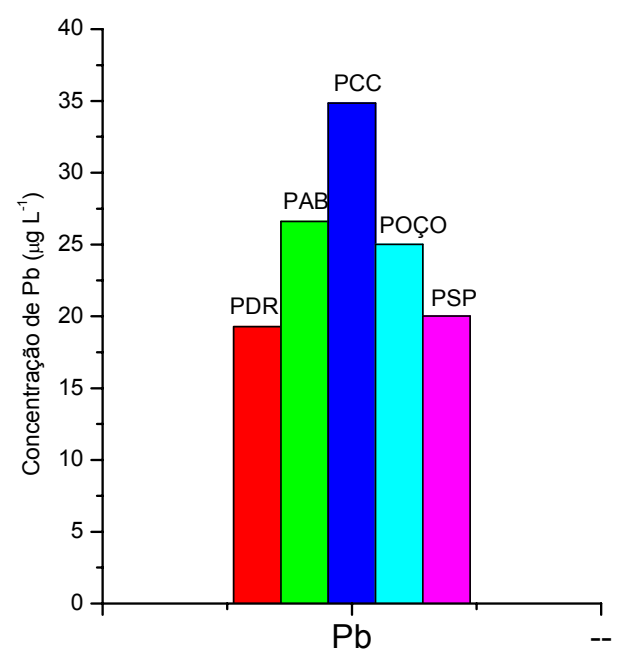

Figura 15: Distribuição das concentrações de $\mathrm{Pb}\left(\mu \mathrm{g} \mathrm{L}^{-1}\right)$ presente nas amostras de água coletadas nos diferentes pontos de amostragem. 
Tabela 7. Concentrações e desvios padrão $\left(\mu \mathrm{g} \mathrm{L}^{-1}\right)$ dos elementos encontrados nas amostras de água, determinadas por EDXRF, após pré-concentração com $\operatorname{APDC}(n=3)$.

\begin{tabular}{cccccc}
\hline Elemento & PDR & PAB & PCC & POÇO & PSP \\
\hline Ti & $20,25 \pm 0.43$ & $53,51 \pm 9,83$ & $27,61 \pm 3,64$ & $24,79 \pm 5,13$ & $16,32 \pm 2,57$ \\
Cr & $13,48 \pm 0,59$ & $20,71 \pm 5,70$ & $18,72 \pm 3,10$ & $11,12 \pm 1,82$ & $10,01 \pm 0,39$ \\
Mn & $25,15 \pm 5,26$ & $18,52 \pm 1,70$ & $20,56 \pm 3,18$ & $9,30 \pm 2,32$ & $9,62 \pm 1,79$ \\
Fe & $1139,5 \pm 65,6$ & $2052,7 \pm 403$ & $1572,8 \pm 93,3$ & $98,04 \pm 0,78$ & $386,1 \pm 7,7$ \\
Co & $56,62 \pm 0,43$ & $90,92 \pm 4,43$ & $20,16 \pm 0,52$ & $8,73 \pm 1,91$ & $40,14 \pm 2,87$ \\
Ni & $5,66 \pm 1,83$ & $32,43 \pm 1,05$ & $8,25 \pm 0,42$ & $3,18 \pm 0,28$ & $5,02 \pm 0,07$ \\
Cu & $3,06 \pm 0,57$ & $29,39 \pm 1,42$ & $3,57 \pm 0,56$ & $12,51 \pm 0,17$ & $2,73 \pm 0,34$ \\
Zn & $46,93 \pm 0,63$ & $78,37 \pm 8,30$ & $34,43 \pm 1,40$ & $15,70 \pm 0,10$ & $11,43 \pm 1,98$ \\
Br & $8,87 \pm 1,18$ & $7,78 \pm 3,29$ & $11,50 \pm 1,15$ & $11,58 \pm 0,36$ & $10,63 \pm 1,56$ \\
Pb & $19,27 \pm 1,93$ & $26,62 \pm 3,94$ & $34,84 \pm 0,15$ & $25,01 \pm 1,16$ & $20,03 \pm 2,08$ \\
\hline
\end{tabular}

Tabela 8. Limites de detecção $\left(\mu \mathrm{g} \mathrm{L}^{-1}\right)$ para os elementos encontrados nas amostras de água, determinadas por EDXRF, após pré-concentração com APDC e 300 s de excitação/detecção.

\begin{tabular}{cccccc}
\hline Elemento & PDR & PAB & PCC & POÇO & PSP \\
\hline $\mathbf{T i}$ & 1,80 & 1,87 & 1,99 & 1,72 & 1,67 \\
$\mathbf{C r}$ & 0,88 & 0,86 & 0,91 & 0,80 & 0,77 \\
$\mathbf{M n}$ & 0,72 & 0,67 & 0,71 & 0,64 & 0,63 \\
$\mathbf{F e}$ & 0,52 & 0,58 & 0,52 & 0,47 & 0,46 \\
$\mathbf{C o}$ & 0,39 & 0,44 & 0,39 & 0,37 & 0,37 \\
$\mathbf{~ N i}$ & 0,31 & 0,34 & 0,30 & 0,31 & 0,30 \\
$\mathbf{C u}$ & 0,25 & 0,27 & 0,24 & 0,26 & 0,26 \\
$\mathbf{Z n}$ & 0,21 & 0,23 & 0,22 & 0,24 & 0,23 \\
$\mathbf{B r}$ & 0,28 & 0,28 & 0,29 & 0,34 & 0,32 \\
$\mathbf{P b}$ & 0,58 & 0,57 & 0,60 & 0,70 & 0,64 \\
\hline
\end{tabular}

Os gráficos que seguem representam as concentrações para todos os elementos encontrados nas amostras de água. O primeiro, Figura 16, está em escalar linear e o segundo, Figura 17, em escala logarítmica para melhor visualização. 


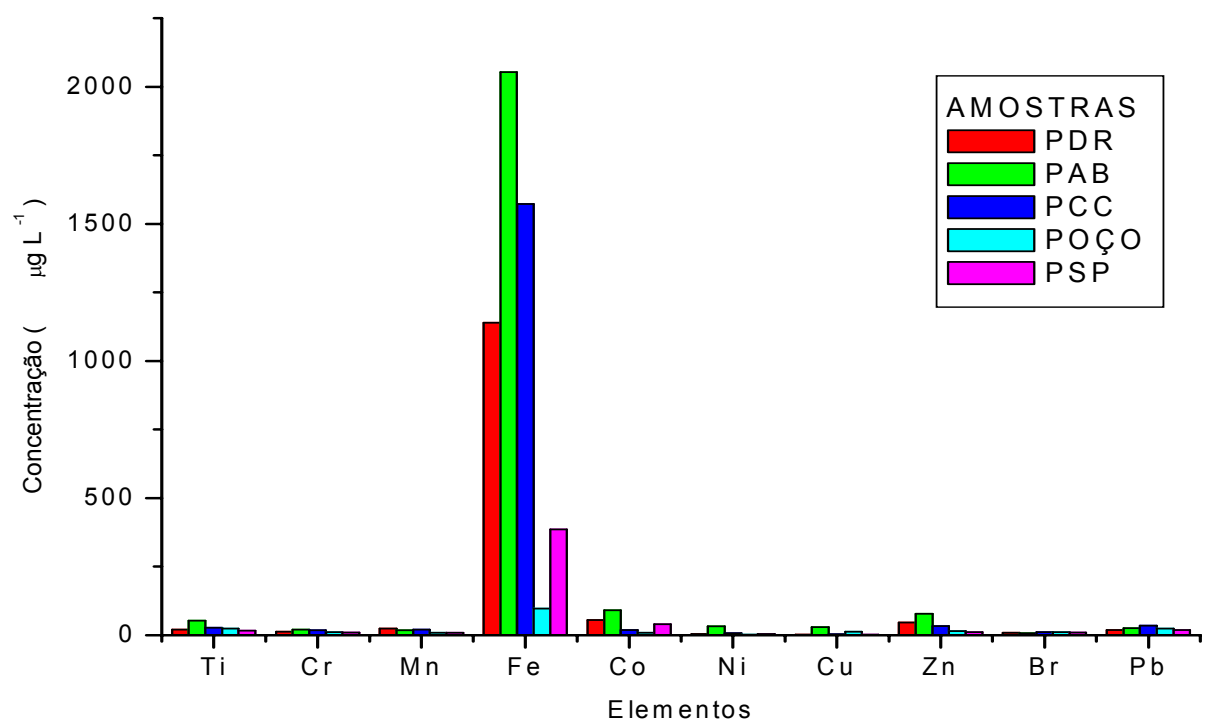

Figura 16. Distribuição das concentrações $\left(\mu \mathrm{g} \mathrm{L}^{-1}\right)$ dos elementos encontrados nas amostras de água, determinadas por EDXRF, após pré-concentração com APDC (escala linear).

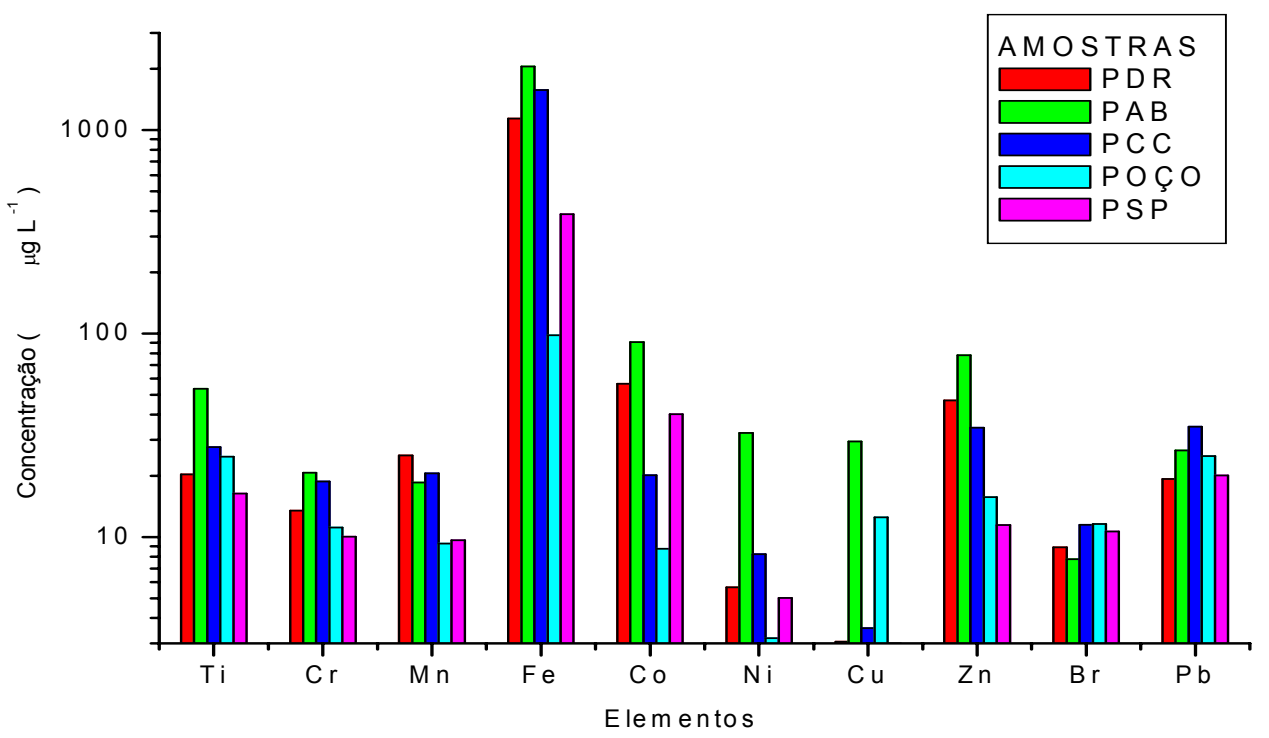

Figura 17. Distribuição das concentrações $\left(\mu \mathrm{g} \mathrm{L}^{-1}\right)$ dos elementos encontrados nas amostras de água, determinadas por EDXRF, após pré-concentração com APDC(escala logarítmica). 
$\mathrm{Na}$ avaliação da amostra de água POÇO, água subterrânea, foi adotado o valor máximo permitido como sendo o padrão de potabilidade da Portaria 1469/2000 do Ministério da Saúde.

Para a avaliação das amostras PDR, PAB, PCC e PSP, águas superficiais, foram utilizados os padrões de qualidade estabelecidos para corpos de água classe 2, estabelecidos pela Resolução CONAMA n 20/86, uma vez que o córrego Vargem Limpa e o Rio Bauru encontram-se enquadrados nesta classe, de acordo com o Decreto Estadual n 10.755/1977.

Nas amostras PDR, PAB e PSP as concentrações de Pb estão abaixo do permitido, $30 \mu \mathrm{g} \mathrm{L}^{-1}$, porém para as amostra PCC e POÇO as concentrações de $\mathrm{Pb}$ estão acima dos limites permitidos, que são $30 \mu \mathrm{L} \mathrm{L}^{-1}$ e 10 $\mu \mathrm{g} \mathrm{L^{-1 }}$, respectivamente.

$\mathrm{O}$ elemento $\mathrm{Fe}$ encontra-se presente em todas as amostras, e com concentrações muito elevadas nas amostras PDR, PAB, PCC e PSP, acima do valor máximo permitido pelo CONAMA, $300 \mu \mathrm{g} \mathrm{L}^{-1}$. Na amostra POÇO a concentração de $98,04 \mu \mathrm{g} \mathrm{L}^{-1}$ está abaixo do limite permitido, $300 \mu \mathrm{g} \mathrm{L}^{-1}$.

Para o elemento Ti não há limites estabelecidos na Portaria nem na Resolução. Em duas amostras nota-se concentrações próximas, 46,93 e $53,51 \mu \mathrm{g} \mathrm{L}^{-1}$, PDR e PAB, respectivamente. O mesmo ocorre com as amostras PCC e POÇO, e somente a amostra PSP apresentou concentração abaixo das outras amostras.

$\mathrm{O} \mathrm{Cr}$ teve comportamento parecido com o elemento $\mathrm{Ti}$, nas amostras PAB e PCC com concentrações muito próximas, 20,71 e 18,72 $\mu \mathrm{g} \mathrm{L}^{-1}$, respectivamente. As amostras PDR, POÇO e PSP também tiveram 
concentrações próximas, 13,48 - 11,12 e 10,01 $\mathrm{g} \mathrm{L} \mathrm{L}^{-1}$, respectivamente. Todas as concentrações estão abaixo do limite máximo permitido, $50 \mu \mathrm{g} \mathrm{L}^{-1}$, valor para $\mathrm{Cr}(\mathrm{VI})$.

Para o elemento $\mathrm{Mn}$ o valor máximo permitido é $100 \mu \mathrm{g} \mathrm{L}^{-1}$. Em três das cinco amostras as concentrações são de 25,15 - 18,52 e 20,56 $\mu \mathrm{g} \mathrm{L}^{-1}$ para PDR, PAB e PCC, respectivamente. As demais amostras tiveram concentrações menores, 9,30 e $9,62 \mu \mathrm{gL}^{-1}$ para POÇO e PSP, respectivamente, e todas estão abaixo do limite permitido.

As concentrações para Co mostraram-se muito diferentes entre as amostras, variando da menor concentração, POÇO com $8,73 \mu \mathrm{g} \mathrm{L}^{-1}$, a mais elevada, PAB com $90,92 \mu \mathrm{g} \mathrm{L}^{-1}$, uma concentração dez vezes maior. Todas as amostras têm concentrações abaixo do valor máximo permitido, $200 \mu \mathrm{g} \mathrm{L}^{-1}$.

Nas amostras PDR, PCC, POÇO e PSP os níveis de Ni foram $5,66-8,25-3,18$ e $5,02 \mu \mathrm{g} \mathrm{L}^{-1}$, respectivamente. Já para a amostra PAB a concentração encontrada foi maior $\left(32,43 \mu \mathrm{g} \mathrm{L}^{-1}\right)$ estando acima do máximo permitido, $25 \mu \mathrm{g} \mathrm{L}^{-1}$.

O elemento $\mathrm{Cu}$ apresentou concentração acima do valor máximo permitido $\left(20 \mu \mathrm{g} \mathrm{L}^{-1}\right)$ para a amostra $\mathrm{PAB}$, com 29,39 $\mathrm{g} \mathrm{L}^{-1}$. As demais amostras apresentaram concentrações menores que o limite máximo permitido.

Em todas as amostras o $\mathrm{Zn}$ apresentou concentrações acima do valor máximo permitido, $10 \mu \mathrm{g} \mathrm{L}^{-1}$, aproximadamente 8 vezes na amostra PAB e 4 vezes nas amostras PDR e PCC. 
Para $\circ \mathrm{Br}$ não há valores máximos permitidos na Resolução CONAMA, havendo somente na Portaria, com o valor de $25 \mu \mathrm{g} \mathrm{L}^{-1}$ na forma de brometo. Este elemento apresentou valores de concentração próximos para todas as amostras. A menor concentração foi encontrada na amostra PAB $\left(7,78 \mu \mathrm{g} \mathrm{L}^{-1}\right)$ e a maior na amostra POÇO $\left(11,58 \mu \mathrm{g} \mathrm{L}^{-1}\right)$ estando todas abaixo do limite máximo permitido.

\section{2 - Análise de sedimento em suspensão por EDXRF}

A título de ilustração a Figura 18 mostra o espectro dos raios $X$ proveniente da amostra de PDR, sedimento em suspensão depositado em filtro de éster de celulose, analisado por EDXRF, podendo-se visualizar os picos dos raios $\mathrm{X}$ característicos dos elementos $\mathrm{Ti}, \mathrm{Mn}, \mathrm{Fe}$ e $\mathrm{Cu}$, e a ausência dos demais elementos, sendo que o $\mathrm{Pb}$ não foi detectado em nenhuma amostra.

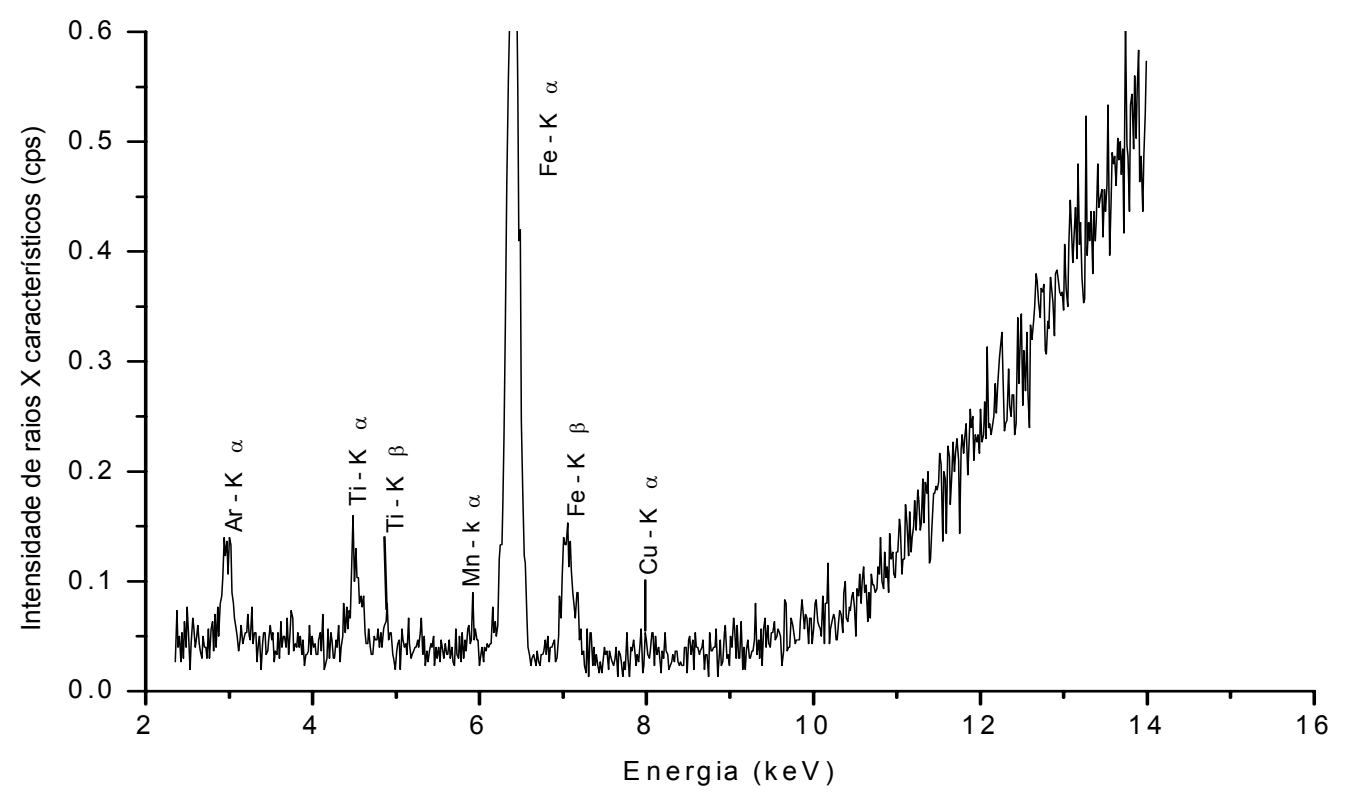

Figura 18. Espectro dos raios $\mathrm{X}$ obtido por EDXRF proveniente da amostra de sedimento em suspensão PDR. 
Assim as concentrações elementares para as amostras de sedimento em suspensão nos filtros estão apresentadas na Tabela 9 e os limites de detecção na Tabela 10.

Tabela 9. Concentrações $\left(\mu \mathrm{g} \mathrm{g}^{-1}\right)$ dos elementos encontrados nas amostras de sedimento em suspensão, determinadas por EDXRF.

\begin{tabular}{ccccc}
\hline Elemento & PDR & PCC & POÇO & PSP \\
\hline Ti & 2060,47 & 596,94 & 3354,38 & 407,24 \\
Mn & 191,41 & nd & nd & nd \\
Fe & 5476,17 & 2677,63 & 4609,49 & 1551,32 \\
Cu & 79,53 & nd & 44,64 & nd \\
Zn & nd & nd & 36,91 & 21,37 \\
\hline
\end{tabular}

nd = não detectado

Tabela 10. Limites de detecção $\left(\mu \mathrm{g} \mathrm{g}^{-1}\right)$ para os elementos encontrados nas amostras de sedimento em suspensão, determinadas por EDXRF em 300s de excitação/detecção.

\begin{tabular}{ccccc}
\hline Elemento & PDR & PCC & POÇO & PSP \\
\hline $\mathrm{Ti}$ & 44,67 & 17,55 & 22,75 & 15,38 \\
$\mathrm{Mn}$ & 16,12 & 5,75 & 7,39 & 5,12 \\
$\mathrm{Fe}$ & 11,95 & 4,43 & 5,45 & 4,02 \\
$\mathrm{Cu}$ & 5,70 & 2,11 & 2,60 & 1,96 \\
Zn & 5,53 & 1,89 & 2,36 & 1,75 \\
\hline
\end{tabular}

Os gráficos a seguir mostram as concentrações dos elementos em todas as amostras. Na Figura 19 o gráfico esta em escala linear, e na Figura 20 esta em escala logarítmica, permitindo uma melhor visualização da distribuição das concentrações dos elementos nas amostras. 


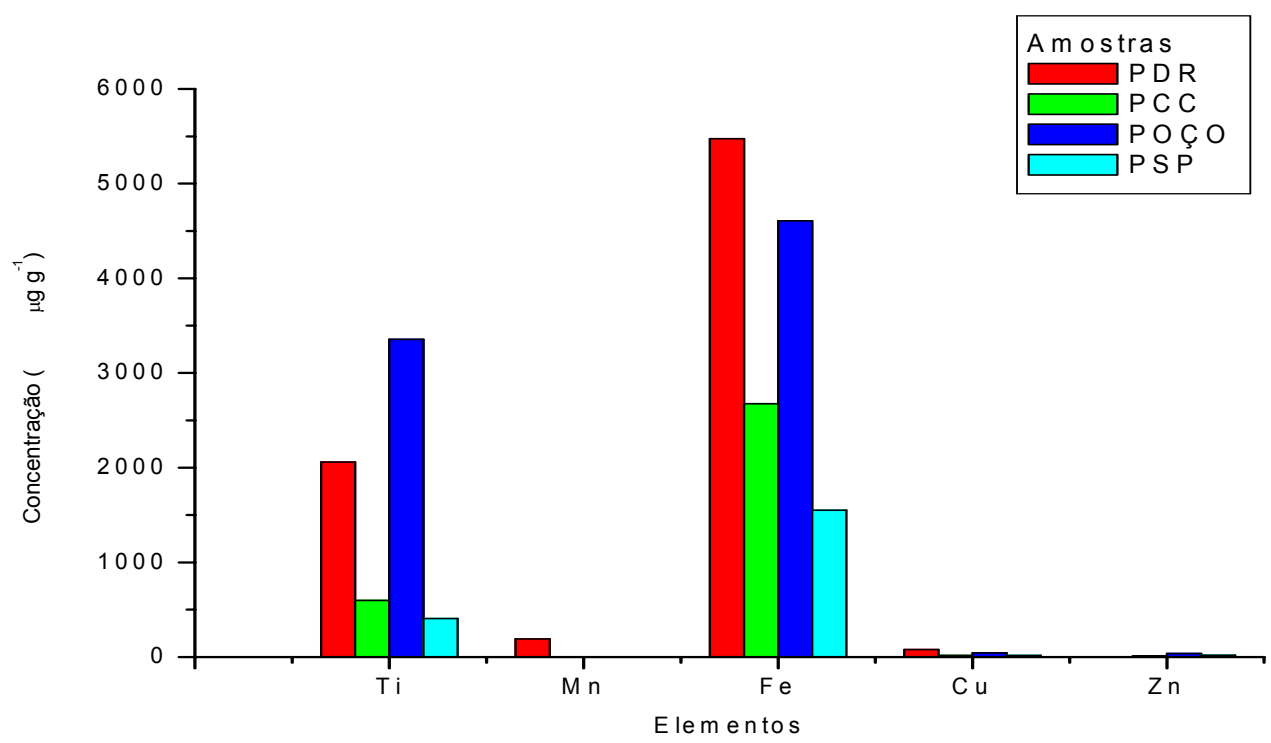

Figura 19. Distribuição das concentrações $\left(\mu \mathrm{g} \mathrm{g}^{-1}\right)$ dos elementos encontrados nas amostras de sedimento em suspensão, determinadas por EDXRF (escala linear).

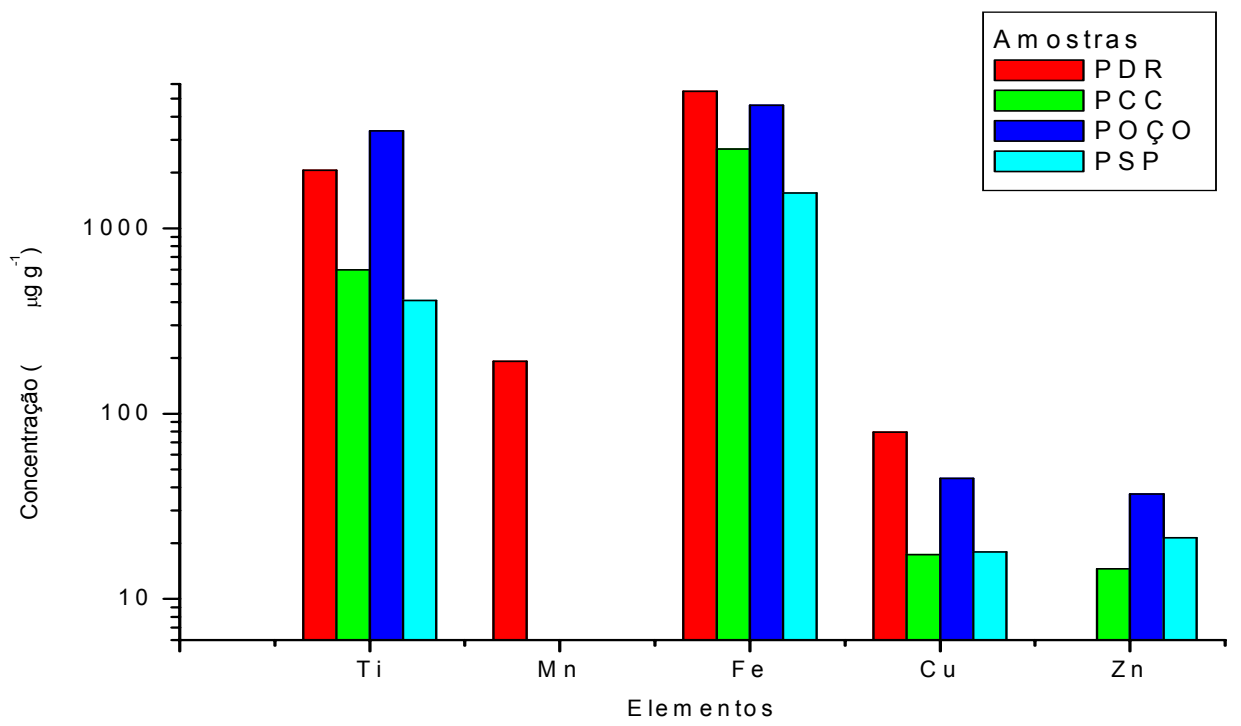

Figura 20. Distribuição das concentrações $\left(\mu \mathrm{g} \mathrm{g}^{-1}\right)$ dos elementos encontrados nas amostras de sedimento em suspensão, determinadas por EDXRF (escala logarítmica). 
Como era de se esperar, $\mathrm{Fe}$ e $\mathrm{Ti}$ estão presentes em todas as amostras. O elemento $\mathrm{Mn}$ foi encontrado somente na amostra PDR, enquanto o Cu e o $\mathrm{Zn}$ apresentaram concentrações abaixo do limite de detecção em duas amostras. Somente uma amostra não pode ser analisada, PAB, devido a grande quantidade de matéria orgânica depositada no filtro.

\section{3 - Análise de água por TXRF}

\subsection{1 - Sensibilidade elementar para Pb e análise de amostra certificada}

Com as soluções contendo $\mathrm{Pb}$ nas concentrações de 0, 10, 100, 500 e $1000 \mu \mathrm{g} \mathrm{L}^{-1}$ foi obtida a curva de calibração (figura 21), sendo determinada a sensibilidade elementar para ser posteriormente utilizada para o teste de recuperação da amostra certificada. A sensibilidade experimental calculada para $\mathrm{Pb}$ é de 1,4364 .

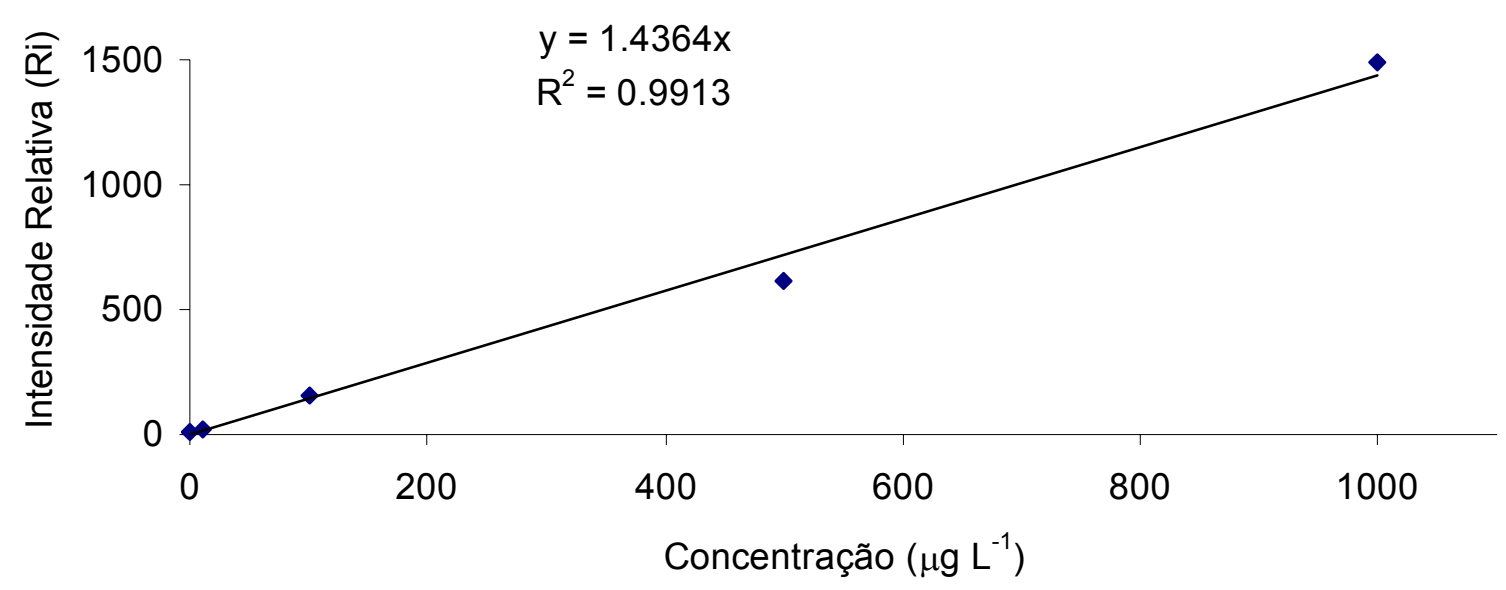

Figura 21. Curva de calibração obtida para Pb por TXRF a partir de soluções com concentrações conhecidas de $\mathrm{Pb}$. 
Para validação da técnica TXRF foi utilizada a amostra certificada de água SRM1640, produzida pelo NIST. Foram feitas triplicatas para os cálculos da concentração e os valores obtido e certificado estão expressos na Tabela 11. A concentração de $\mathrm{Pb}$ encontrada na amostra certificada foi concordante com o valor certificado com nível de confiança de $95 \%$.

Tabela 11. Concentração $\left(\mu \mathrm{g} \mathrm{L}^{-1}\right)$ de $\mathrm{Pb}$ obtida para a amostra certificada de água SRM1640 produzida pelo NIST, determinada por TXRF $(n=3)$.

\begin{tabular}{lcccc}
\hline & \multicolumn{2}{c}{ Certificado } & \multicolumn{2}{c}{ Obtido } \\
\hline & Média & IC & Média & IC \\
$\mathbf{P b}$ & 27,89 & $27,54-28,24$ & 27,39 & $18,34-36,43$ \\
\hline${ }^{*}$ média e intervalo de confiança ao nível de $95 \%$ &
\end{tabular}

\subsection{2 - Teste de recuperação de $\mathrm{Pb}$ em solução-padrão}

Além do uso da amostra certificada para validação da metodologia, foi utilizada a solução-padrão SM (item 4.5) e os valores de três testes de recuperação estão na Tabela 12. $\mathrm{O}$ teste de recuperação para $\circ \mathrm{Pb}$ na solução-padrão SM mostrou-se satisfatório, com média levemente acima de $100 \%$.

Tabela 12. Recuperação para Pb na solução-padrão SM.

\begin{tabular}{ccccc}
\hline Elemento & \multicolumn{3}{c}{ Recuperação (\%) } & Média \\
\hline & $\mathbf{I}$ & $\mathbf{I I}$ & III & \\
$\mathbf{P b}$ & 104,19 & 109,18 & 102,99 & 105,45 \\
\hline
\end{tabular}




\subsection{3 - Teste de recuperação de Pb nas amostras de água}

Para validação da metodologia foi também realizado um teste de recuperação em amostra de água. Uma quantidade conhecida de $\mathrm{Pb}$ foi adicionada de modo a aumentar a concentração de $1000 \mu \mathrm{g} \mathrm{L}^{-1}$, e em seguida foi feito o teste de recuperação. Os valores da recuperação encontram-se na Tabela 13.

Tabela 13. Teste de Recuperação para $\mathrm{Pb}$ nas amostras de água, determinadas por TXRF $(n=3)$.

\begin{tabular}{cc}
\hline Amostras & Recuperação Pb (\%) \\
\hline PDR & 115,58 \\
PAB & 148,00 \\
PCC & 131,91 \\
POÇo & 106,63 \\
PSP & 140,01 \\
\hline
\end{tabular}

Comparando-se os valores da recuperação entre as soluçõespadrão SM e PM, (item 5.1.2) e as amostras de água com adição, pode-se dizer que a recuperação foi muito satisfatória em ambas, apresentando valores acima de $100 \%$.

A Figura 22 mostra o espectro dos raios $X$ proveniente da amostra POÇO após adição de $1000 \mu \mathrm{L} \mathrm{L}^{-1}$ de $\mathrm{Pb}$, depositada em suporte de quartzo e analisada por TXRF. 


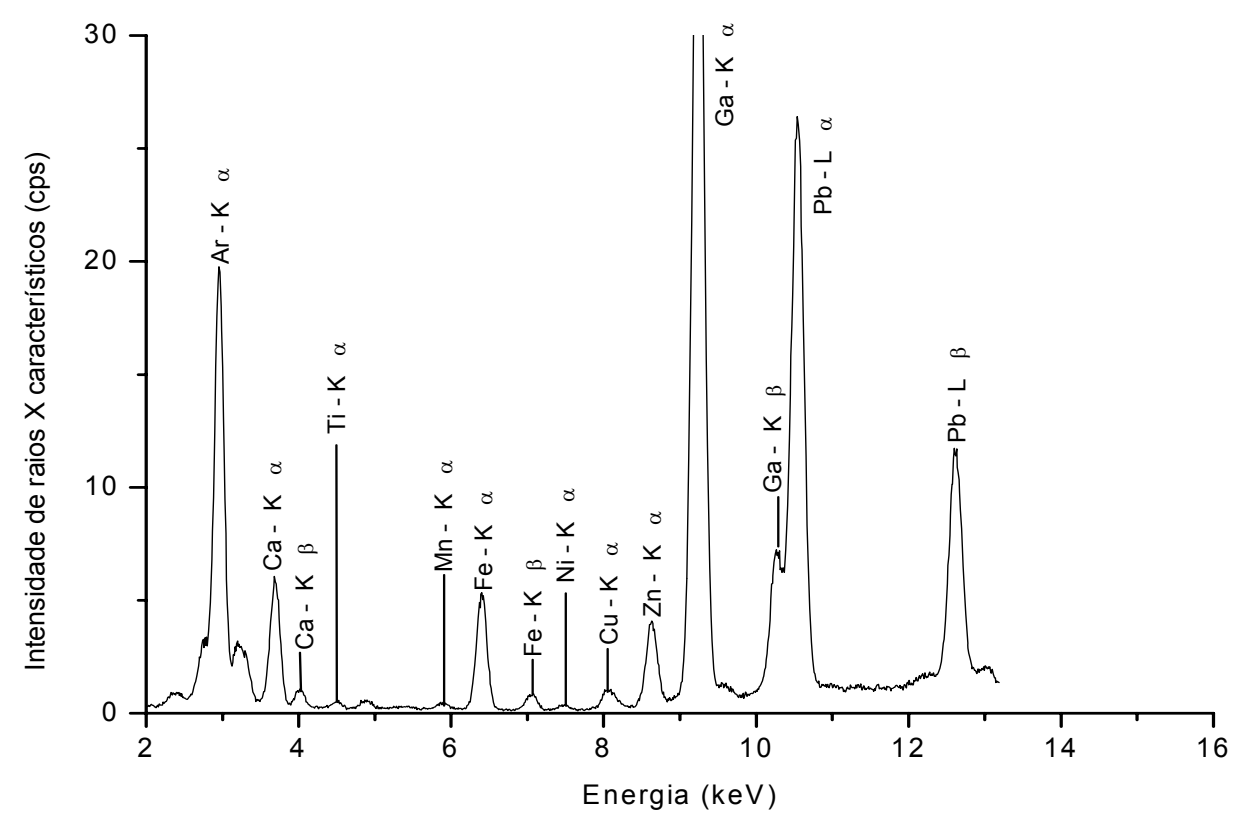

Figura 22. Espectro dos raios $X$ obtido por TXRF proveniente da amostra de água $\mathrm{POÇO}$, com adição de $1000 \mu \mathrm{g} \mathrm{L}^{-1}$ de $\mathrm{Pb}$ para o teste de recuperação (o elemento Ga foi adicionado como padrão interno).

\subsection{4 - Análise de Pb em amostras de água}

As amostras de água também foram submetidas à análise depois da filtração, e na Tabela 14 e Figura 23 estão expressos os valores encontrados para concentrações de $\mathrm{Pb}$. Os valores dos limites de detecção estão na Tabela 15. 
Tabela 14. Concentração e desvio padrão $\left(\mu \mathrm{g} \mathrm{L}^{-1}\right)$ de $\mathrm{Pb}$ encontrado nas amostras de água, determinadas por TXRF $(n=3)$.

\begin{tabular}{|c|c|c|c|c|c|}
\hline & PDR $^{\star *}$ & $\mathrm{PAB}^{\star *}$ & $P C C^{* *}$ & POÇO* & PSP** \\
\hline $\mathbf{P b}$ & $45,90 \pm 4,89$ & $46,73 \pm 0,57$ & $43,42 \pm 13,59$ & $18,58 \pm 0,13$ & $24,32 \pm 1,14$ \\
\hline
\end{tabular}

Tabela 15. Limites de detecção $\left(\mu \mathrm{g} \mathrm{L}^{-1}\right)$ para $\mathrm{Pb}$ encontrado nas amostras de água, determinadas por TXRF, em $200 \mathrm{~s}$ de excitação/detecção.

\begin{tabular}{cccccc}
\hline & PDR & PAB & PCC & POÇO & PSP \\
\hline $\mathbf{P b}$ & 4,46 & 3,59 & 2,77 & 1,91 & 2,12 \\
\hline
\end{tabular}

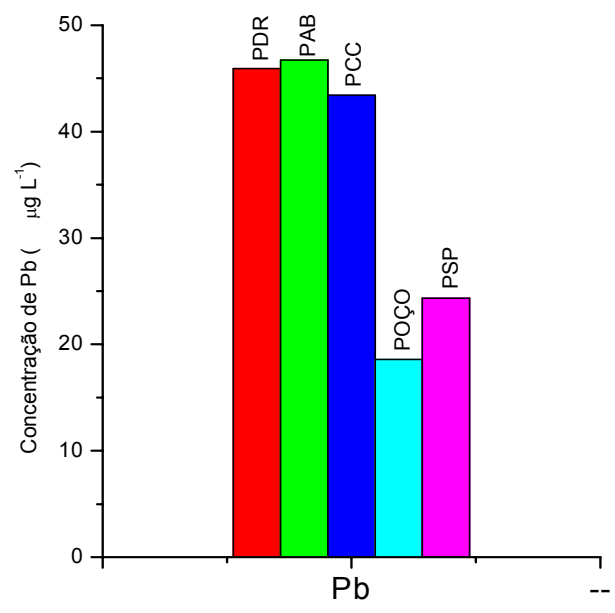

Figura 23. Distribuição das concentrações de $\mathrm{Pb}\left(\mu \mathrm{g} \mathrm{L}^{-1}\right)$ presente nas amostras de água, determinadas por TXRF. 
$\mathrm{O}$ valor máximo permitido para $\mathrm{Pb}$ em água é de $10 \mu \mathrm{g} \mathrm{L}^{-1}$ e a amostra POÇO apresentou valor de concentração acima, 18,58 $\mathrm{g} \mathrm{L}^{-1}$, mostrando que está imprópria para consumo.

Nas amostras PDR, PAB e PCC os níveis de concentração encontrados para $\mathrm{Pb}, 45,90$ - 46,73 e 43,42 $\mathrm{g} \mathrm{L} \mathrm{L}^{-1}$, respectivamente, estão acima do limite máximo permitido, $30 \mu \mathrm{g} \mathrm{L}^{-1}$, estando somente a amostra PSP abaixo desse limite, $24,32 \mu \mathrm{g} \mathrm{L}^{-1}$.

\subsection{5 - Sensibilidade elementar para outros elementos em TXRF}

Também foi elaborada uma curva de sensibilidade elementar para outros elementos presentes na água, para camada K (Figura 24) e camada L (Figura 25), utilizando-se a solução-padrão PM (item 4.4). Os valores das sensibilidades elementares estão expressos na Tabela 16.

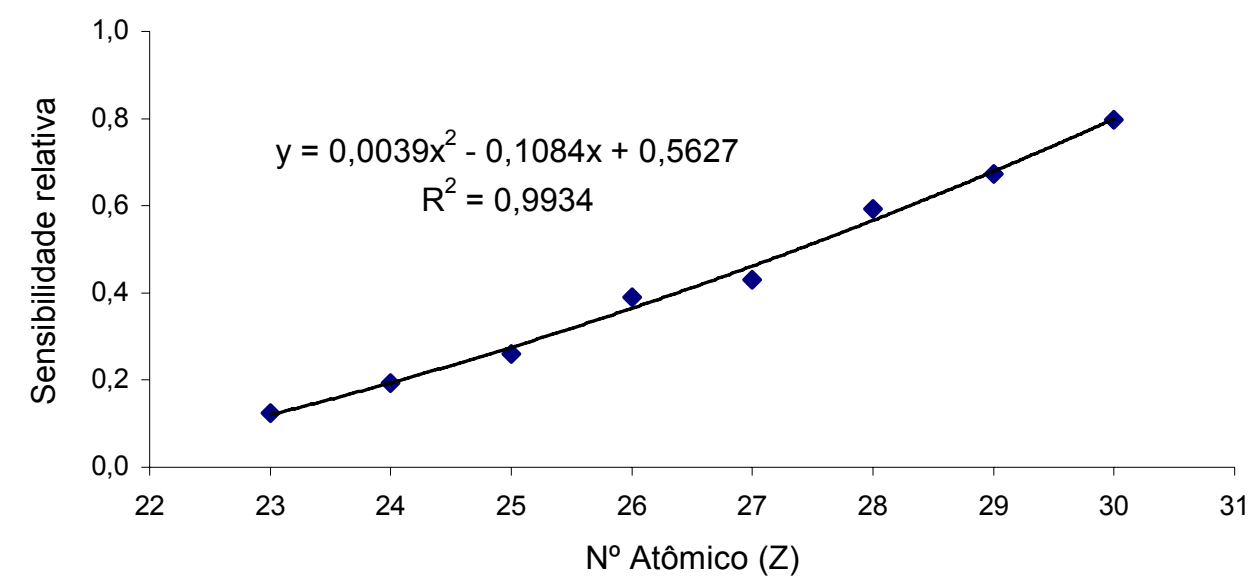

Figura 24. Sensibilidade elementar em função do número atômico, para os elementos presentes na solução-padrão PM, elementos camada K. 


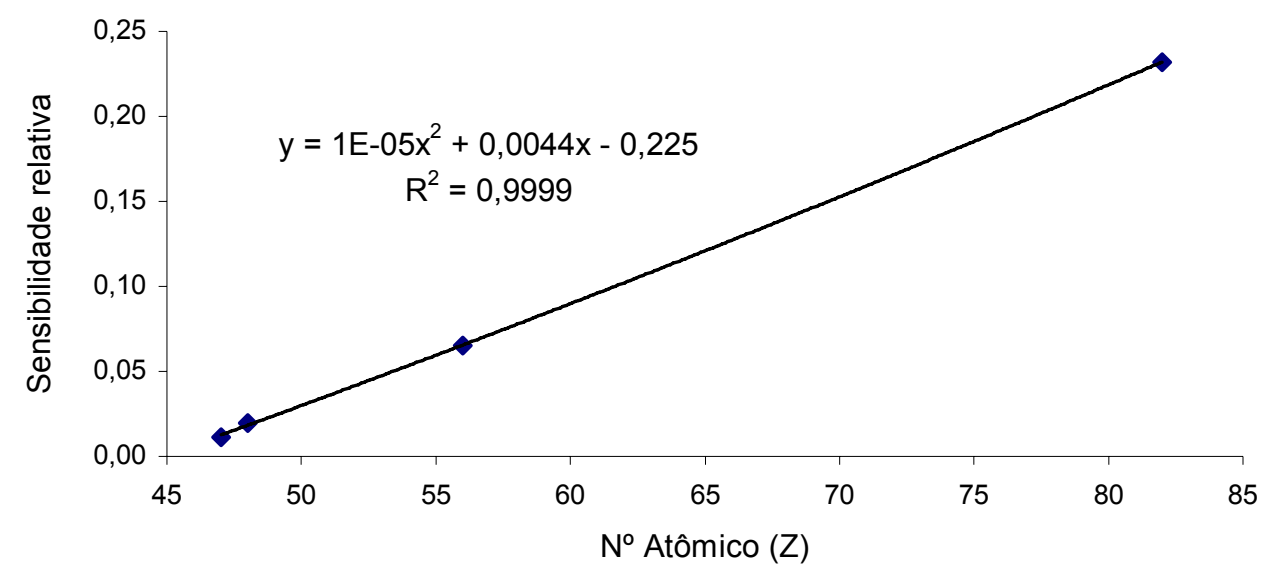

Figura 25. Sensibilidade elementar em função do número atômico, para os elementos presentes na solução-padrão PM, elementos camada L.

Tabela 16. Sensibilidade elementar ( $c p s \mu \mathrm{g}^{-1} \mathrm{~L}$ ) por TXRF para os elementos que compõem a solução-padrão $\mathrm{PM}$, analisados por raios $\mathrm{X} \mathrm{K \alpha}$ ( $\mathrm{Ti}$ ao $\mathrm{Br}$ ) e $\mathrm{L} \alpha$ (Ag ao $\mathrm{Pb})$.

\begin{tabular}{ccc}
\hline Elemento & $\begin{array}{c}\text { Sensibilidade } \\
\text { Pontual }\end{array}$ & $\begin{array}{c}\text { Sensibilidade } \\
\text { Experimental }\end{array}$ \\
\hline $\mathbf{T i}$ & - & 0,0655 \\
$\mathbf{V}$ & 0,1238 & 0,1326 \\
$\mathbf{C r}$ & 0,1930 & 0,2075 \\
$\mathrm{Mn}$ & 0,2570 & 0,2902 \\
$\mathrm{Fe}$ & 0,3905 & 0,3807 \\
$\mathbf{C o}$ & 0,4305 & 0,4790 \\
$\mathbf{N i}$ & 0,5926 & 0,5847 \\
$\mathbf{C u}$ & 0,6725 & 0,6990 \\
$\mathbf{Z n}$ & 0,7973 & 0,8207 \\
$\mathbf{B r}$ & - & 1,5462 \\
$\mathbf{A g}$ & 0,0115 & 0,0039 \\
$\mathbf{C d}$ & 0,0195 & 0,0093 \\
$\mathbf{B a}$ & 0,0653 & 0,0528 \\
$\mathbf{P b}$ & 0,2321 & 0,2031 \\
\hline
\end{tabular}




\subsection{6 - Análise de outros elementos em amostra certificada por TXRF}

Com os valores das sensibilidades elementares (item 5.3.5) e as intensidades relativas obtidas foram calculadas as concentrações de oito elementos contidos na amostra certificada de água SRM1640, produzida pelo NIST, e os valores certificados e obtidos estão na Tabela 17 e Figura 26.

Tabela 17. Concentração ( $\left.\mu \mathrm{g} \mathrm{L}^{-1}\right)$ dos elementos contidos na amostra certificada de água SRM1640/NIST, determinada por TXRF $(n=3)$.

\begin{tabular}{ccccc}
\hline \multicolumn{3}{c}{ Certificado } & \multicolumn{2}{l}{ Obtido } \\
\hline Elementos & Média & IC & Média & IC \\
Cr & 38,6 & $34,63-42,57$ & 70,16 & $48,76-91,56$ \\
Mn & 121,5 & $118,77-124,23$ & 286,71 & $148,09-425,33$ \\
Fe & 34,3 & $30,33-38,27$ & 51,26 & $38,63-63,89$ \\
Co & 20,28 & $19,51-21,05$ & 42,81 & $25,59-60,03$ \\
Ni & 27,4 & $25,41-29,39$ & 55,25 & $32,63-77,87$ \\
Cu & 85,2 & $82,22-88,18$ & 153,30 & $108,41-198,19$ \\
Zn & 53,2 & $50,47-55,93$ & 93,15 & $75,9-110,40$ \\
As & 26,67 & $25,65-27,69$ & 23,38 & $13,95-32,81$ \\
Se & 21,96 & $20,69-23,23$ & 21,18 & $10,13-32,23$ \\
Pb & 27,89 & $27,57-28,24$ & 27,39 & $18,34-36,43$ \\
\hline
\end{tabular}




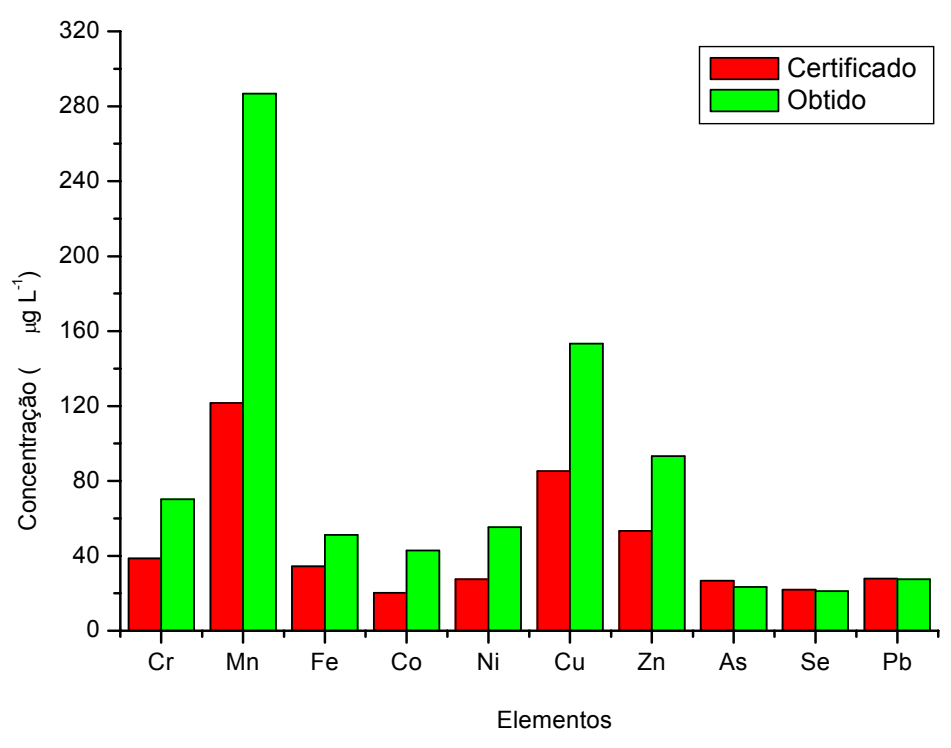

Figura 26. Distribuição dos valores certificado e obtido para as concentrações ( $\mu \mathrm{g} \mathrm{L}^{-1}$ ) dos elementos contidos na amostra certificada de água SRM1640/NIST, determinada por TXRF.

Os elementos analisados na amostra certificada SRM1640 apresentaram praticamente o dobro do valor certificado das concentrações, com exceção para As e Se, cujos valores podem ser considerados muito próximos. Estes dois elementos possuem energias dos raios $\mathrm{X}$ característicos $K \alpha$ muito próximas às energias dos raios $X$ característicos $L \alpha$ do $P b, 10,552$ $\mathrm{keV}$, e essa proximidade poderia ser um fator comprometedor na análise desses elementos.

$\mathrm{Na}$ tentativa de se explicar a maior concentração, quando analisado por TXRF, para os elementos analisados na amostra certificada (com exceção do $\mathrm{As}$, Se e $\mathrm{Pb}$ ) foram levantadas três hipóteses. Esta concentração se deve a superestimativa das intensidades dos raios $X$ característicos destes elementos, e a sua origem pode ser devida: (1) irradiação da amostra na 
condição de não reflexão total (refração); (2) presença de elementos contaminantes no colimador de Ta utilizado no detector; e (3) presença de elementos contaminantes na alíquota de $\mathrm{Ga}$ adicionado como padrão interno.

Para testar a primeira hipótese foram irradiados vários suportes de quartzo limpo, ou seja, sem amostra ou alíquota de Ga. Para melhor ilustrar a Figura 27 mostra o espectro obtido por TXRF para um dos quartzos limpos.

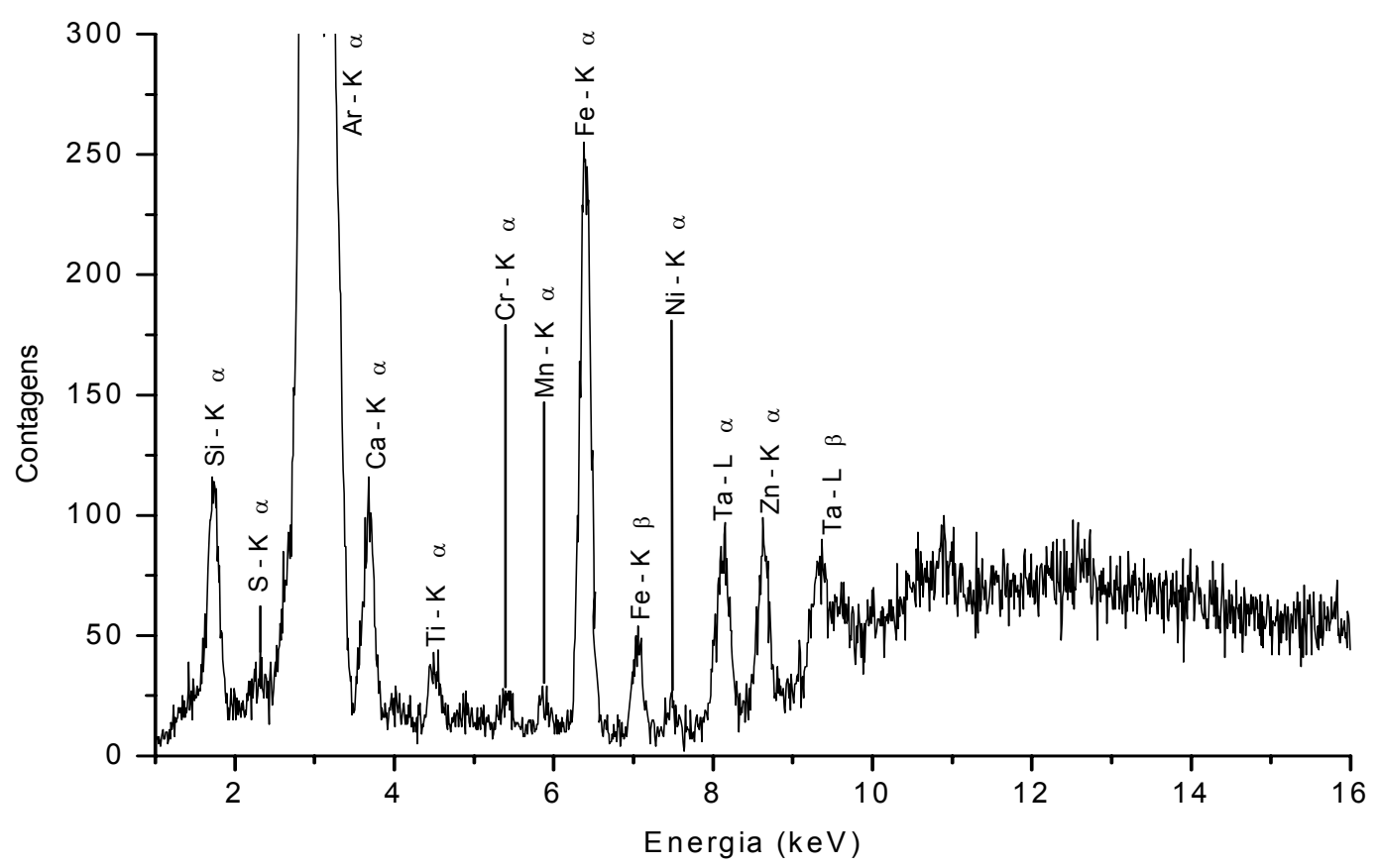

Figura 27. Espectro dos raios $X$ obtidos por TXRF proveniente de um suporte de quartzo limpo.

Pode-se observar uma considerável quantidade de picos entre as regiões dos raios $\mathrm{X}$ característicos dos elementos $\mathrm{Si}$ ao $\mathrm{Zn}$, dando uma indicativa que a fonte de interferência seja o quartzo em condição de não reflexão total, ou seja, em condição de refração. Se a primeira hipótese for verdadeira, as razões entre as intensidades destes elementos em relação ao Si 
deveriam permanecer constantes em uma irradiação de vários quartzos limpos, visto que o Si é o elemento principal da composição do quartzo. Assim se a condição de reflexão total não tivesse sido obedecida o elemento Si e os outros componentes do quartzo $(\mathrm{Cr}$ ao $\mathrm{Zn})$ seriam igualmente excitados e apresentariam uma mesma razão irradiando-se vários suportes de quartzo. Deste modo foram irradiados três suportes de quartzo limpos, mas as razões das intensidades foram totalmente ao acaso, indicando ser falsa essa hipótese e por tanto os raios $\mathrm{X}$ característicos do $\mathrm{Ca}$ ao $\mathrm{Zn}$ não são provenientes deste suporte refletor. Isto foi confirmado irradiando-se suportes refletores de lucite limpos, e na Figura 28 é mostrado um espectro obtido com esse material, composto basicamente de $\mathrm{C}$ e $\mathrm{H}$, elementos não produtores de raios $\mathrm{X}$ característicos detectáveis. Na Figura 28 pode-se observar os picos dos elementos do $\mathrm{Ca}$ ao $\mathrm{Zn}$, com exceção do Si, comprovando, então, não ser o refletor de quartzo a fonte de interferências.

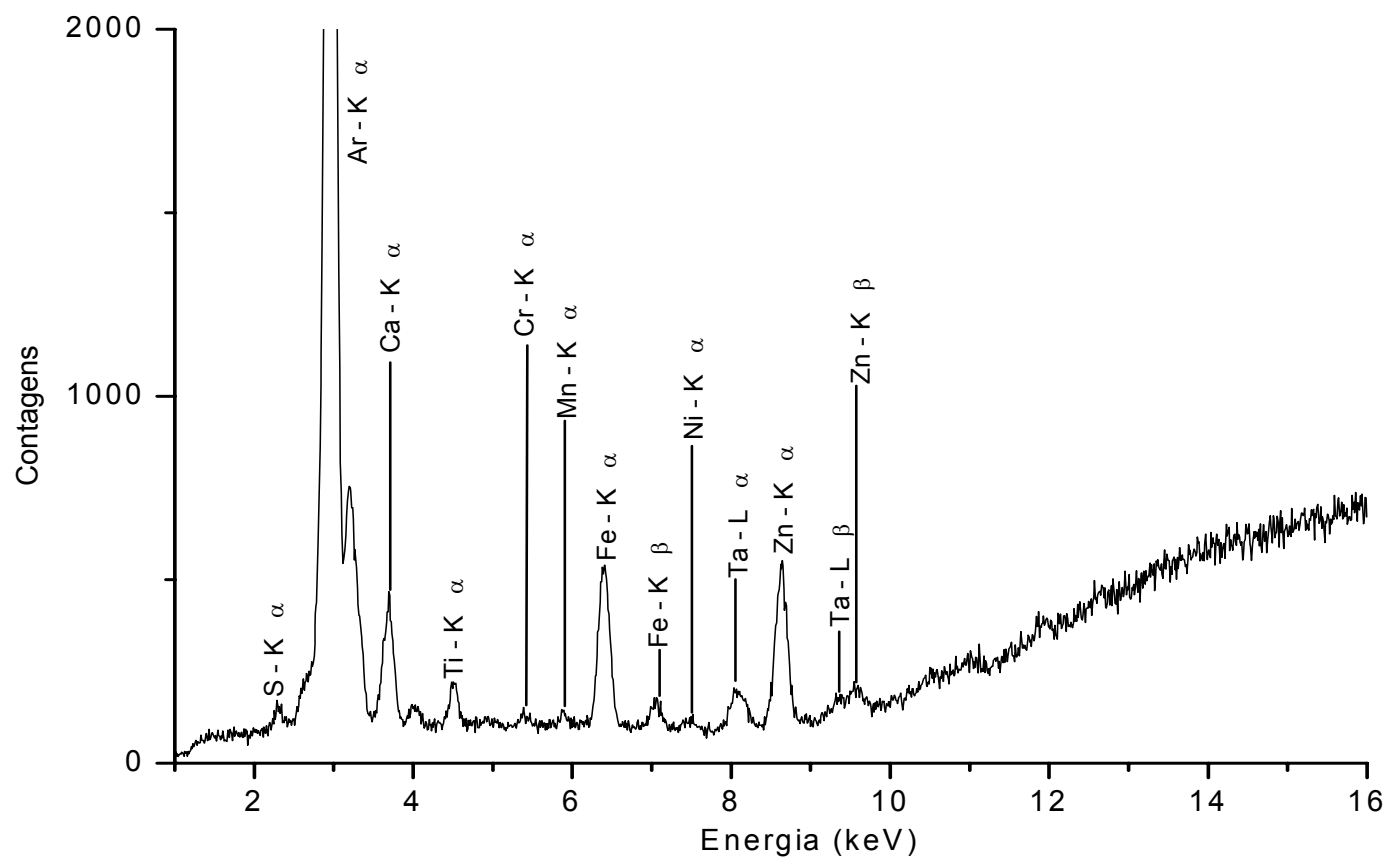

Figura 28. Espectro de raios $\mathrm{x}$ obtido por TXRF proveniente de um suporte de lucite limpo. 
Para comprovar a pureza dos suportes refletores de quartzo e lucite foram irradiados os dois suportes por EDXRF, nas mesmas condições operacionais utilizadas para as amostras de água após pré-concentração e as amostras de sedimento em suspensão e de fundo. A Figura 29 mostra os espectros obtidos para quartzo e lucite. Com exceção do pico do elemento Si no suporte de quartzo e do $\operatorname{Ar}$ (proveniente do ar atmosférico) nenhum outro pico foi observado, portanto pode ser comprovado que os raios $X$ característicos dos elementos interferentes não provem do suporte refletor de quartzo.

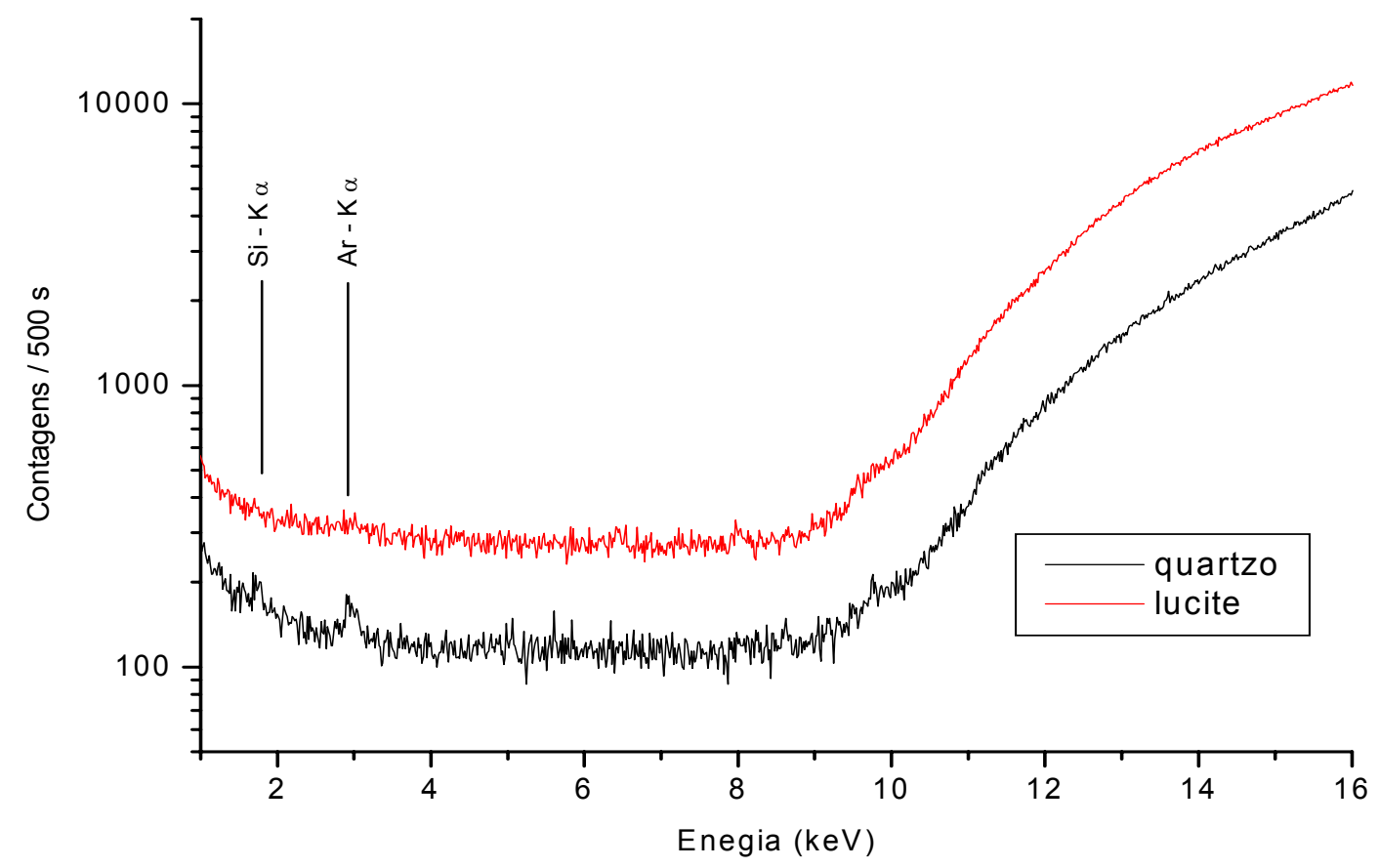

Figura 29. Espectro de raios $x$ obtido por EDXRF proveniente de um suporte de quartzo e lucite limpos.

Nas Figuras 27 e 28 pode-se ainda observar a presença dos raios $X$ característicos $L$ do Ta, metal utilizado como colimador em frente ao detector, 
levando a segunda hipótese, ou seja, a presença de elementos contaminantes neste colimador.

Do mesmo modo, as razões entre as intensidades dos elementos $\mathrm{Ti}$ ao $\mathrm{Zn}$ em relação à intensidade do Ta deveriam ser constantes em irradiações de vários suportes refletores limpos. Tanto no quartzo como no lucite essas razões não permaneceram constantes, indicando que os elementos Ti ao Zn não fazem parte da matriz do colimador.

$\mathrm{Na}$ terceira hipótese as razões entre as intensidades dos elementos $\mathrm{Ti}$ ao $\mathrm{Zn}$ em relação à intensidade do $\mathrm{Ga}$ deveriam permanecer constantes, quando irradiados suportes refletores de quartzo e lucite após a adição de uma mesma alíquota desse elemento usado como padrão interno.

Para melhor ilustração a Figura 30 mostra o espectro de um refletor de quartzo irradiado após a adição de $20 \mu \mathrm{L}$ de uma solução contendo $500 \mu \mathrm{g} \mathrm{L}^{-1}$ de $\mathrm{Ga}$.

Pode-se observar pela Figura 30 os picos dos elementos $\mathrm{Si}$ (principal componente do quartzo), $\mathrm{Ca}$ a $\mathrm{Zn}, \mathrm{Ta}$ (componente do colimador utilizado em frente ao detector) e Ga (adicionado como padrão interno). 


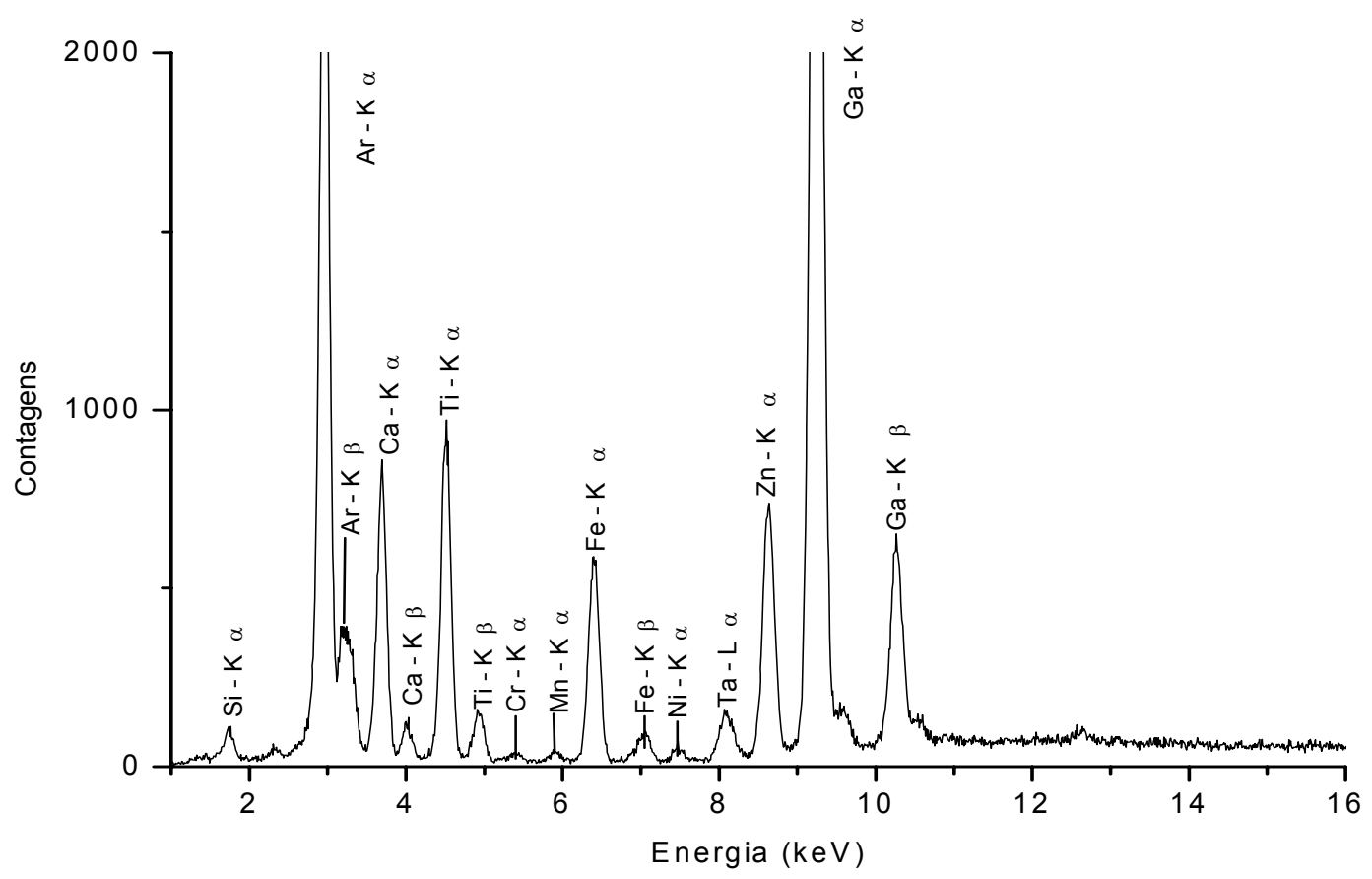

Figura 30. Espectro dos raios $X$ obtidos por TXRF proveniente de uma amostra de branco de solução $\left(0 \mu \mathrm{g} \mathrm{L}^{-1} \mathrm{~Pb}\right)$ com adição do padrão interno $\mathrm{Ga}$ (500 $\mu \mathrm{g} \mathrm{L}^{-1}$ ) em suporte de quartzo.

Foram calculadas as razões das intensidades desses elementos em relação à intensidade do $\mathrm{Ga}$, porém elas não se mostraram constantes, indicando também que a solução de padrão interno $\mathrm{Ga}$ não é a fonte de interferência. De acordo com a ficha técnica da solução-padrão de $\mathrm{Ga}$, produzida pela Aldrich, o único elemento traço presente é o Si na concentração de $0,5 \mu \mathrm{g} \mathrm{L}^{-1}$ na solução original de concentração $10 \mathrm{mg} \mathrm{L}^{-1}$. Deve ser lembrado que a solução de trabalho foi de $500 \mathrm{~g} \mathrm{~L} \mathrm{~L}^{-1}$ de $\mathrm{Ga}$, resultando uma concentração de $0,025 \mu \mathrm{g} \mathrm{L}^{-1}$ de Si.

Desse modo resta uma quarta hipótese, mas sem a possibilidade de ser testada: provavelmente os metais utilizados na construção do arranjo 
experimental contenham os elementos $\mathrm{Ca}$ ao $\mathrm{Zn}$. Assim as concentrações dos elementos $\mathrm{Cr}$ ao $\mathrm{Zn}$, determinadas por TXRF não pode ser validada pela análise da amostra certificada de água SRM1640 e os resultados podem ser utilizados somente como parâmetros qualitativos, sendo de maior confiabilidade os resultados obtidos com EDXRF após pré-concentração com APDC.

Deve ser ressaltado que para os elementos $\mathrm{As}$, Se e $\mathrm{Pb}$ os resultados foram concordantes e por tanto a técnica TXRF pôde ser validada, pois esses elementos não foram observados nos espectros dos suportes refletores de quartzo e lucite limpos e mesmo após a adição do padrão interno Ga.

\subsection{7 - Análise de outros elementos em água por TXRF}

Apesar da afirmativa de que a técnica TXRF pode ser utilizada somente para fins qualitativos (item 5.3.6), foram realizadas as análises das amostras de água coletadas, determinando-se os elementos $\mathrm{Ti}, \mathrm{Cr}, \mathrm{Mn}, \mathrm{Fe}, \mathrm{Co}$, $\mathrm{Ni}, \mathrm{Cu}, \mathrm{Zn}$ e $\mathrm{Br}$. As concentrações se encontram na Tabela 18 e seus respectivos limites de detecção na Tabela 19.

As Figuras 31 e 32 mostram as concentrações dos elementos em todas as amostras. Na Figura 31 o gráfico está em escala linear, e na Figura 32 em escala logarítmica, permitindo uma melhor visualização da distribuição das concentrações dos elementos nas amostras. 


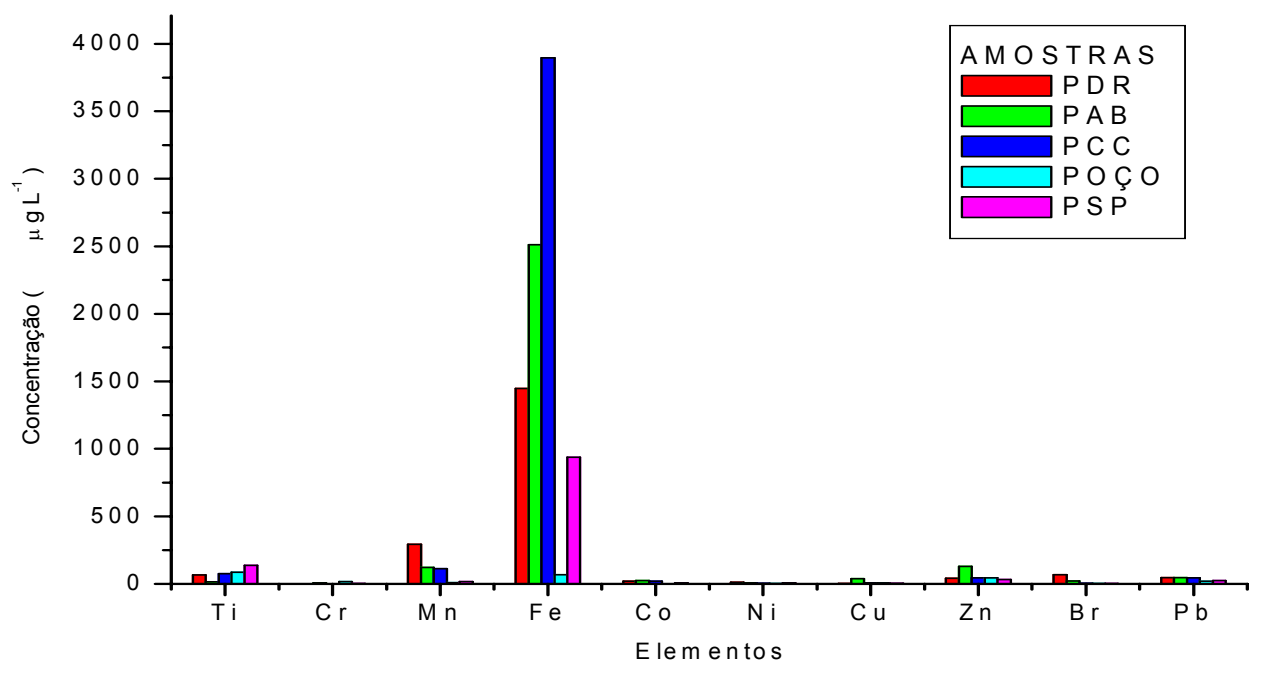

Figura 31. Distribuição das concentrações $\left(\mu \mathrm{g} \mathrm{L}^{-1}\right)$ dos elementos encontrados nas amostras de água, determinadas por TXRF (escala linear).

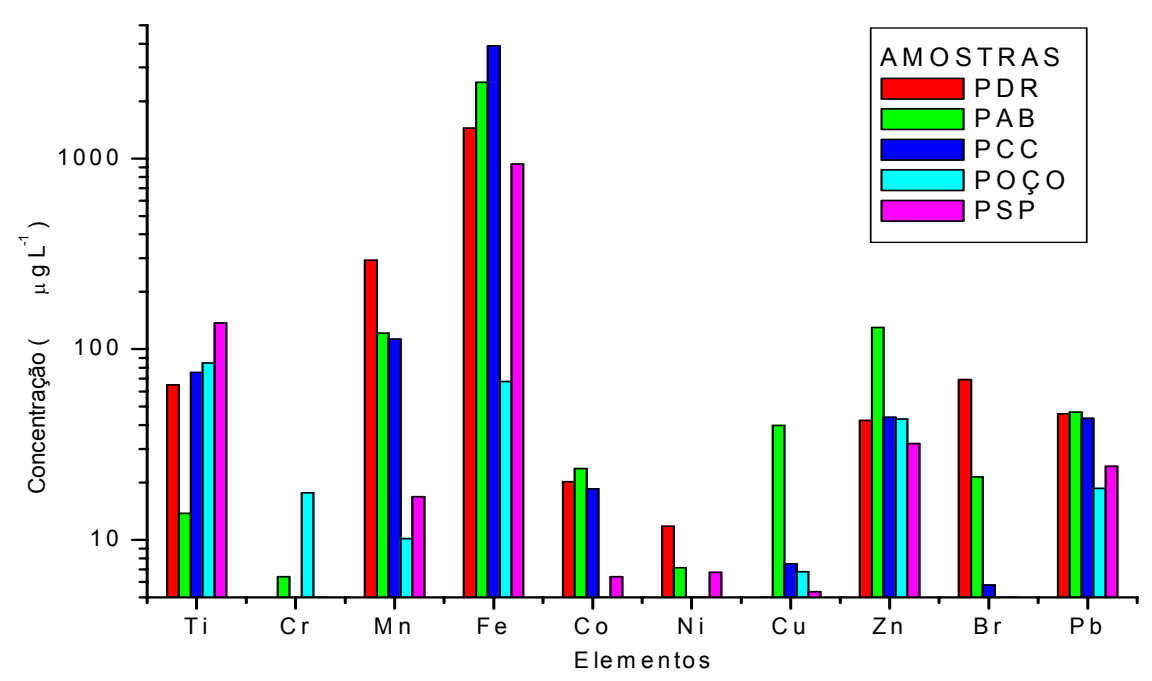

Figura 32. Distribuição das concentrações $\left(\mu \mathrm{g} \mathrm{L}^{-1}\right)$ dos elementos encontrados nas amostras de água, determinadas por TXRF (escala logarítmica). 
Tabela 18. Concentração e desvio padrão $\left(\mu \mathrm{g} \mathrm{L}^{-1}\right)$ dos elementos encontrados nas amostras de água, determinadas por $\operatorname{TXRF}(n=3)$.

\begin{tabular}{cccccc}
\hline Elemento & PDR & PAB & PCC & POÇO & PSP \\
\hline $\mathbf{T i}$ & $64,95 \pm 0,06$ & $13,76 \pm 3,40$ & $75,20 \pm 29,93$ & $84,64 \pm 56,73$ & $137,15 \pm 6,41$ \\
$\mathbf{C r}$ & $\mathrm{nd}$ & $6,42 \pm 0,37$ & $\mathrm{nd}$ & $\mathrm{nd}$ & $2,69 \pm 1,71$ \\
$\mathrm{Mn}$ & $292,64 \pm 30,62$ & $121,27 \pm 1,92$ & $112,83 \pm 9,55$ & $10,16 \pm 1,90$ & $16,85 \pm 1,60$ \\
$\mathrm{Fe}$ & $1446,5 \pm 65$ & $2541,4 \pm 100,1$ & $3897 \pm 1015$ & $67,52 \pm 11,97$ & $938,5 \pm 110,9$ \\
$\mathbf{C o}$ & $20,20 \pm 1,30$ & $23,65 \pm 1,59$ & $18,53 \pm 4,53$ & $0,65 \pm 0,09$ & $6,40 \pm 0,88$ \\
$\mathbf{N i}$ & $11,77 \pm 0,08$ & $7,14 \pm 1,12$ & $4,80 \pm 0,16$ & $1,77 \pm 0,12$ & $6,75 \pm 0,37$ \\
$\mathbf{C u}$ & $2,59 \pm 0,40$ & $39,80 \pm 1,36$ & $7,49 \pm 1,85$ & $6,81 \pm 0,61$ & $5,35 \pm 1,37$ \\
$\mathbf{Z n}$ & $42,31 \pm 0,94$ & $129,29 \pm 0,27$ & $43,86 \pm 0,71$ & $43,01 \pm 1,48$ & $31,99 \pm 1,93$ \\
$\mathbf{B r}$ & $69,26 \pm 10,30$ & $21,45 \pm 1,22$ & $5,79 \pm 0,35$ & $2,44 \pm 0,20$ & $3,09 \pm 0,10$ \\
$\mathbf{P b}$ & $45,90 \pm 4,89$ & $46,73 \pm 0,57$ & $43,42 \pm 13,59$ & $18,58 \pm 0,13$ & $24,32 \pm 1,14$ \\
\hline
\end{tabular}

nd $=$ não detectado

Tabela 19. Limites de detecção $\left(\mu \mathrm{g} \mathrm{L}^{-1}\right)$ para $s$ elementos encontrados nas amostras de água, determinadas por TXRF em 200s de excitação/detecção.

\begin{tabular}{cccccc}
\hline Elemento & PDR & PAB & PCC & POÇO & PSP \\
\hline $\mathbf{T i}$ & 13,40 & 8,37 & 5,93 & 3,62 & 4,18 \\
$\mathbf{C r}$ & 4,35 & 2,95 & 1,97 & 1,15 & 1,39 \\
$\mathbf{M n}$ & 3,13 & 2,20 & 1,47 & 0,82 & 1,03 \\
$\mathbf{F e}$ & 2,06 & 1,45 & 0,97 & 0,52 & 0,68 \\
$\mathbf{C o}$ & 1,76 & 1,34 & 0,90 & 0,46 & 0,62 \\
$\mathbf{~ N i}$ & 1,18 & 0,96 & 0,64 & 0,36 & 0,44 \\
$\mathbf{C u}$ & 1,04 & 0,89 & 0,60 & 0,36 & 0,42 \\
$\mathbf{Z n}$ & 0,98 & 0,85 & 0,59 & 0,38 & 0,43 \\
$\mathbf{B r}$ & 0,72 & 0,62 & 0,46 & 0,31 & 0,35 \\
$\mathbf{P b}$ & 4,46 & 3,59 & 2,77 & 1,91 & 2,12 \\
\hline
\end{tabular}


Para o elemento Ti não há valores máximos permitidos na Resolução N 20/86 do CONAMA nem na Portaria 1469/00 do Ministério da Saúde. Apresentou altas concentrações nas amostras PDR, PCC, POÇO e PSP, somente na amostra PAB mostrou uma concentração mais baixa.

O $\mathrm{Cr}$ foi detectado somente nas amostras PAB e PSP, e suas concentrações estão abaixo do valor máximo permitido que é de $50 \mu \mathrm{g} \mathrm{L}^{-1}$ (valor para $\mathrm{Cr}$ VI).

Para o elemento Mn o máximo permitido é de $100 \mu \mathrm{g} \mathrm{L}^{-1}$, e nas amostras PDR, PAB e PCC as concentrações estão acima desse valor, 292,64 - 121,27 e 112,83 $\mu \mathrm{g} \mathrm{L}^{-1}$, respectivamente. Para as amostras POÇO e PSP os valores estão abaixo do permitido.

Para as amostras PDR $\left(1446,47 \mu \mathrm{g} \mathrm{L}^{-1}\right)$, PAB $\left(2541,44 \mu \mathrm{g} \mathrm{L}^{-1}\right)$, PCC $\left(3897,00 \mu \mathrm{g} \mathrm{L}^{-1}\right)$ e PSP $\left(938,51 \mu \mathrm{g} \mathrm{L}^{-1}\right)$ as concentrações de Fe estão bem acima do valor permitido, $300 \mu \mathrm{g} \mathrm{L}^{-1}$. Somente a amostra POÇO $\left(67,52 \mu \mathrm{g} \mathrm{L}^{-1}\right)$ tem concentração abaixo do permitido.

Em todas as amostras as concentrações de Co e Ni estão abaixo do valor máximo permitido, $200 \mu \mathrm{g} \mathrm{L}^{-1}$ e $25 \mu \mathrm{g} \mathrm{L}^{-1}$, respectivamente.

$\mathrm{Na}$ amostra PAB, o $\mathrm{Cu}$ apresentou concentração acima do valor máximo permitido de $20 \mu \mathrm{g} \mathrm{L}^{-1}$. Nas demais amostras as concentrações estão abaixo desse valor.

Já em todas as amostras o elemento $\mathrm{Zn}$ encontra-se com concentração acima do valor máximo permitido, $10 \mu \mathrm{g} \mathrm{L}^{-1}$, principalmente na 
amostra PAB, cuja concentração é de $129,29 \mu \mathrm{g} \mathrm{L}^{-1}$, um valor muito elevado para esse elemento.

No caso do Br há estabelecido pela Portaria 1469/00 do Ministério da Saúde, o valor máximo permitido de $25 \mu \mathrm{g} \mathrm{L}^{-1}$, porém na forma de brometos. Usando como parâmetro este valor, a amostra PDR encontra-se com valor acima do permitido: $69,26 \mu \mathrm{g} \mathrm{L}^{-1}$.

\section{4 - Análise de sedimento de fundo por EDXRF}

\subsection{1 - Análise de Pb em amostras certificadas}

As amostras certificadas, na forma de pastilhas, foram analisadas e os valores obtidos das concentrações de $\mathrm{Pb}$ foram concordantes com os valores especificados, conforme mostrado na Tabela 20. O fator de absorção para $\mathrm{Pb}$ foi calculado teoricamente através da equação 16 com o auxílio do programa AXIL e os valores são 0,303 e 0,329 para as amostras certificadas SRM2711 e SRM1646a, respectivamente.

Tabela 20. Concentrações $\left(\mu \mathrm{g} \mathrm{g}^{-1}\right)$ de $\mathrm{Pb}$ obtidas nas amostras certificadas de solo SRM2711 e de sedimento SRM1646a, produzidas pelo NIST, e analisadas por EDXRF na forma de pastilhas $(n=3)$.

\begin{tabular}{cccccccccc}
\hline & \multicolumn{4}{c}{ SRM2711 - Solo } & \multicolumn{3}{c}{ SRM1646a - Sedimento } \\
\hline \multicolumn{4}{c}{ Certificado } & \multicolumn{2}{c}{ Obtido } & \multicolumn{2}{c}{ Certificado } & \multicolumn{2}{c}{ Obtido } \\
& Média & IC & Média & IC & Média & IC & Média & IC \\
Pb & 1162 & $1085-1239$ & 1026,74 & $877,2-1176,3$ & 11,7 & $8,72-14,68$ & 10,47 & $8,57-12,37$ \\
\hline
\end{tabular}

* média e intervalo de confiança em nível de $95 \%$ 


\subsection{2 - Análise de Pb em amostras de sedimentos de fundo}

A título de ilustração na Figura 33 encontra-se o espectro dos raios $\mathrm{X}$ proveniente da amostra $\mathrm{PSP}$, analisada por EDXRF, na foram de pastilha.

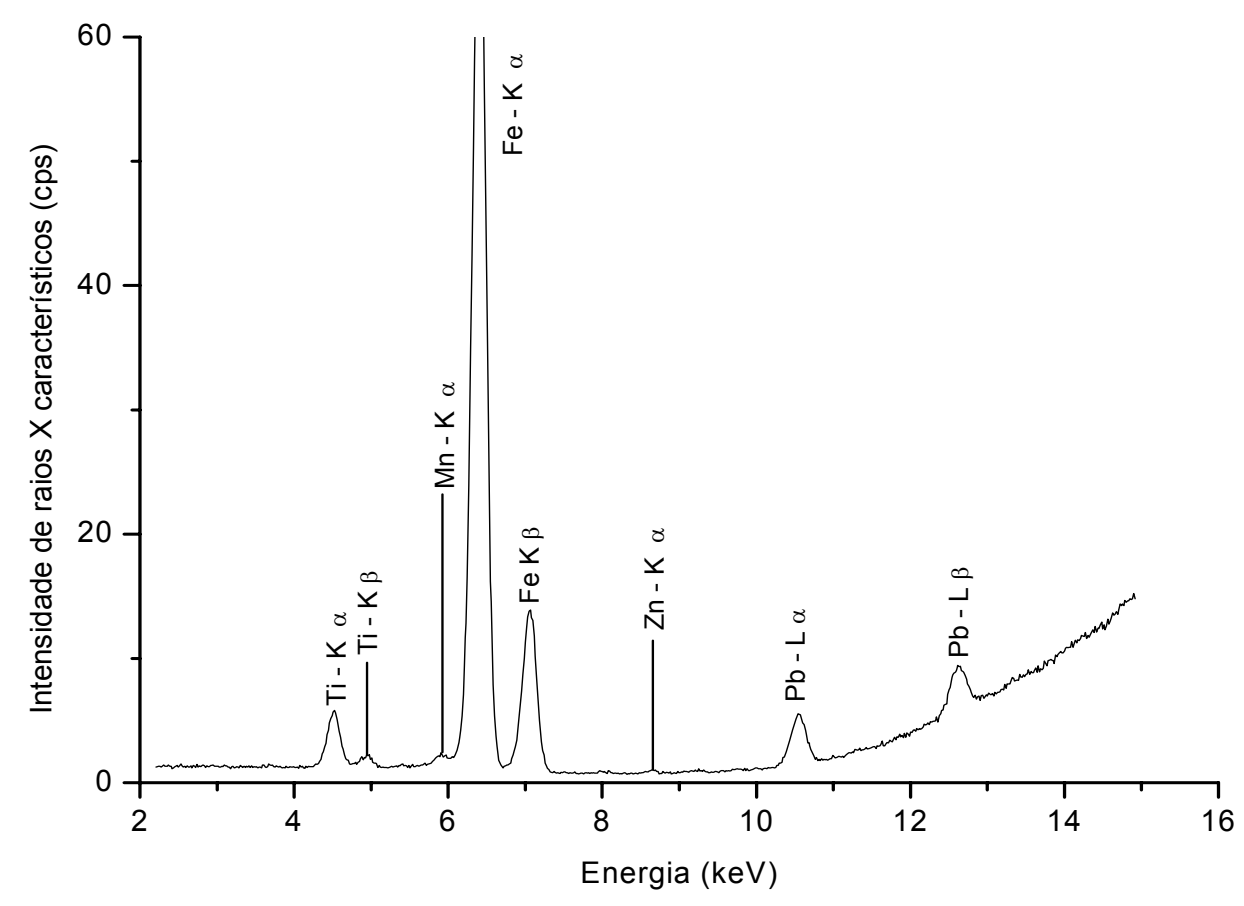

Figura 33. Espectro dos raios $X$ obtido por EDXRF proveniente da amostra de sedimento de fundo PSP na forma de pastilha.

Foi realizado com o auxílio do programa AXIL a determinação do fator de absorção para $\mathrm{Pb}$, para análise na forma de pastilha semi-espessa (equação 16), admitindo-se em uma primeira aproximação um sedimento de referência (com composição média de $\mathrm{Na}=0,058 \%, \mathrm{Mg}=0,187 \%$, $\mathrm{Al}=10,948 \%, \quad \mathrm{Si}=32,47 \%, \quad \mathrm{O}=50,184 \%, \quad \mathrm{~K}=0,714 \%, \quad \mathrm{Ca}=0,119 \%$, $\mathrm{Ti}=3,366 \%$ e $\mathrm{Fe}=1,938 \%)$ e ácido bórico $(\mathrm{H}=4,89 \%, \quad \mathrm{~B}=17,48 \%$ e 
$\mathrm{O}=77,63 \%$ ), misturados na proporção de $0,5 \mathrm{~g}$ de sedimento para $1,2 \mathrm{~g}$ de ácido bórico. Em seguida foram calculadas as concentrações de Fe e Ti deste sedimento e recalculados os fatores de absorção. Esse procedimento foi realizado para as quatro amostras de sedimento de fundo, e os fatores de absorção encontrados para $\mathrm{Pb}$ foram 0,274 - 0,327 - 0,278 e 0,289 para PDR, PAB, PCC e PSP, respectivamente.

Os valores de concentração para $\mathrm{Pb}$ nesses sedimentos de fundo estão mostrados na Tabela 21 e visualizados na Figura 34 , e os limites de detecção na Tabela 22. No sedimento de fundo POÇO não foi detectado esse elemento.

Tabela 21. Concentração e desvio padrão $\left(\mu \mathrm{g} \mathrm{g}^{-1}\right)$ de $\mathrm{Pb}$ encontrado nas amostras de sedimento de fundo, determinadas por EDXRF, na forma de pastilha $(n=3)$. Para comparação são dados os limites TEL e PEL.

\begin{tabular}{ccccccc}
\hline & PDR & PAB & PCC & PSP & TEL* $^{*}$ & PEL $^{* *}$ \\
\hline $\mathbf{P b}$ & $52,64 \pm 0,14$ & $2,44 \pm 0,45$ & $8,24 \pm 0,23$ & $122,42 \pm 6,45$ & 35 & 91,3 \\
\hline
\end{tabular}

${ }^{*} \mathrm{TEL}=$ Threshold Effect Level

${ }^{* *} \mathrm{PEL}=$ Probable Effect Level

Tabela 22. Limites de detecção $\left(\mu \mathrm{g} \mathrm{g}^{-1}\right)$ para $\mathrm{Pb}$ encontrado nas amostras de sedimento de fundo, determinadas por EDXRF, na forma de pastilha em $500 \mathrm{~s}$ de excitação/detecção.

\begin{tabular}{lllll}
\hline & PDR & PAB & PCC & PSP \\
\hline Pb & 2,19 & 1,82 & 2,04 & 2,06 \\
\hline
\end{tabular}




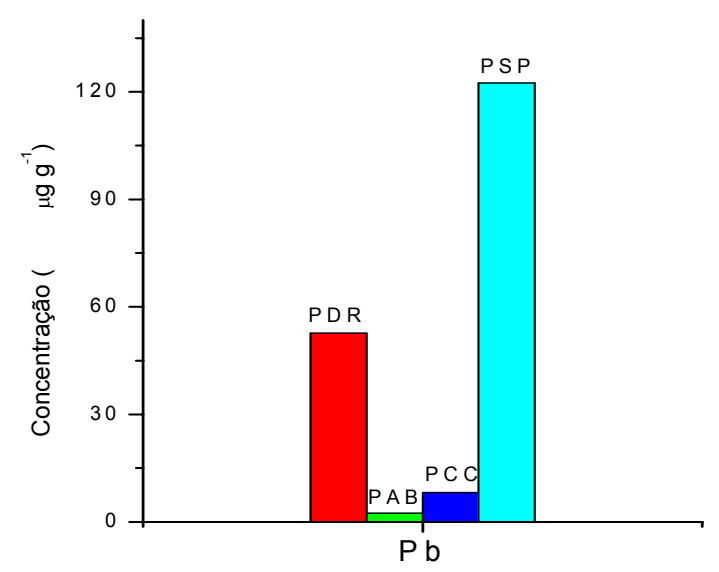

Figura 34. Distribuição das concentrações de $\mathrm{Pb}\left(\mu \mathrm{g} \mathrm{g}^{-1}\right)$ presente nas amostras de sedimento de fundo, determinadas por EDXRF, na forma de pastilhas.

Como não há legislação nacional para avaliação da qualidade de sedimentos, foram adotados os valores limites estabelecidos nos critérios da Agência Ambiental Canadense (Canadá, 2001), usando os níveis de classificação: TEL (Threshold Effect Level, nível limiar do efeito) e PEL (Probable Effect Level, nível provável do efeito). O primeiro nível consiste numa concentração abaixo da qual não são esperados efeitos adversos sobre organismos aquáticos, enquanto o segundo nível representa uma concentração acima da qual são esperados efeitos adversos severos sobre organismos aquáticos. Para $\mathrm{Pb}$ os valores são 35 e 91,3 $\mu \mathrm{g} \mathrm{g}^{-1}$, respectivamente (Tabela 21).

As amostras PAB e PCC apresentaram concentrações abaixo do valor permitido TEL, que é de $35 \mu \mathrm{g} \mathrm{g}^{-1}$ para $\mathrm{Pb}$. A amostra PDR apresentou concentração acima do limite TEL e abaixo do limite permitido PEL, que é de $91,3 \mu \mathrm{g} \mathrm{g}^{-1}$. Somente a amostra PSP apresentou valor de concentração acima do limite PEL. Essa amostra foi coletada no primeiro ponto, ao lado da Indústria 
Ajax (Figura 7), podendo-se afirmar que neste ponto o sedimento encontra-se contaminado.

Para a amostra PDR o teor de $\mathrm{Pb}$ também é considerado alto. $\mathrm{O}$ local onde foi coletada esta amostra é um dreno do córrego Vargem Limpa dentro de uma propriedade em frente da Indústria Ájax.

\subsection{3 - Análise de outros elementos em amostras de sedi- mentos de fundo}

Nos espectros de raios $\mathrm{X}$ foram visualizados os elementos $\mathrm{Ti}, \mathrm{Cr}$, $\mathrm{Mn}, \mathrm{Fe}, \mathrm{Co}, \mathrm{Ni}, \mathrm{Cu}$ e $\mathrm{Zn}$ nas amostras de sedimento de fundo. Para os cálculos das concentrações e limites de detecção para todos os elementos encontrados nas amostras foram utilizados os fatores de absorção (Tabela 23), calculados da mesma forma que para o $\mathrm{Pb}$ (item 5.42). Os valores das concentrações e dos limites de detecção para estes elementos estão nas Tabelas 24 e 25, respectivamente.

Tabela 23. Fatores de absorção para os elementos encontrados nas amostras de sedimento de fundo, obtidos com o auxílio do programa AXIL.

\begin{tabular}{ccccc}
\hline Elementos & PDR & PAB & PCC & PSP \\
\hline $\mathrm{Ti}$ & 0,0356 & 0,0364 & 0,0358 & 0,0359 \\
$\mathrm{Cr}$ & 0,0558 & 0,0589 & 0,0537 & 0,0575 \\
$\mathrm{Mn}$ & 0,0706 & 0,0748 & 0,0680 & 0,0729 \\
$\mathrm{Fe}$ & 0,0892 & 0,0947 & 0,0859 & 0,0910 \\
$\mathrm{Co}$ & 0,1110 & 0,1180 & 0,1070 & 0,1150 \\
$\mathrm{Ni}$ & 0,1170 & 0,1410 & 0,1270 & 0,1330 \\
$\mathrm{Cu}$ & 0,1420 & 0,1720 & 0,1440 & 0,1500 \\
$\mathbf{Z n}$ & 0,1710 & 0,2060 & 0,1730 & 0,1800 \\
\hline
\end{tabular}


Tabela 24. Concentrações e desvio padrão $\left(\mu \mathrm{g} \mathrm{g}^{-1}\right)$ para os elementos encontrados nas amostras de sedimento de fundo, determinadas por EDXRF, na forma de pastilhas ( $n=3)$. Para comparação são dados os limites TEL e PEL.

\begin{tabular}{ccccccc}
\hline Elementos & PDR & PAB & PCC & PSP & TEL $^{*}$ & PEL $^{* *}$ \\
\hline Ti & $6272 \pm 737$ & $3549 \pm 534$ & $10983 \pm 1508$ & $4044 \pm 436$ & - & - \\
Cr & $199,97 \pm 14,7$ & $59,52 \pm 0,23$ & $158,7 \pm 3,3$ & $141,5 \pm 1,6$ & 37,3 & 90 \\
Mn & $329,31 \pm 14,33$ & $98,62 \pm 8,20$ & $334,34 \pm 30,44$ & $308,95 \pm 23,14$ & - & - \\
Fe & $11101 \pm 713$ & $2272 \pm 167$ & $7715 \pm 363$ & $9665 \pm 642$ & - & - \\
Co & $79 \pm 5,6$ & $12,12 \pm 2,11$ & $57,81 \pm 0,16$ & $58,13 \pm 4,02$ & - & - \\
Ni & $3,95 \pm 0,95$ & nd & nd & nd & 18 & 35,9 \\
Cu & $12,17 \pm 0,28$ & $3,80 \pm 0,43$ & $8,12 \pm 0,26$ & $5,46 \pm 0,69$ & 35,7 & 197 \\
Zn & $10,71 \pm 0,57$ & $6,30 \pm 0,15$ & $6,48 \pm 0,02$ & $5,16 \pm 0,34$ & 123 & 315 \\
Pb & $52,64 \pm 0,14$ & $2,44 \pm 0,45$ & $8,24 \pm 0,23$ & $122,42 \pm 6,45$ & 35 & 91,3 \\
\hline
\end{tabular}

nd = não detectado

* TEL $=$ Threshold Effect Level

${ }^{* *}$ PEL $=$ Probable Effect Level

Tabela 25. Limites de detecção $\left(\mu \mathrm{g} \mathrm{g}^{-1}\right)$ para os elementos encontrados nas amostras de sedimento de fundo, determinadas por EDXRF, na forma de pastilhas em $500 \mathrm{~s}$ de excitação/detecção.

\begin{tabular}{ccccc}
\hline Elementos & PDR & PAB & PCC & PSP \\
\hline $\mathbf{T i}$ & 82,75 & 60,97 & 78,01 & 81,27 \\
$\mathbf{C r}$ & 22,43 & 17,13 & 22,74 & 21,60 \\
$\mathbf{M n}$ & 13,59 & 10,42 & 13,64 & 13,36 \\
$\mathbf{F e}$ & 7,33 & 5,80 & 7,48 & 7,45 \\
$\mathbf{C o}$ & 4,34 & 3,67 & 4,46 & 3,81 \\
$\mathbf{N i}$ & 3,07 & 2,36 & 2,94 & 3,08 \\
$\mathbf{C u}$ & 2,05 & 1,61 & 2,04 & 2,12 \\
$\mathbf{Z n}$ & 1,45 & 1,18 & 1,50 & 1,49 \\
$\mathbf{P b}$ & 2,19 & 1,82 & 2,04 & 2,06 \\
\hline
\end{tabular}

A titulo de ilustração os gráficos das Figuras 35 e 36 representam a distribuição das concentrações nas amostras de sedimento de fundo para os elementos encontrados. A Figura 35 se refere às concentrações em escala 
linear e a Figura 36 apresenta as concentrações em escala logarítmica para melhor visualização da distribuição.

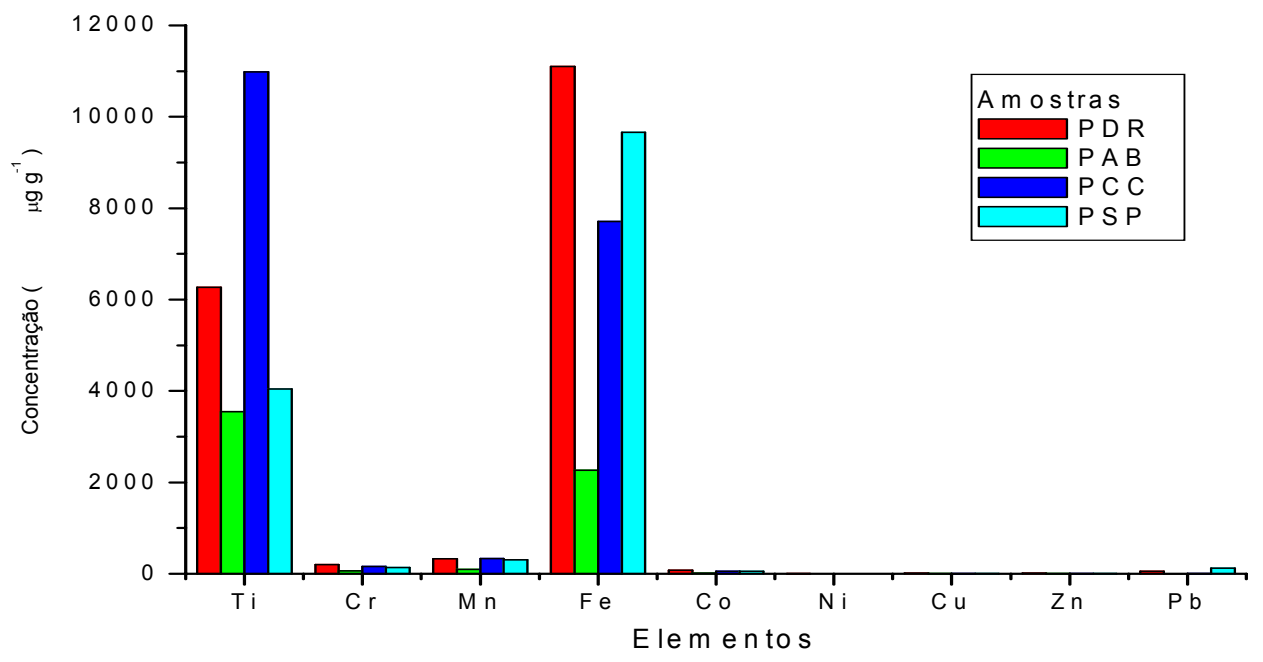

Figura 35. Distribuição das concentrações $\left(\mu \mathrm{g} \mathrm{g}^{-1}\right)$ dos elementos encontrados nas amostras de sedimento de fundo, determinadas por EDXRF, na foram de pastilhas (escala linear).

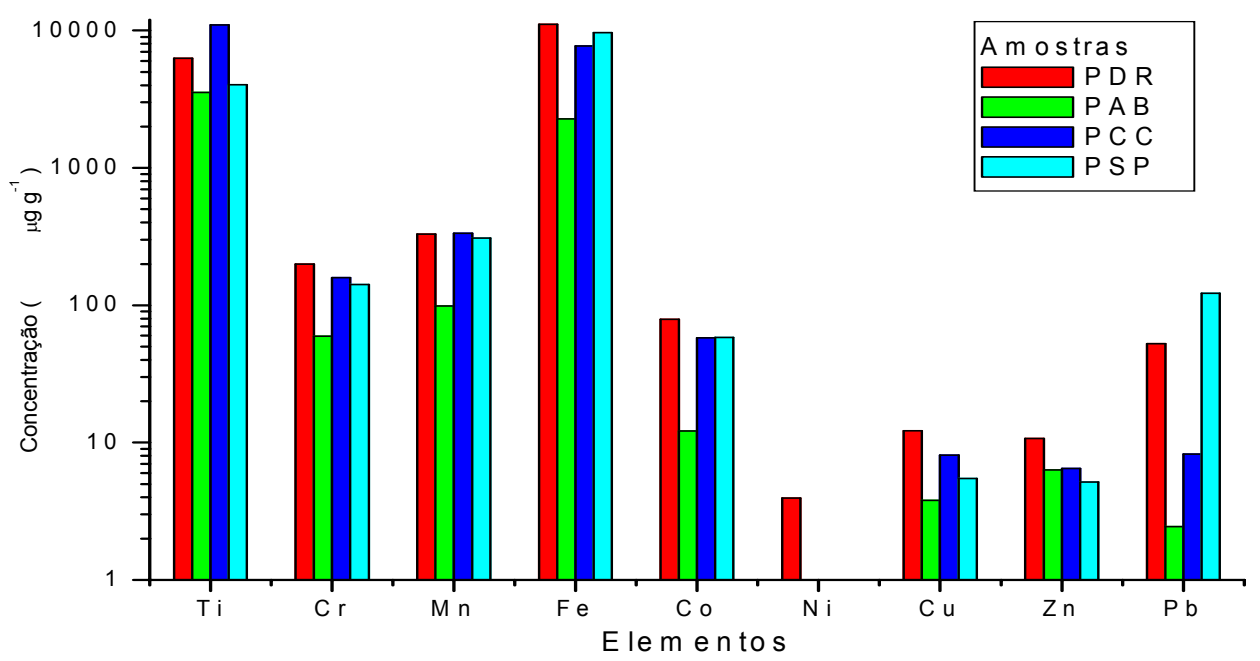

Figura 36. Distribuição das concentrações $\left(\mu \mathrm{g} \mathrm{g}^{-1}\right)$ dos elementos encontrados nas amostras de sedimento de fundo, determinadas por EDXRF, na forma de pastilhas (escala logarítmica). 
Dos sete elementos quantificados, quatro deles, ou seja, $\mathrm{Ti}, \mathrm{Mn}$, Fe e Co, não possuem valores máximos permitidos nos critérios usados pela Agência Ambiental Canadense. Para as quatro amostras os elementos $\mathrm{Ti}$ e $\mathrm{Fe}$ apresentaram concentrações muito elevadas em comparação com os demais elementos.

Para $\mathrm{Cr}$ as concentrações nas amostras PDR, PCC e PSP apresentaram valores acima do máximo permitido $\mathrm{PEL}, 90 \mu \mathrm{g} \mathrm{g}^{-1}$. A amostra $\mathrm{PAB}$ apresentou um valor de concentração menor que o PEL, porém acima do permitido TEL, $37,3 \mu \mathrm{g} \mathrm{g}^{-1}$.

O elemento $\mathrm{Mn}$ teve um comportamento parecido com o $\mathrm{Cr}$. As mesmas amostras, PDR, PCC e PSP apresentaram concentrações mais elevadas e na amostra $\mathrm{PAB}$ teve uma concentração bem menor em relação às outras.

O Co em duas amostras mostrou uma concentração muito próxima, $57,81 \mu \mathrm{g} \mathrm{g}^{-1}$ para PCC e $58,13 \mu \mathrm{g} \mathrm{g}^{-1}$ para PSP. A maior concentração foi encontrada na amostra PDR, $79 \mu \mathrm{g} \mathrm{g}^{-1}$, e a menor na amostra PAB, 12,12 $\mu \mathrm{g}^{-1}$.

Não foram obtidas intensidades de raios $\mathrm{X}$ para $\mathrm{Ni}$ nas amostras PCC e PSP e na amostra PAB a concentração encontrada foi abaixo do limite de detecção. Somente na amostra PDR observou-se uma concentração pequena e está abaixo do valor máximo permitido TEL, $18 \mu \mathrm{g} \mathrm{g}^{-1}$.

Para o Cu o valor máximo permitido TEL é $35,7 \mu \mathrm{g} \mathrm{g}^{-1}$ e PEL é $197 \mu \mathrm{g} \mathrm{g}^{-1}$. Todas as amostras apresentaram concentrações abaixo desses níveis. 
O elemento $\mathrm{Zn}$ apresentou concentrações abaixo de $11 \mu \mathrm{g} \mathrm{g}^{-1}$, para todas as amostras e esses valores estão abaixo do máximo permitido TEL $123 \mu \mathrm{g} \mathrm{g}^{-1}$.

\section{5 - Comparação das concentrações de $\mathrm{Pb}$ encontrado nas amostras de água nas análises realizadas por EDXRF (com pré-concentração) e TXRF (direto)}

Comparando os resultados obtidos para as amostras de água, pelas variantes EDXRF e TXRF, nota-se que as concentrações encontradas para $\mathrm{Pb}$ são maiores quando feita a análise por TXRF, conforme pode ser observado na Tabela 26. Somente a amostra POÇO apresentou concentração pouco maior quando analisada por EDXRF.

Já, para os limites de detecção, as amostras de água préconcentradas e analisadas por EDXRF apresentaram valores menores que para a análise das amostras sem preparo químico e analisadas por TXRF (Tabela 27).

Tabela 26. Resultados obtidos para as concentrações e desvio padrão ( $\mu \mathrm{g} \mathrm{L}^{-1}$ ) de $\mathrm{Pb}$ nas amostras de água pré-concentradas com APDC (EDXRF) e sem preparo químico (TXRF).

\begin{tabular}{cccccc}
\hline \multicolumn{5}{c}{ Amostras } \\
\hline & PDR & PAB & PCC & POÇO & PSP \\
EDXRF & $19,27 \pm 1,93$ & $26,62 \pm 3,94$ & $34,84 \pm 0,15$ & $25,01 \pm 1,16$ & $20,03 \pm 2,08$ \\
TXRF & $45,90 \pm 4,89$ & $46,73 \pm 0,57$ & $43,42 \pm 13,59$ & $18,58 \pm 0,13$ & $24,32 \pm 1,14$ \\
\hline
\end{tabular}


Tabela 27. Resultados obtidos para os limites de detecção $\left(\mu \mathrm{g} \mathrm{L}^{-1}\right)$ de $\mathrm{Pb}$ nas amostras de água pré-concentradas com APDC (EDXRF) e sem preparo químico (TXRF).

\begin{tabular}{lllccc}
\hline \multicolumn{7}{c}{ Amostras } \\
\hline & PDR & PAB & PCC & POÇO & PSP \\
EDXRF* & 0,58 & 0,57 & 0,60 & 0,70 & 0,64 \\
TXRF** $^{*}$ & 4,46 & 3,59 & 2,77 & 1,91 & 2,12 \\
\hline${ }^{*} 300$ s de excitação/detecção \\
${ }^{* *}$ 200 s de excitação/detecção
\end{tabular}

\section{6 - Comparação das concentrações dos elementos encontrados nas amostras de água nas análises realizadas por EDXRF (com pré-concentração) e TXRF (direto)}

Apenas alguns dos elementos encontrados nas amostras de água tiveram suas concentrações próximas quando determinados pelas duas técnicas utilizadas, EDXRF e TXRF, como pode ser observado na Tabela 28.

A Tabela 29 mostra os limites de detecção determinados nas duas técnicas, para os nove elementos encontrados nas amostras de água. Todos os elementos apresentaram bons limites de detecção, abaixo de $1 \mu \mathrm{g} \mathrm{L}^{-1}$ para EDXRF e abaixo de $3 \mu \mathrm{g} \mathrm{L}^{-1}$ para TXRF. As exceções foram para o Ti que apresentou limites de detecção acima desses valores nas duas técnicas e em todas as amostras, $\mathrm{Cr}$ com limite de detecção de $4,35 \mu \mathrm{g} \mathrm{L}^{-1}$ na amostra PDR por TXRF e Mn na mesma amostra com limite de detecção de $3,13 \mu \mathrm{g} \mathrm{L}^{-1}$ também por TXRF. 
Tabela 28. Resultados obtidos para as concentrações e desvio padrão ( $\mu \mathrm{g} \mathrm{L}^{-1}$ ) dos elementos encontrados nas amostras de água pré-concentradas com APDC (EDXRF) e sem preparo químico (TXRF).

\begin{tabular}{|c|c|c|c|c|c|c|c|c|c|c|}
\hline \multirow[t]{2}{*}{ Elementos } & \multicolumn{2}{|c|}{ PDR } & \multicolumn{2}{|c|}{ PAB } & \multicolumn{2}{|c|}{ PCC } & \multicolumn{2}{|c|}{ POÇO } & \multicolumn{2}{|c|}{ PSP } \\
\hline & EDXRF & TXRF & EDXRF & TXRF & EDXRF & TXRF & EDXRF & TXRF & EDXRF & TXRF \\
\hline $\mathrm{Ti}$ & $20,25 \pm 0,43$ & $64,95 \pm 0,06$ & $53,51 \pm 9,83$ & $13,76 \pm 3,40$ & $27,61 \pm 3,64$ & $75,20 \pm 29,93$ & $24,79 \pm 5,13$ & $84,64 \pm 56,73$ & $16,32 \pm 2,57$ & $137,15 \pm 6,41$ \\
\hline $\mathrm{Cr}$ & $13,48 \pm 0,59$ & nd & $20,71 \pm 5,70$ & $6,42 \pm 0,37$ & $18,72 \pm 3,10$ & nd & $11,12 \pm 1,82$ & nd & $10,01 \pm 0,39$ & $2,69 \pm 1,71$ \\
\hline $\mathrm{Mn}$ & $25,15 \pm 5,26$ & $292,64 \pm 30,62$ & $18,52 \pm 1,70$ & $121,27 \pm 1,92$ & $20,56 \pm 3,18$ & $112,83 \pm 9,55$ & $9,30 \pm 2,32$ & $10,16 \pm 1,90$ & $9,62 \pm 1,79$ & $16,85 \pm 1,60$ \\
\hline $\mathrm{Fe}$ & $1139,5 \pm 65,6$ & $1446,5 \pm 65$ & $2052,7 \pm 403$ & $2541,4 \pm 100,1$ & $1572,8 \pm 93,3$ & $3897 \pm 1015$ & $98,04 \pm 0,78$ & $67,52 \pm 11,97$ & $386,1 \pm 7,7$ & $938,5 \pm 110,9$ \\
\hline Co & $56,62 \pm 0,43$ & $20,20 \pm 1,30$ & $90,92 \pm 4,43$ & $23,65 \pm 1,59$ & $20,16 \pm 0,52$ & $18,53 \pm 4,53$ & $8,73 \pm 1,91$ & $0,65 \pm 0,09$ & $40,14 \pm 2,87$ & $6,40 \pm 0,88$ \\
\hline $\mathrm{Ni}$ & $5,66 \pm 1,83$ & $11,77 \pm 0,08$ & $32,43 \pm 1,05$ & $7,14 \pm 1,12$ & $8,25 \pm 0,42$ & $4,80 \pm 0,16$ & $3,18 \pm 0,28$ & $1,77 \pm 0,12$ & $5,02 \pm 0,07$ & $6,75 \pm 0,37$ \\
\hline $\mathrm{Cu}$ & $3,06 \pm 0,57$ & $2,59 \pm 0,40$ & $29,39 \pm 1,42$ & $39,80 \pm 1,36$ & $3,57 \pm 0,56$ & $7,49 \pm 1,85$ & $12,51 \pm 0,17$ & $6,81 \pm 0,61$ & $2,73 \pm 0,34$ & $5,35 \pm 1,37$ \\
\hline $\mathrm{Zn}$ & $46,93 \pm 0,63$ & $42,31 \pm 0,94$ & $78,37 \pm 8,30$ & $129,29 \pm 0,27$ & $34,43 \pm 1,40$ & $43,86 \pm 0,71$ & $15,70 \pm 0,10$ & $43,01 \pm 1,48$ & $11,43 \pm 1,98$ & $31,99 \pm 1,93$ \\
\hline $\mathrm{Br}$ & $8,87 \pm 1,18$ & $69,26 \pm 10,30$ & $7,78 \pm 3,29$ & $21,45 \pm 1,22$ & $11,50 \pm 1,15$ & $5,79 \pm 0,35$ & $11,58 \pm 0,36$ & $2,44 \pm 0,20$ & $10,63 \pm 1,56$ & $3,09 \pm 0,10$ \\
\hline $\mathrm{Pb}$ & $19,27 \pm 1,93$ & $45,90 \pm 4,89$ & $26,62 \pm 3,94$ & $46,73 \pm 0,57$ & $34,84 \pm 0,15$ & $43,42 \pm 13,59$ & $25,01 \pm 1,16$ & $18,58 \pm 0,13$ & $20,03 \pm 2,08$ & $24,32 \pm 1,14$ \\
\hline
\end{tabular}

nd = não detectado

Tabela 29. Resultados obtidos para os limites de detecção $\left(\mu \mathrm{g} \mathrm{L}^{-1}\right)$ dos elementos encontrados nas amostras de água préconcentradas com APDC (EDXRF) e sem preparo químico (TXRF).

\begin{tabular}{|c|c|c|c|c|c|c|c|c|c|c|}
\hline \multirow[t]{2}{*}{ Elementos } & \multicolumn{2}{|c|}{ PDR } & \multicolumn{2}{|c|}{ PAB } & \multicolumn{2}{|c|}{ PCC } & \multicolumn{2}{|c|}{ POÇO } & \multicolumn{2}{|c|}{ PSP } \\
\hline & EDXRF & TXRF & EDXRF & TXRF & EDXRF & TXRF & EDXRF & TXRF & EDXRF & TXRF \\
\hline $\mathrm{Ti}$ & 1,80 & 13,40 & 1,87 & 8,37 & 1,99 & 5,93 & 1,72 & 3,63 & 1,67 & 4,18 \\
\hline $\mathrm{Cr}$ & 0,88 & 4,35 & 0,86 & 2,95 & 0,91 & 1,97 & 0,80 & 1,15 & 0,77 & 1,39 \\
\hline Mn & 0,72 & 3,13 & 0,67 & 2,20 & 0,71 & 1,47 & 0,64 & 0,82 & 0,63 & 1,03 \\
\hline $\mathrm{Fe}$ & 0,52 & 2,06 & 0,58 & 1,45 & 0,52 & 0,97 & 0,47 & 0,52 & 0,46 & 0,68 \\
\hline Co & 0,39 & 1,76 & 0,44 & 1,34 & 0,39 & 0,90 & 0,37 & 0,46 & 0,37 & 0,62 \\
\hline $\mathrm{Ni}$ & 0,31 & 1,18 & 0,34 & 0,96 & 0,30 & 0,64 & 0,31 & 0,36 & 0,30 & 0,44 \\
\hline $\mathrm{Cu}$ & 0,25 & 1,04 & 0,27 & 0,89 & 0,24 & 0,60 & 0,26 & 0,36 & 0,26 & 0,42 \\
\hline$Z n$ & 0,21 & 0,98 & 0,23 & 0,85 & 0,22 & 0,59 & 0,24 & 0,38 & 0,23 & 0,43 \\
\hline $\mathrm{Br}$ & 0,28 & 0,72 & 0,28 & 0,62 & 0,29 & 0,46 & 0,34 & 0,31 & 0,32 & 0,35 \\
\hline $\mathrm{Pb}$ & 0,58 & 4,43 & 0,57 & 3,59 & 0,60 & 2,77 & 0,70 & 1,91 & 0,64 & 2,12 \\
\hline
\end{tabular}


Um fator a considerar na comparação dos resultados de EDXRF e TXRF é a presença de colóides. As amostras de água após a filtragem apresentaram uma certa turbidez, indicando a remanescência de colóides. Em TXRF a irradiação é direta e a concentração de cada elemento é a soma da quantidade do elemento dissolvido com a quantidade do elemento presente no colóide, enquanto que em EDXRF, com pré-concentração com APDC, a concentração é devida somente a quantidade do elemento dissolvido. Desse modo é de se esperar uma maior concentração por TXRF em relação a EDXRF nas amostras que apresentaram uma maior turbidez após a filtragem.

De modo geral as concentrações de $\mathrm{Ti}, \mathrm{Mn}$ e Fe (elementos indicativos da presença de colóides oriundos de sedimentos em suspensão) mostraram ser superiores por TXRF em relação a EDXRF nas amostras que apresentaram turbidez após a filtragem.

A amostra PCC apresentou maior turbidez, e analisando-se a Tabela 28 pode ser notado que as concentrações de $\mathrm{Ti}$, Mn e Fe foram superiores na análise por TXRF em relação a EDXRF, e o mesmo ocorreu para as amostras com grau de turbidez um pouco menor, PDR, PAB e PSP. As amostras que apresentaram maior turbidez foram PAB e PCC e em menor grau, PDR e PSP. A amostra POÇO não apresentou turbidez e nem maior concentração para Fe (e praticamente também para $\mathrm{Mn}$ ). 


\section{6 - CONCLUSÕES}

As metodologias para determinação de $\mathrm{Pb}$ em amostras de água, através da pré-concentração com APDC com posterior medida por EDXRF e medida direta por TXRF, foram bastante satisfatórias. Uma amostra certificada de água natural SRM1640, produzida pelo NIST, e soluções-padrão foram analisadas e as concentrações encontradas foram compatíveis com o valor certificado. A primeira técnica resultou em limites de deteç̧ão da ordem de 0,70 $\mu \mathrm{g} \mathrm{L}^{-1}$, com tempo de análise de $300 \mathrm{~s}$, melhor do que pela segunda técnica $\left(4,46 \mu \mathrm{g} \mathrm{L}^{-1}\right)$, com um tempo de $200 \mathrm{~s}$.

Cinco amostras de água foram coletadas em locais próximos à Indústria Ajax, fabricante de baterias, e analisadas por estas técnicas, obtendose valores coincidentes para a concentração de $\mathrm{Pb}$. Com base nos valores máximos permitidos para $\mathrm{Pb}$, estabelecidos pela Portaria 1469/00 e Resolução 20/1986 CONAMA, as amostras PDR, PAB, PCC e POÇO encontram-se contaminadas por $\mathrm{Pb}$, comparando os valores obtidos por TXRF. Quando se comparam os valores obtidos por EDXRF, somente as amostras PCC e POÇO encontram-se contaminadas.

Para análise de sedimentos em suspensão foi utilizada a técnica de EDXRF, assumindo a amostra como filme fino, atingindo limite de detecção da ordem de $2 \mu \mathrm{g} \mathrm{g}^{-1}$, com um tempo de análise de $500 \mathrm{~s}$. As amostras de sedimento coletadas apresentaram uma concentração menor que este limite. 
A determinação de $\mathrm{Pb}$ em amostras de sedimento de fundo por EDXRF, assumindo a amostra a amostra como espessa, mostrou-se satisfatória, sendo validada com amostras certificadas de sedimento (SRM1646a/NIST) e solo (SRM2711/NIST), com limites de detecção em torno de $2 \mu \mathrm{g} \mathrm{g}^{-1}$, para um tempo de análise de $500 \mathrm{~s}$.

$\mathrm{Na}$ legislação brasileira não há limite máximo permitido para $\mathrm{Pb}$ em solos e sedimentos e portanto foram adotados os limites TEL (Threshold Effect Level, nível limiar do efeito) de 35,0 $\mu \mathrm{g} \mathrm{g}^{-1}$ e PEL (Probable Effect Level, nível provável do efeito) de $91,3 \mu \mathrm{g} \mathrm{g}^{-1}$, utilizados pela Agência Ambiental Canadense (Environment Canadá). A amostra PDR apresentou um valor de concentração acima do limite TEL, e a amostra PSP, coletada num ponto bem ao lado da Indústria Ájax, acima do limite PEL.

Outros elementos químicos, como o Ti, $\mathrm{Cr}, \mathrm{Mn}, \mathrm{Fe}, \mathrm{Co}, \mathrm{Ni}, \mathrm{Cu}, \mathrm{Zn}$ e $\mathrm{Br}$, puderam ser analisados por estas duas variantes da fluorescência de raios X. Para amostras de água a técnica de pré-concentração com APDC e posterior medida por EDXRF mostrou também melhores limites de detecção em relação a TXRF, para todos os elementos. Para os elementos $\mathrm{Ni}$, $\mathrm{Cu}$ e $\mathrm{Zn}$, importantes na indústria de baterias, foram encontrados os limites de detecção $0,34-0,27$ e $0,24 \mu \mathrm{g} \mathrm{L}^{-1}$, respectivamente, enquanto que por TXRF foram encontrados $1,18-1,04$ e $0,98 \mu \mathrm{g} \mathrm{L}^{-1}$, respectivamente.

$\mathrm{Na}$ validação destas duas metodologias para análise destes elementos em água, a EDXRF mostrou resultados mais próximos aos valores das soluções-padrão, enquanto que os resultados obtidos por TXRF foram superestimados na maioria das vezes. Foi constatada uma fonte de interferência na TXRF para quase todos os elementos analisados, com exceção para $\mathrm{As}$, Se e $\mathrm{Pb}$, e foi comprovado que esta interferência não é devido deles no suporte refletor de quartzo, colimador do detector ou solução do padrão 
interno, e provavelmente devido à presença nos componentes metálicos do arranjo experimental.

Sem a eliminação dessa interferência os resultados de concentração obtidos por TXRF para estes elementos, com exceção para As, $\mathrm{Se}$ e $\mathrm{Pb}$, só podem ser utilizados como qualitativos. Mesmo assim, uma amostra (PAB) ultrapassou os limites de concentração permissíveis para $\mathrm{Ni} e$ $\mathrm{Cu}$ em água, e três ultrapassaram os limites para Zn (PAB, PDR e PCC) pela análise dos resultados da EDXRF, enquanto que pela TXRF uma ultrapassou para $\mathrm{Cu}(\mathrm{PAB})$ e todas as cinco para $\mathrm{Zn}$.

$\mathrm{Na}$ análise destes outros elementos em amostras de sedimento de fundo por EDXRF, os limites de detecção foram de 3,07 $\mu \mathrm{g} \mathrm{g}^{-1}$ para Ni, 2,12 $\mu \mathrm{g} \mathrm{g}^{-1}$ para $\mathrm{Cu}$ e $1,50 \mu \mathrm{g} \mathrm{g}^{-1}$ para $\mathrm{Zn}$, com um tempo de análise de $500 \mathrm{~s}$, validada pela análise de amostras certificadas produzidas pelo NIST.

As concentrações para os elementos $\mathrm{Ni}$, $\mathrm{Cu}$ e $\mathrm{Zn}$ nas amostras de sedimento em suspensão e de fundo, obtidas nos vários pontos de coleta, mantiveram quase que inalteradas e sempre abaixo dos limites TEL. 


\section{7 - REFERÊNCIAS BIBLIOGRÁFICAS}

AIGINGER, H.; WOBRAUSCHECK, P. A method for quantitative X-ray fluorescence analysis in the nanogram region. Nuclear Instruments and Methods, v.144, p.1313-1321, 1974.

ALMEIDA, E. Utilização das técnicas de fluorescência de raios $X$ por dispersão de energia e reflexão total na pesquisa agropecuária. Piracicaba, 2001. 62p. Dissertação (Mestrado) - Centro de Energia Nuclear na Agricultura, Universidade de São Paulo.

ALMEIDA, E.; NASCIMENTO FILHO, V.F.; VALENCIA, E.P.E.; CUNHA e SILVA, R.M. Concentrations of $\mathrm{Fe}, \mathrm{Cu}$ and $\mathrm{Zn}$ in rum by EDXRF using APDC preconcentration. Journal of Radioanalytical and Nuclear Chemistry, v.252, p.541-544, 2002.

ALVAREZ, A.M.; ALVAREZ, J.R.E.; ALVAREZ, P.R. Heavy metal analysis of rainwaters by nuclear related techniques: Application of APDC precipitation and energy dispersive X-ray fluorescence. Journal of Radioanalytical and Nuclear Chemistry, v.245, n.3, p.485-489, 2000. 
ARGYRAKI, A.; RAMSEY, M.H.; POTTS, P.J. Evaluation of portable X-ray fluorescence instrumentation for in situ measurements of lead on contaminated land. Analyst, v.122, p.743-749, 1997.

AYALA, R.E.; ALVAREZ, E.M.; WOBRAUSCHEK, P. Direct determination of lead in whole human blood by total reflection X-ray fluorescence spectrometry. Spectrochimica Acta, v.46B, p.142-1432, 1991.

BERNICK, M.B.; GETTY, D.; PRINCE, G.; SPRENGER, M. Statistical evaluation of field-portable X-ray fluorescence soil preparation methods. Journal of Hazardous Materials, v.43, p.111-116, 1995.

BERTIN, E.P. Principles and practices of X-ray spectrometric analysis. London: Plenum Press, 1975. 1079p.

BRASIL. Leis, decretos, etc. Decreto Estadual n 10755 de 22 de novembro de 1977. Dispõe sobre o enquadramento dos corpos de água receptores na classificação prevista no Decreto $n^{\circ} 8468$, de 8 de setembro de 1976, e dá providências correlatas.

BRASIL. Ministério do Meio Ambiente. Conselho Nacional do Meio Ambiente. Resolução $n^{0}$ 20, de 18 de junho de 1986. Diário Oficial, 30 jul. 1986. Dispõe sobre a classificação das águas doces, salobras e salinas do Território Nacional. 
BRASIL. Ministério da Saúde. Secretaria Nacional de Vigilância Sanitária. Portaria $n^{\circ}$ 1469, de 29 de dezembro de 2000. Diário Oficial, 19 fev. 2001. Seção 1, p.84. Normas de qualidade da água para consumo humano.

CANADA. Environment Canada. Table B-4. Sediment toxicity screening values for aquatic life. Ottawa: Lower Ottawa River SLRA, 2001. p.1-2.

CUNHA e SILVA, R.M.; NASCIMENTO FILHO, V.F.; VALENCIA, E.P.E.; ALMEIDA, E. Determination of $\mathrm{Fe}, \mathrm{Cu}$ and $\mathrm{Zn}$ in Brazilian sugar-cane spirit from Piracicaba city region, SP, using total reflection X-ray fluorescence technique. Journal of Radioanalytical and Nuclear Chemistry, v.252, n.3, p.541-544, 2002.

CURIE, L.A. Limits for quantitative detection and quantitative determination. Analytical Chemistry, v.40, p.586-593, 1968.

DAVIDSON, C.M.; THOMAS, R.P.; McVEY, S.E.; PERALA, R.; LITTLEJOHN, D.; URE, A.M. Evaluation of a sequential extraction procedure for the speciation of heavy metals in sediments. Analytica Chimica Acta, v.291, p.277-286, 1994.

DEPENA, Y.P.; GALLEGO, M.; VALCARCEL, M. On-line sorbent extraction, preconcentration and determination of lead by atomic-absorption spectrometry. Talanta, v.42, p.211-218, 1995. 
EKSPERIANDOVA, L.P.; BLANK, A.B.; MAKAROVSKAYA, Y.N. Analysis of waste water by X-ray fluorescence spectrometry. X-Ray Spectrometry, v.31, p.259-263, 2002.

ELDER, J.F.; PERRY, S.K.; BRADY, F.P. Application of energy-dispersive Xray fluorescence to trace metal analysis of natural waters. Environmental Science \& Technology, v.9, n.12, p.1039-1042, 1975.

ELLIS, A.T.; LEYDEN, D.E.; WEGSCHEIDER, W.; JABLONSKI, B.B.; BODNAR, W.B. Preconcentration methods for the determination of trace elements in water by X-ray fluorescence spectrometry. Part 1. Analytica Chimica Acta, v.142, p.73-87, 1982a.

ELLIS, A.T.; LEYDEN, D.E.; WEGSCHEIDER, W.; JABLONSKI, B.B.; BODNAR, W.B. Preconcentration methods for the determination of trace elements in water by X-ray fluorescence spectrometry. Part 2. Interference studies. Analytica Chimica Acta, v.142, p.89-100, 1982b.

HOLYNSKA, B.; OSTACHOWICZ, B.; WEGRZYNEK, D. Simple method of determination of copper, mercury and lead in potable water with preliminary preconcentration by total reflection X-ray fluorescence spectrometry. Spectrochimica Acta, v.51B, p.769-773, 1996.

JIN, L.Z.; WU, D.C.; NI, Z.M. Determination of lead, cadmium, cobalt, copper, tin, arsenic and molybdenum in seawater and biological samples by graphitefurnace atomic-absorption spectrometry after pre-separation and preconcentration with APDC precipitation. Acta Chimica Sinica, v.45, n.8, p.808-812, 1987. 
KUMP, P.; NECEMER, M.; VEBER, M. Determination of trace elements in mineral water using total reflection X-ray fluorescence spectrometry after preconcentration with ammonium pyrrolidinedithiocarbamate. X-Ray Spectrometry, v.26, p.232-236, 1997.

LAU, O.W.; HO, S.Y. Simultaneous determination of traces of iron, cobalt, nickel, copper, mercury and lead in water by energy-dispersive X-ray fluorescence spectrometry after preconcentration as their piperazino-1,4bis(dithiocarbamate) complexes. Analytica Chimica Acta, v.280, p.269277, 1993.

LEDERER, C.M.; HOLLANDER, J.M.; PERLMAN, I. Table of isotopes. 6.ed. New York: John Wiley, 1967. 594p.

NASCIMENTO FILHO, V.F. Técnicas analíticas nucleares de fluorescência de raios $X$ por dispersão de energia (EDXRF) e por reflexão total (TXRF). Piracicaba: ESALQ, Depto. de Física e Meteorologia; CENA, 1999. 32p. http://www.cena.usp.br/apostilas/Virgilio/cen-5723/EDXRF TXRF.doc

NASCIMENTO FILHO, V.F.; POBLETE, V.H.; PARREIRA, P.S.; MATSUMOTO, E; SIMABUCO, S.M.; ESPINOZA, E.P.; NAVARRO, A.A. Limits of detection of a total reflection X-ray fluorescence system with double reflection module. Biological Trace Elements Research, v.71, p.423-430, 1999.

OHLWEILER, O.A. Fundamentos de análise instrumental. Rio de Janeiro: Livros Técnicos e Científicos, 1981. 486p. 
PRADZYNSKI, A.H.; HENRY, R.E.; STEWART, J.S. Determination of ppb concentrations of transition metals by radioisotope-excited energy-dipersive X-ray Spectrom. Journal of Radioanalytical Chemistry, v.32, p.219-228, 1976.

PRANGE, A.; BÖDDEKER, H.; KRAMER, K. Determination of trace elements in river-water using total-reflection X-ray fluorescence. Spectrochimica Acta, v.48B, p.207-215, 1993.

QUERALT, I.; MARQUES, A.F.; CARVALHO, M.L.; BORDALO, M. Total reflection $\mathrm{X}$-ray fluorescence and energy-dispersive $\mathrm{X}$-ray analysis of runoff water and vegetation from abandoned mining of $\mathrm{Pb}-\mathrm{Zn}$ ores. Spectrochimica Acta, v.58B, p.2191-2198, 2003.

SARTINI, R.P. Determinação espectrofotométrica automatizada de chumbo em materiais vegetais, baseada no complexo ternário chumbo/iodeto/verde de malaquita. Piracicaba, 1995. 79p. Dissertação (Mestrado) - Centro de Energia Nuclear na Agricultura, Universidade de São Paulo.

SIMABUCO, S.M. Emprego da fluorescência de raios-X por dispersão de energia no estudo da dinâmica da vinhaça no solo. São Paulo, 1993. 153p. Tese (Doutorado) - Instituto de Pesquisas Energéticas e Nucleares.

SIMABUCO, S.M.; MATSUMOTO, E.; NASCIMENTO FILHO, V.F. Determinação de metais pesados em águas naturais por fluorescência de raios $X$ com radiação síncrotron. In: SEMINÁRIO LATINO-AMERICANO DE 
ANÁLISIS POR TÉCNICAS DE RAYOS X, 5., Huerta Grande, Argentina, 1998. Anais. Huerta Grande, 1998. p.84-89.

SIMABUCO, S.M.; FIGUEROA, R.; GARCÍA, M.; NASCIMENTO FILHO, V.F Comparação das concentrações de metais em águas potáveis das cidades de Córdoba, Temuco e Campinas por EDXRF. In: SEMINÁRIO LATINOAMERICANO DE ANÁLISIS POR TÉCNICAS DE RAYOS X, 5., Huerta Grande, Argentina, 1998. Anais. Huerta Grande, 2000. p.31-36.

TERTIAN, R.; CLAISSE, F. Principles of quantitative X-Ray fluorescence analysis. London: Hieden, 1982. 385p.

TURNER, D.R. The chemistry of metal pollutants in water. In: HARRISON, H.M. (Ed.) Pollution: causes, effects and control. Cambridge: The Royal Society of Chemistry, 1990. p.19-32.

ULRICH, M.M.; HOPKE, P.K. Preconcentration for trace analysis. ResearchDevelopment, v.28, n.1, p.34, 1977.

VAN GRIEKEN, R. Preconcnetration methods for the analysis of water by X-ray spectrometric techniques. Analytical Chimica Acta, v.143, p.3-34, 1982.

YONEDA, Y.; HORIUCHI, T. Optical flats for use in X-ray spectrochemical microanalysis. The Review of Scientific Instruments, v.42, n.7, p.10691070, 1971. 
ZUCCHI, O.L.A.D.; NASCIMENTO FILHO, V.F. Caracterização qualitativa e quantitativa de elementos, pela técnica de fluorescência de raios $X$, em suplementos minerais para animais. Parte 2: Dispersão de energia. Pesquisa Agropecuária Brasileira, v.30, p.1441-1452, 1995. 


\section{BIBLIOGRAFIA RECOMENDADA}

JENKINS, R.; GOULD, R.W.; GEDCKE, D. Quantitative X-ray spectrometry.

New York: Marcel Dekker, 1981. 588p. 